\author{
University of São Paulo \\ "Luiz de Queiroz" College of Agriculture"
}

Characterization of nucleolar expression and its correlation with the size of the $45 \mathrm{~S}$ rDNA arrangements in Zea mays inbred lines and hybrids

Yajahaira Nevenka Carbajal Gonzales

Dissertation presented to obtain the degree of Master in

Science. Area: Genetics and Plant Breeding

Piracicaba

2021 
Yajahaira Nevenka Carbajal Gonzales

Professional Title in Biology Genetics and Biotechnology

Bachelor in Genetics and Biotechnology

Characterization of nucleolar expression and its correlation with the size of the 45S rDNA arrangements in Zea mays inbred lines and hybrids

versão revisada de acordo com a resolução CoPGr 6018 de 2011

Advisor:

Prof. Dr. MATEUS MONDIN

Dissertation presented to obtain the degree of Master in Science. Area: Genetics and Plant Breeding 
Dados Internacionais de Catalogação na Publicação DIVISÃO DE BIBLIOTECA - DIBD/ESALQ/USP

Carbajal Gonzales, Yajahaira Nevenka

Characterization of nucleolar expression and its correlation with the size of the 45S rDNA arrangements in Zea mays inbred lines and hybrids / Yajahaira Nevenka Carbajal Gonzales. - - versão revisada de acordo com a resolução CoPGr 6018 de 2011. - - Piracicaba, 2021.

$67 \mathrm{p}$.

Dissertação (Mestrado) - USP / Escola Superior de Agricultura "Luiz de Queiroz".

1. Heteromorfismo 2. Homomorfismo 3. rDNA de 45S 4. Nucléolo 5. Linhagens endogâmicas 6 . Híbridos 7. Milho I. Título 
To my mother, Liliana

For holding my hands, inspiring my days, and accompanying my steps

To my grandmother, Lourdes

forever supporting my plans and adventures

To my aunt, Adela

for being close despite the distance

To my family, my safe harbor 


\section{ACKNOWLEDGMENTS}

To God for having guided me through this new stage.

To the "Luiz de Queiroz" School of Agriculture, University of São Paulo, and to the Department of Genetics, for the opportunity to carry out this master's degree.

To National Council for Scientific and Technological Development (CNPq)for the scholarship awarded.

To Professor Dr. Mateus Mondin for having given me the opportunity to be part of his laboratory and for the guidance and teachings throughout this stage.

To Professor Dr. Maria Lúcia Carneiro Vieira and Carlos Alberto de Oliveira, the laboratory technician, for their willingness and collaboration in the use of some equipment.

To Prof. Dr. Rafael de Andrade Moral of the Maynooth University for his collaboration and willingness to carry out the statistical analyzes.

To the Department of Genetics, to all the professors who shared interesting ideas and knowledge, for their prompt availability in the event of any eventuality during the development of this work.

To Silvia Cristina Menuzzo Molina, laboratory technician at CYNGELA. Thanks for all her help, patience, and dedication.

To my dear friends from the CYNGELA team, Renata Flavia de Carvalho, Gabriel Fernando da Silva, and Frederico Hickmann, for having been my great support in these last two years and for being there to laugh, sorrows and challenges. Without you, this story would not have been the same.

To my mother for being an example of perseverance, improvement, and love, always supporting me in each new challenge and encouraging me to continue.

To my grandmother, my aunt, and my cousins for making me feel their love despite the distance and for making time and distance less than they are.

To Évellyn Giselly de Oliveira Couto, Massaine Bandeira e Sousa and Marcia Leite Mondin for being my first guides when I still didn't know almost anything about ESALQ or Piracicaba.

To Renata, for accompanying me in these two long years, for that daily coexistence that fed our love with coffees, runs, trips, laughter, sadness, and despair. Thank you for always having the right words at the right time.

To the great family that we form here in Piracicaba: Ricardo, Diana, Lina, Risely, Renata, Gabriel, Ana, Alex, Guilherme, Rodrigo, Caio, Marquinhos, Brenda, Mari, Alice, and all those who did their bit to make this road away from home a great experience not only academic but also personal. Wonderful ties that made me feel at home.

To my friends in Peru, for staying present despite the distance. Especially Melanie, for inspiring me to fulfill this purpose.

To all those who in any way contributed to my personal and professional growth during this experience. 
That's what living is:

balancing yourself all the time,

between choices and consequences

Jean-Paul Sartre 


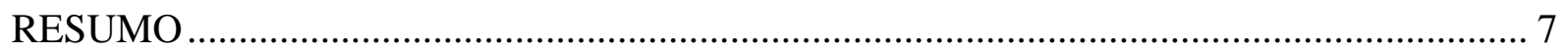

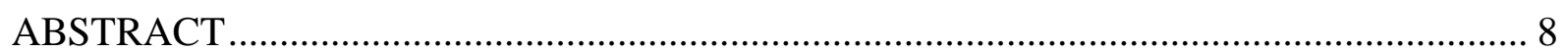

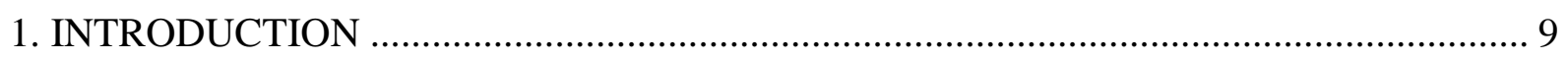

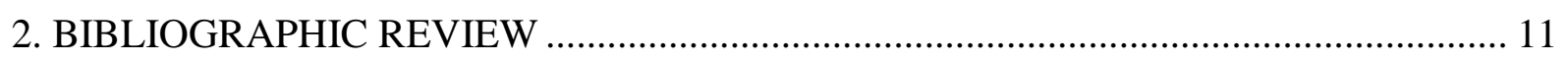

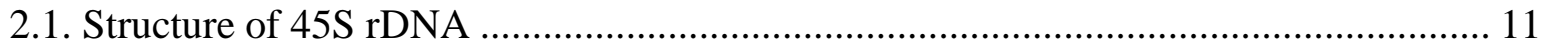

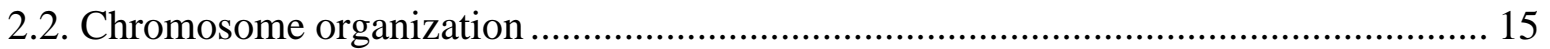

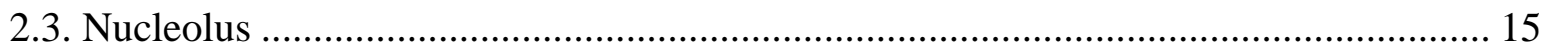

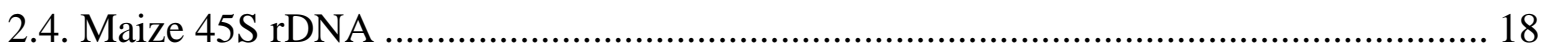

2.5. Nucleolus/Secondary Constrictions 45S rDNA: Heteromorphism............................ 19

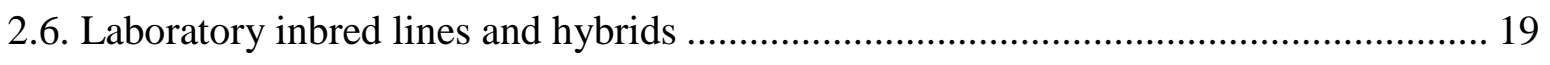

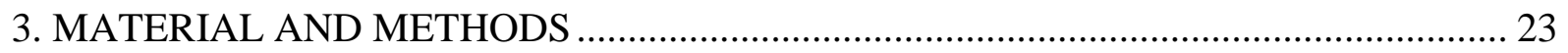

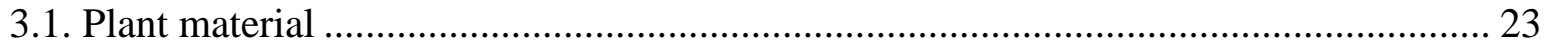

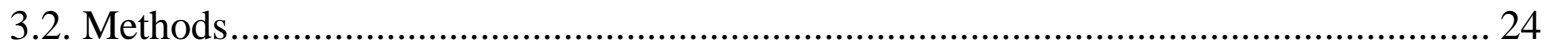

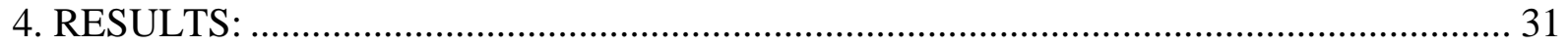

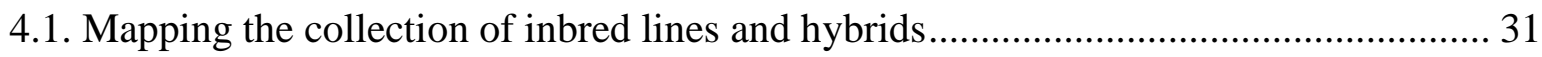

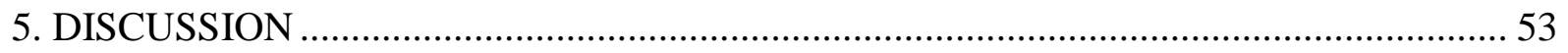

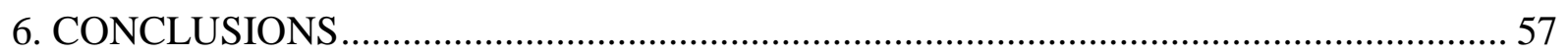

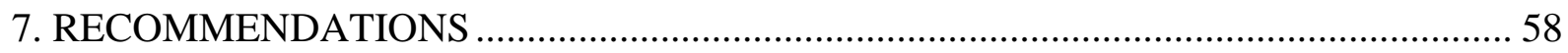

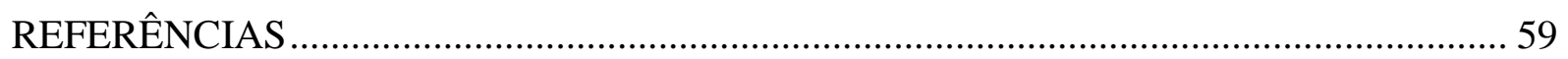

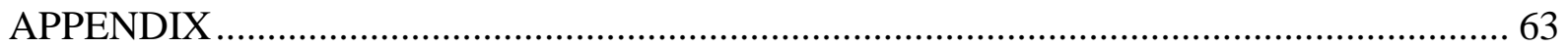


RESUMO

\section{Caracterização da expressão nucleolar e sua correlação com o tamanho dos arranjos de rDNA de 455 em linhagens e híbridos de Zea mays}

O DNA ribossomal (rDNA de 45S) é um dos arranjos in tandem mais bem caracterizados, formado por um cistron de genes 18S-5.8S-26S e também ITS (internal transcribed spacer) e ETS (external transcribed spacer). Nos cromossomos mitóticos é possível distinguir a constrição secundária como uma manifestação de um subconjunto de motivos do rDNA de $45 \mathrm{~S}$ com transcrição ativa em virtude da persistência da RNA Polimerase I. Cada gene ativo codifica um transcrito de RNA de 18S, 5.8S e 26S. Como resultado da expressão e processamento dos genes ribossomais e sua associaçãocom polipeptídeos, forma-se uma estrutura nuclear denominada nucléolo. Consequêntemente existe uma relação entre a transcrição do rDNA de $45 \mathrm{~S}$ e a organização do nucléolo. A literatura tem relatado a expressão diferencial da constrição secundária entre os cromossomos homólogos tanto no tamanho quanto na intensidade do heteromorfismo do rDNA de 45S. Em função disso, foi hipotetizado que o heteromorfismo/homomorfismo do rDNA de $45 \mathrm{~S}$ pode ocorrer em diferentes graus, influenciando a morfologia nucleolar. Neste estudo, famílias de linhagens de milho (JD 1-3, JD 2-1, JD 4-1 e JD 4-4) e seus híbridos foram analisadas. A caracterização qualitativa por hibridização molecular in situ fluorescente (FISH) com sondas rDNA de $45 \mathrm{~S}$ e imunodetecção de fibrilarina, para descrever a constrição secundária no cromossomo 6 e no nucléolo de células binucleolares do início da interfase, respectivamente. A análise quantititativa dos parâmetros foi realizada por análise de imagem e os dados foram analisados utilizando-se modelos mistos e estatísticas multivariadas e univariadas. Os resultados não reportaram homomorfismo propriamente dito, ao contrário, foi observado heteromorfismo tanto para o rDNA de $45 \mathrm{~S}$ quanto para o nucléolo, nas linhagens e híbridos analisados. Os casos de heteromorfismos foram subdividos quantitativamente em 3 categorias de acordo com o valor dos índices das variáveis e do heatmap, sendo considerado como levemente, significativamente e notoriamente heteromórifco. As análises de FISH demonstraram que o DNA ribossomal varia independentemente da fase do ciclo celular. Além disso, as linhagens da família JD 4-4 (3), JD 2-1 (2), JD 4-1 (1) foram as mais heteromórficas, enquanto as linhagens JD 1-3 apresentaram valores menores, próximos ao homomorfismo. Cinco linhagens da família JD 4-4 foram discriminadas como parentais de híbridos heteromórficos com base nos sinais de marcação para a sonda de rDNA 45S. As análises de nucléolo mostraram heteromorfismo em linhagens endogâmicas e nos híbridos, envolvendo principalmente linhagens da família JD 4-4. Assumindo linhagens irmãs e híbridos como dois tipos de material em estudo, não foi observada diferença estrutural entre eles. Porém, a partir da correlação dos resultados da expressão do rDNA de $45 \mathrm{~S}$ com a morfologia nucleolar foi possível agrupar todos os genótipos em clusters, observando que existe uma leve variação no grau de heteromorfismo do rDNA de $45 \mathrm{~S}$ entre os clusters, enquanto a estruturação do nucléolo teve um comportamento homogêneo entre eles. O heteromorfismo do rDNA de 45S pode ser explicado porque os sítios de rDNA podem estar sujeitos a uma maior taxa de recombinação desigual, podendo causar variação no número de cópias do gene. Isso porque há mecanismos de inativação epigenética que poderiam estar envolvidos no controle de expressão dos genes ribossomais.

Palavras-chave: Heteromorfismo, Homomorfismo, rDNA de 45S, Nucléolo, Linhagens endogâmicas, Híbridos, Milho 


\title{
ABSTRACT \\ Characterization of nucleolar expression and its correlation with the size of the 45S rDNA arrangements in Zea mays inbred lines and hybrids
}

\begin{abstract}
Ribosomal DNA (45S rDNA) is one of the most well-characterized tandem arrays, formed by a cluster of 18S-5.8S-26S genes and also ITS (internal transcribed spacer) and ETS (external transcribed spacer). In mitotic chromosomes, it is possible to distinguish secondary constriction as a manifestation of a subset of $45 \mathrm{~S} \mathrm{rDNA}$ motifs with active transcription due to RNA polymerase I persistence. Each active motif encodes an 18S, 5.8S, and $26 \mathrm{~S}$ rRNA transcript. As a result of the ribosomal gene expression and processing and the association with polypeptides, a nuclear structure called a nucleolus is formed. Consequently, there is a relationship between the $45 \mathrm{~S} \mathrm{rDNA}$ transcription and the organization of the nucleolus. The literature has reported the differential expression of secondary constrictions between homologous chromosomes, observing the heteromorphism in the size and intensity of the $45 \mathrm{~S} \mathrm{rDNA}$. As a result, it was hypothesized that the heteromorphism/homomorphism of the $45 \mathrm{~S} \mathrm{rDNA}$ could occur to different degrees, affecting the nucleolar morphology. In this study, inbred families of maize (JD 1-3, JD 2-1, JD 4-1, and JD 4-4) and their hybrids were analyzed. Qualitative characterization was performed using Fluorescence In Situ Hybridization (FISH) with 45S rDNA probes and fibrillarin immunodetection to describe the secondary constriction in chromosome 6 and in the nucleus of binucleolar cells during the initial interphase. Measurements were made by image analysis, and the data were analyzed using mixed models and multivariate and univariate statistics. The results did not report homomorphism itself; on the contrary, heteromorphism was observed for both the 45S rDNA and the nucleolus in the inbred lines and hybrids. The heteromorphism cases were quantitatively subdivided into three categories according to the value of the indexes of the variables and the heatmap, as slightly, significantly, and notoriously heteromorphic. FISH analyzes have shown that ribosomal DNA varies independently of the mitotic phase. In addition, inbred lines of the families JD 4-4 (3), JD 2-1 (2), JD 4-1 (1) were the most heteromorphic, while the JD 1-3 inbred lines showed lower values, close to the homomorphism. Five different inbred lines of the JD 4-4 family were discriminated as parents of heteromorphic hybrids based on the marking signals for the rDNA 45S probe. The nucleolus analyzes showed heteromorphism in inbred and hybrid lines, mainly involving lines of the JD family 4-4. No structural difference was observed between inbred lines and hybrids. However, the correlation of the results of the 45S rDNA expression with the nucleolar morphology, it was possible to group all genotypes in clusters, observing a slight variation in the degree of heteromorphism of the $45 \mathrm{~S}$ rDNA between the clusters. At the same time, the structuring of the nucleolus had a homogeneous behavior between them. The heteromorphism in the $45 \mathrm{~S}$ rDNA can be explained because the rDNA sites may be subject to a higher rate of unequal recombination, which may cause variation in gene copy number. This results in possible epigenetic inactivation mechanisms that could be involved in the control of the ribosomal gene expression.
\end{abstract}

Keywords: Heteromorphism, Homomorphism, 45S rDNA, Nucleolus, Inbred lines, Hybrids, Maize 


\section{INTRODUCTION}

The $45 \mathrm{~S}$ ribosomal DNA is a single transcription unit that encodes for clustered genes $18 \mathrm{~S}, 5.8 \mathrm{~S}$, and 25S. Moreover, each motif of the 45S rDNA contains two internal transcribed spacers (ITS 1 and ITS2) that separate transcription regions and external transcribed spacers (ETS 1 and ETS2) in the boundaries of the coding region. These $45 \mathrm{~S}$ rDNA motifs are arranged in long in tandem repeating units, and they could be located in multiple loci, but not all of them are active. As a type of repetitive DNA sequence, ribosomal rDNA presents several repeats highly variable between distantly related species, as well as members of a single species or population (Boisvert et al., 2007; McStay and Grummt, 2008; Shaw and Brown, 2012; Hamperl et al., 2013; McStay, 2016; Potapova and Gerton, 2019).

$45 \mathrm{~S}$ rDNA subunit is located in the secondary constriction; a chromosome unpacked segment in the mitotic chromosome well-known as Nucleolus Organizer Region (NOR). The active subunit of the 45S rDNA array forms the NORs, where the transcription process took place in the previous interphase. Therefore, the NOR has two functions: the synthesis of $18 \mathrm{~S}, 5.8 \mathrm{~S}$, and $25 \mathrm{~S}$ rRNA; and the organization of the nucleolus (Givens and Phillips, 1976).

Consequently, the nucleolus is a dynamic substructure of the interphase nucleus, originated by the NOR, being the transcription and processing site of the ribosomal RNA as a part of the ribosomal biogenesis (Trinkle-Mulcahy, 2018; Cerqueira and Lemos, 2019; Potapova and Gerton, 2019). Thus, the nucleolus structure as a tripartite model is in accordance to carry out this function. The three morphological components are fibrillar component (FC) and dense fibrillar component (DFC) that contain pre-RNAs, transcription factors, and proteins; and the granular component (GC), where is accumulated the synthesized rRNA and pre-ribosomal particles copies (Shaw and Brown, 2012; McStay, 2016; Potapova and Gerton, 2019). The linking between the transcription of ribosomal DNA and nucleolar structure is based on the nucleation model, explaining nuclear body formation in the nucleus. This model suggests that nucleation events are stimulated by specific gene transcription. In this case, the activation of the RNA Polymerase I and the recruitment of the transcription machinery coincided with the nucleolus assembly (Dundr and Misteli, 2010; Falahati H, Pelham-Webb B, Blythe S, 2016).

Different cytogenetic characterization studies showed variations in the size of secondary constriction in the mitotic chromosome, assumed as differential expression of the $45 \mathrm{~S}$ rDNA. Some of these studies were made in cacao (Dantas and Guerra, 2010), bean (Pedrosa-Harand et. al., 2006) and Crotalaria juncea (Mondin, Santos-Serejo and Aguiar-Perecin, 2007).

Zea mays $(2 \mathrm{n}=20)$ is a model crop that exhibits high levels of phenotypic variations among inbred lines. For example, different cytogenetic characterizations evidenced the structural variations of the maize chromosomes (Springer et al., 2009). Our laboratory developed a program of inbred lines of maize from a single plant of the commercial variety Jack Duro (JD), in which, through successive self-crossing from S2 to S9 progenies, were obtained four inbred line families with a specific knobs composition JD 1-3, JD 2-1, JD 4-1 and JD 4-4 (Decico, 1991). Hybrids of these lines also were produced. This collection of inbred lines and hybrids 
were widely characterized cytogenetically by C-banding and FISH with different probes (Aguiar-Perecin and Decico, 1988; Decico, 1991; Mondin et al. 2014). Preliminary analyses of $45 \mathrm{~S} \mathrm{rDNA}$ of some accessions showed heteromorphism in the secondary constriction of chromosome 6 (data not published); however, this matter was not deepened.

Considering the relation between rDNA activity and nucleolus formation, some questions about 45S rDNA size variation and its consequences on the size of the nucleoli have not been answered.

Moreover, the collection of inbred lines and hybrids represents an excellent model for understanding how these heteromorphisms are produced in the $45 \mathrm{~S}$ rDNA sites and their influence on the nucleolus morphology. Different situations are hypothesized: homomorphic $45 \mathrm{~S}$ rDNA signals could form homomorphic or heteromorphic nucleolus; on the other hand, heteromorphic $45 \mathrm{~S}$ rDNA signals could form homomorphic or heteromorphic nucleolus.

In the sense of testing such hypotheses, the present work aims to:

- Determine the correlation between $45 \mathrm{~S}$ rDNA size variation in mitotic chromosomes and its consequences on the interphase nucleolus size. 


\section{BIBLIOGRAPHIC REVIEW}

\subsection{Structure of $45 S$ rDNA}

\subsubsection{Molecular organization: Genes, Lengths, spacers}

During cell growth and development, there is a high demand for proteins required to carry out their metabolic activity. After the ribosome biogenesis, proteins are formed from rRNA processing and assembly of the ribosome (Weis et al., 2015). Hence, eukaryotic ribosomes are composed of large (60S) and small (40S) units, which are formed from the rRNAs 18S, 5.8S, 25S/28S, and 5S (Sáez-Vásquez and Delseny, 2019).

A single transcription unit named $45 \mathrm{~S}$ rDNA in plants, $47 \mathrm{~S}$ rDNA in mammalian cells, and $35 \mathrm{~S}$ rDNA in yeast encodes for clustered genes 18S, 5.8S, and 25S (or 28S in mammals), while a separate 5S rDNA unit encodes 5S rRNA using another transcription machinery in a different cellular space (Rogers and Bendich, 1987; Potapova and Gorbsky, 2017; Sáez-Vásquez and Delseny, 2019).

Plant and animal genomes have rRNA genes cluster organized in tandem repeats located in multiples loci among the chromosome ( $45 \mathrm{~S}$ rDNA sites). Concerning the number of copies of the $45 \mathrm{~S}$ rDNAs, it is known that plants generally present a higher number than other organisms (Rogers and Bendich, 1987; Roa and Guerra, 2012; Potapova and Gerton, 2019).

In mammals, the most described models are humans and mice. Both cases present large transcription units ( 43-45 kb approximately) and several hundred nearly identical copies (Shaw and Brown, 2012; McStay, 2016; Potapova and Gerton, 2019). On the other hand, plant genomes have thousands of in tandem copies of the 45S rDNA motifs, which are highly conserved between species, and generally are organized in a similar way to the rDNA arrays of other organisms (Roa and Guerra, 2012; Shaw and Brown, 2012; Sáez-Vásquez and Delseny, 2019).

Thus, the rDNA motif structure is the transcribed region that gives rise to a $45 \mathrm{~S}$ pre-rRNA where internal transcribed spacers (ITS1 and ITS2) separate the coding subunits. The ITS1 separates 18S and 5.8S genes, and the ITS2 separates $5.8 \mathrm{~S}$ and $25 \mathrm{~S}$ genes. The coding region boundaries contain external transcribed spacers $\left(5^{\circ} \mathrm{ETS}\right.$ in the $5^{\prime}$ end of $18 \mathrm{~S}$ gene and $3^{\circ} \mathrm{ETS}$ in the $3^{\prime}$ end of 25S) (Figure 1). Moreover, each 45S rDNA motif is separated from the adjacent ones by an intergenic spacer (IGS). This region contains different regulatory genetics elements such as gene and spacer promoters, repetitive enhancer elements, transcription terminators, and fork replication barriers that prevent collisions between replication and transcription machinery. Different studies in plants and animals (including humans) showed that a notorious variation in size characterizes IGS by the position and presence/absence of other regulatory elements (Boisvert et al., 2007; McStay and Grummt, 2008; Shaw and Brown, 2012; Hamperl et al., 2013; McStay, 2016; Potapova and Gerton, 2019). 


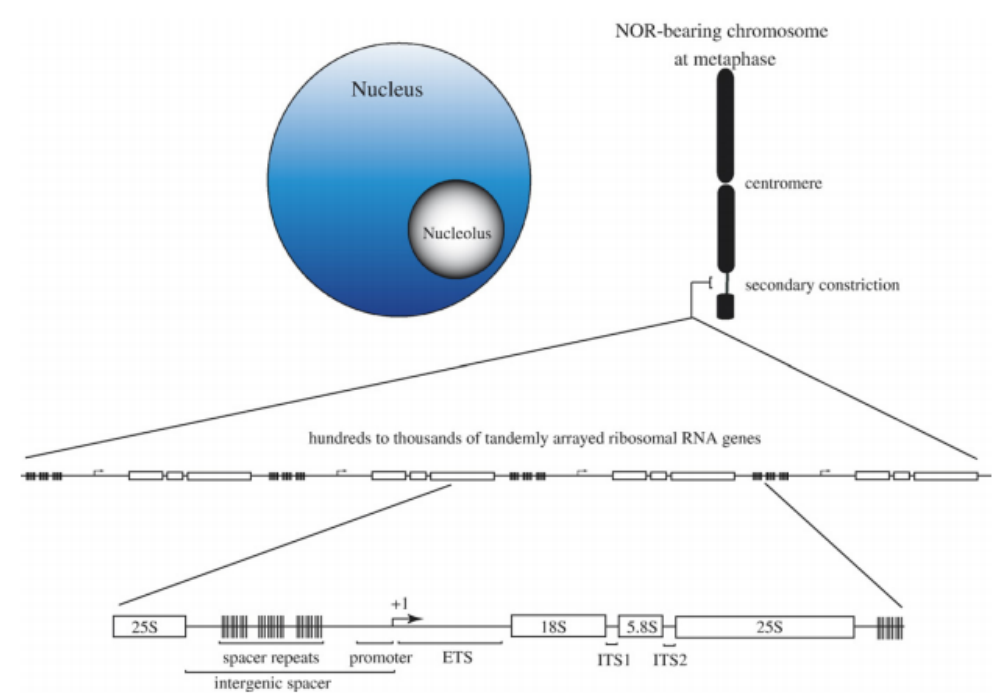

Figure 1. Schematization of the relationship between nucleolus, secondary constriction, NOR, and ribosomal genes (rRNA). The lower part shows the structural organization of the 45S rDNA, showing the coding region made up of the rRNA 18S-5.8S-25S transcription unit and the non-coding spacer regions ITS (internal transcribed sequences) and ETS (external transcribed sequences). Source: Preuss and Pikaard (2007).

\subsubsection{Conservation}

Coding regions are highly conserved in all eukaryotic organisms, making rRNA genes ideal for comparative analysis between distantly related organisms and understanding transcriptional regulation principles. On the other hand, IGS, ITS, and ETS, which are rapidly evolving variable regions, are used for diversity studies of closely related taxa, such as primates, due to variability between the repetitive elements that make them up (Gonzalez and Sylvester, 2007).

Because of the catalytic functions that rRNAs perform protein synthesis, rRNA molecule presences as regulatory agents can be inferred as an ancient characteristic of cellular organisms. However, the sense of conservation of rRNA is more related to its molecular structure than with the nucleotide sequence. This explains why some rRNA functions that depend on secondary and tertiary structures have been conserved between kingdoms and phyla. For example, some rRNA domains present in prokaryotic and archaebacterial are also found in human 18S and 28S rRNAs. So, the structure conservation was possible through compensatory base changes that maintained intramolecular base pairing in the rRNAs. However, primary nucleotide sequences are not conserved; they diverged (Gonzalez and Sylvester, 2007).

\subsubsection{Transcription of genes}

The first step for ribosome biogenesis is the transcript processing of the $45 \mathrm{~S}$ subunits. Each phase of the process takes place in one of the three morphological areas of the nucleolus.

45S rDNA unit encodes a large precursor transcript (pre-mRNA) containing the 18S, 5.8S, and 28S genes (McStay and Grummt, 2008). The rRNA synthesis is regulated by the interaction of RNA Pol I with effectors that are part of signaling pathways generated by events such as growth, availability of nutrients, or during the cell cycle (McStay and Grummt, 2008). RNA Pol I is a multi-subunit protein enzyme that forms a holoenzymatic complex with additional 
GTF molecules. Unlike other polymerase enzymes, RNA Pol I synthesizes a single transcript type (McStay and Grummt, 2008; Sáez-Vásquez and Delseny, 2019).

In mammals, such as humans and mice, the rDNA transcription unit contains a promoter sequence that is divided into two regions: 1 ) basal promoter, from position -45 to +20 , including transcription start site +1 , it is capable of promoting the initiation of transcription; 2) distal regulatory sequence, located near the 5 'end. These distal elements may contact the core promoter or proximal promoter to assist transcription (McStay and Grummt, 2008; Potapova and Gerton, 2019). In plants, dicotyledons present a sequence that approximates the TATATA(A/G)GGG consensus as a transcription start site (Doelling and Pikaard, 1996).

The transcription initiation activity requires the pre-initiation complex assembly in the basal promoter region, composed of proteins such as UBF (upstream binding factor) and SLF1 (promoter selectivity factor). UBF is considered the main protein defining the structure and activity of rDNAs. Molecularly, this protein binds to both promoter regions, acting as an activator of transcription, as an antirepressor, and also as a regulator of the RNA product elongation. SLF1 is a heterodimer made up of TBP (TATA-binding protein) and three TAF (TBP associated factors) proteins that interact with UBF for the recruitment of RNA Pol I (Preuss and Pikaard, 2007; McStay and Grummt, 2008; Potapova and Gerton, 2019).

With the protein complex assembly necessary for the process initiation, RNA pol I continue with the following phases to form the pre-RNA transcript: elongation and termination. The pre-rRNA processing involves the removing of the external (5' ETS and 3'ETS) and internal (ITS1 and ITS2) transcribed spacers through exonucleolytic and endonucleolytic cleavages, respectively, to produce mature 18S, 5.8S and 25 / 28S rRNAs (Doelling and Pikaard, 1996)

Moreover, as part of the processing, pre-rRNAs are subjected to cotranscriptional sugar and base modifications such as 2'-O-ribose methylation and base pseudouridylation, respectively. Both chemical modifications are guided by snoRNAs (small nucleolar RNAs) which working together with particular proteins like Fibrillarin (FBL) to form small nucleolar riboprotein (snoRNPs). All these early pre-rRNA processing occur in the dense fibrillar component (DFC) of the nucleolus, characterized by the presence of fibrillarin. So, different approaches showed that fibrillarin is a key nucleolar conserved protein involved in rRNA maturation (Cerdido and Medina, 1995; Barneche, Steinmetz and Echevarría, 2000; Sáez-Vásquez and Delseny, 2019).

\subsection{4. rDNA transcription and nucleolar structure}

The RNA Polymerase I activation during transcription coinciding with the nucleolus assembly. This fact supports a model in which transcription of specific gene loci stimulates nucleation events to form nuclear body components such as nucleolus (Dundr and Misteli, 2010; Falahati H, Pelham-Webb B., Blythe S, 2016; Németh and Grummt, 2018).

RNA transcription can modulate thermodynamic parameters of nucleolar protein assembly by recruitment mechanism or self-assembly, as in some RNA binding protein-like nucleolin and fibrillarin (Nemeth \& Grummt 2018).

Measurement of the nucleolar area occurs when the transcription of active genes was a controversial topic for research groups. That is why the strategy was to mark the nascent rRNA to locate these active genes. Hozak et al. (1994 apud Shaw et al. 2012) used BrUTP transcript labeling for this purpose and showed actively transcribed genes within the DFC region of the nucleolus. Thompson et al. (1997) compared BrUTP transcript labeling in pea with labeling obtained by double FISH assay with probes for the transcribed NTS region and rDNA regions, showing 
labeling overlaps between labeled BrUTP transcripts and rDNA regions, while the NTS region showed slight overlapping. So, it can be assumed that RNA transcripts are located in DFC, and that repeats are arranged to the level of one gene per transcription unit.

\subsubsection{Variation in copy number or redundancy}

Ribosomal RNA genes (rDNA) are considered the most dynamic loci in the eukaryotic genomes. Due to their metabolic importance, they constitute the highest percentage of the total RNAs of the cell (Rogers and Bendich, 1987; Roa and Guerra, 2012; Gibbons et al., 2015).

Considering the rDNA structure, variations of arrays can occur both in transcription units and in IGS-like spacers. Zhang et al. (1990) cite four modes of variation: 1) variations in the IGS length caused by variations in the number of sub-repeats that make it up, 2) modifications in the nucleotide sequence and/or base modification in the transcription units, 3) nucleotide sequence modifications and/or base modification in the IGS regions, 4) variation in rDNA copy number per haploid genome.

Numerous studies reinforce the idea this locus is characterized by extensive copy number variation (CNV) in a large number of organisms, with variations between distant species and within the same species (Ritossa and Scala, 1969; Rogers and Bendich, 1987; Zhang, Maroof and Allard, 1990; Gibbons et al., 2015). Based on this idea, copy number variation is considered redundant because it exceeds the minimum number of genes necessary for the normal functioning of the cell. However, it has also been thought that this excess can guarantee the transcription rate of genes in high metabolic demand situations, being that only a fraction of the total $\mathrm{rDNA}$ will be active to transcribe in a specific time (Ritossa and Scala, 1969).

Drosophila melanogaster was one of the first models used to understand the redundancy of the rDNA. Bobbed phenotype is characterized by the presence of smaller, thinner bristles on the scutellum of the fly. The wild-type bb+ locus is characterized by carrying 130 copies of both $28 \mathrm{~S}$ and $18 \mathrm{~S}$ rRNA subunits. Ritossa (1968) and Ritossa and Scala (1969) described that the intensity of the mutant phenotype is inversely proportional to the number of rRNA genes. The mutant genotype also has less than 130 copies of the $28 \mathrm{~S}$ and $18 \mathrm{~S}$ genes. After executing various crosses, the authors reported that the mutant effect is reversed from an increasing rRNA copy number through a possible mechanism like unequal crossing-over and/or intrachromosomal exchange.

Lassner and Dvorak (1986) point out that unequal crossing-over could favor changes in the rDNA copy number at a locus and even changes subrepetition number and lengths of the NTS region. Furthermore, the authors argue that unequal crossing-over is considered one of the mechanisms that allow concerted or horizontal evolution, which is characteristic of a multigene family where the repeated genes evolve as a set.

In humans and mice, ribosomes are formed by transcription products of the $45 \mathrm{~S}$ and $5 \mathrm{~S}$ rDNA arrays. Both elements are genetically unlinked and non-homologous; however, they are functionally related. Indeed, the 5S rDNA transcription product shows more correlation with the $5.8 \mathrm{~S}$ and $28 \mathrm{~S}$ rRNA once they form the large ribosomal unit (the 60S), whereas $18 \mathrm{~S}$ rRNA forms the small unit of the ribosome (40S). Hence if some disruption between the $45 \mathrm{~S}$ and $5 \mathrm{~S}$ rDNA dosage would happen, it may cause alterations in ribosome biogenesis and functioning. To avoid that, a concerted evolution between the copy number of $45 \mathrm{~S}$ and $5 \mathrm{~S} \mathrm{rDNA}$ loci shows a way to attenuate gene dosage imbalance of rRNA ribosome components (Gibbons et al., 2015).

Different forms to supply a high demand for RNA were described; being the most used by eukaryotes is the high copy number of ribosomal genes caused by recombination events. On the other hand, heterogeneity in 
intergenic spacer (ITS) length is due to the variability number of elements from one IGS to another. This has been caused by unequal crossing-over between subrepetitive IGS units of the same chromosome or its homolog (Rogers and Bendich, 1987).

\subsection{Chromosome organization}

The first relationship between the nucleolus and a chromosomal segment, which corresponds to the nucleolus organizing region (NOR), was established in the early 1930s (Givens and Phillips, 1976). During the development of the theory of chromosomal heredity in the early 20th century, Heitz (1931, apud Givens \& Phillips, 1976) observed that the number of secondary constrictions in mitotic chromosomes (defined as thin regions with little or no DNA detected using the Feulgen staining method) correlated with the number and size of the nucleolus in interphase cells.

McClintock (1934) observed that after a reciprocal translocation between chromosomes 6 and 9, we had chromosomes $9^{6}$ and $6^{9}$ in metaphase. The interesting detail was to find that in those cells where the reciprocal translocation occurs, they presented two nucleoli during the interphase: one generated by the secondary constriction of chromosome $9^{6}$ and the other by the constriction of chromosome $6^{9}$. This concludes that the nucleoli are associated with both translocated chromosomes, whence the rupture site on chromosome 6 must have been inside a nucleolar organizer with redundant genetic information. Thus, the author demonstrated that chromatin in these regions acts as a nucleolar organizing element, named as NOR "nucleolar organizing region", confirming that the nucleolus is a genetically determined structure.

Subsequently, molecular and cell biology studies revealed that NOR sites are composed of sets of ribosomal genes (rDNA) organized in a head-to-tail orientation. In maize particularly, two main functions have been assigned to NOR: 1) synthesis of the $18 \mathrm{~S}$ and $28 \mathrm{~S}$ rRNAs, and 2) the organization of these rRNA and other nucleolar components within an organized nucleolus (Givens and Phillips, 1976). In the same work, the authors propose that NORs can be divided into two parts: 1) the heterochromatic portion that contains most of the rRNA cistrons and 2) the secondary constriction region that contains the least amount of rRNA cistrons.

During nucleologenesis, not all NORs are necessarily activated. Some will be utterly inactive if many are present, while only a few subsets of the genes will be transcribed (McKeown and Shaw, 2009). Not all the rRNA genes are active simultaneously. The activation can vary during differentiation, as seen in comparisons of primary and adventitious onion roots (McKeown and Shaw, 2009; McStay, 2016). However, the morphology of active NORs, their ability to maintain themselves throughout the cell cycle, and their participation in the nucleolus assembly are based on the genomic stability of the rDNAs contained in that loci.

\subsection{Nucleolus}

\subsubsection{Biogenesis}

The nucleolus was initially described as a prominent substructure located within the nucleus, drawing attention to its high density and membrane absence. Later studies reported variations in nucleoli number per cell, morphology, and the presence/absence of the nucleoli throughout the cell cycle (Trinkle-Mulcahy, 2018). 
Currently, the nucleolus is considered a dynamic structure of the interphase nucleus with great importance in processing ribosomal RNA. It originated from the nucleolus organizer regions (NORs), which contain active regions of 45S rDNA from different chromosomes, representing the transcription site (Trinkle-Mulcahy, 2018; Cerqueira and Lemos, 2019; Potapova and Gerton, 2019).

The nucleolus is formed by three morphological areas: fibrillar component (FC), dense fibrillar component (DFC), and granular component (GC), which were initially revealed by conventional stains, and then described by electron microscopy. Also, a perinucleolar heterochromatin shell surrounding the nucleolus has been described, which it is suspected that is formed by clusters of inactive rDNA regions (Carmo-Fonseca, Mendes-Soares and Campos, 2000; McKeown and Shaw, 2009; Shaw and Brown, 2012).

The fibrillar component (FC) is considered the concentration area of rDNA sequences of the cell genome. Of all these sequences, only a group of them are active, and they are located on the FC periphery, though in a more significant proportion in the dense fibrillar component (DFC). Granular component (GC) represents mainly preribosomal particles at various maturation stages, but some recent studies have reported that other particles may also occupy specific parts of the GC (Németh and Grummt, 2018; Trinkle-Mulcahy, 2018).

This concentric tripartite nucleolar architecture was found in most amniotic beings. Still, the sub-groups of chordates are an exception to this model by presents only a bipartite structure with no FC. Within the amniotic beings group, there are considerable variations in kingdoms, species, cell types, and individual cells. Moreover, in some species, differentiation between the three morphological components is difficult. (Shaw and Brown, 2012; Cerqueira and Lemos, 2019).

In the higher eukaryotes, such as animals and plants, the three components are present. In addition, in animals and plants, nucleolus has a dynamic structure due to their function and activity. Hence, nucleolus in high activity has a larger size and a less defined architecture (FC, DFC, and GC), while in quiescent cells or with nucleolar inactivation (which involves a transcriptional arrest), the tripartite nucleolus model is more defined and compact (McKeown and Shaw, 2009). On the other hand, plants present two different characteristics: 1) a vacuole or cavity in the central part of the nucleolus, and 2) a larger DFC (Carmo-Fonseca et al., 2000).

McKeown and Shaw (2009) suggested that the formation of the nucleolus is a consequence of the transcription process and an evolutionary strategy to increase ribosome synthesis efficiency.

Nemeth and Grumth (2018) proposed whether a disturbance in rDNA transcription occurred, it could affect the tripartite nucleolus model. For example, the inhibition of RNA polymerase I (RNA pol I) by drugs led to a rearrangement of the nucleolus components preventing its typical disintegration in the cell cycle and changes in the nucleolar proteome. Consequently, morphological changes in the nucleolus may reflect abnormalities in the metabolic processes such as transcription, replication, and DNA repair.

Therefore, there is a strong correlation between the rDNA transcription rate and the structuration of the nucleolus. Therefore, for nucleolus biogenesis is necessary to coalescence the transcription machinery of rDNA (Olson and Dundr, 2005). 


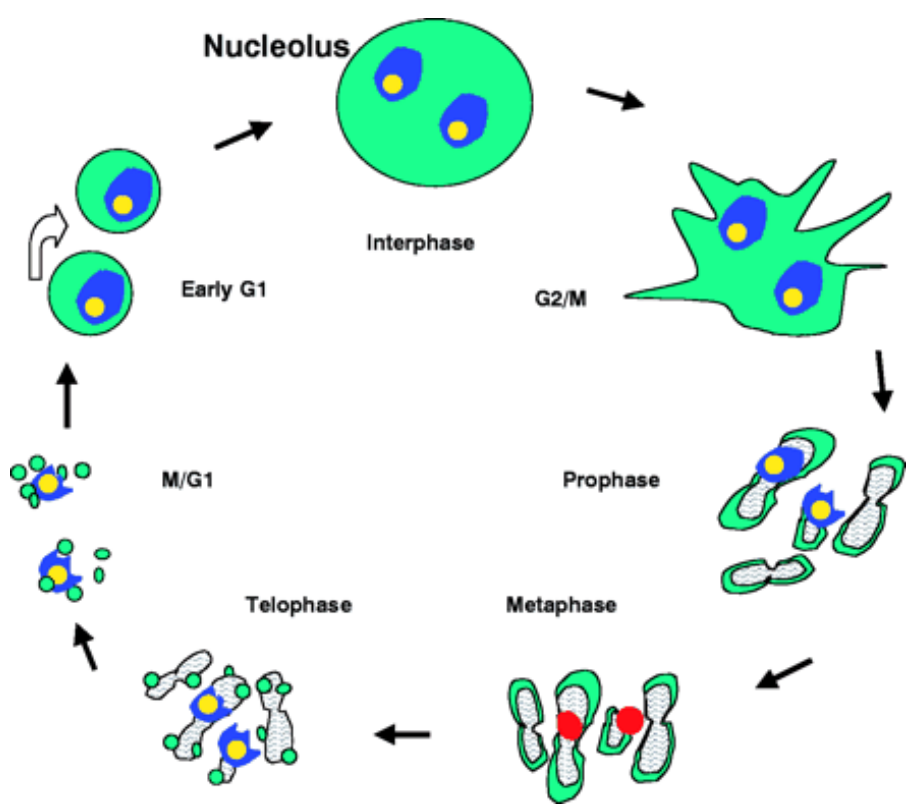

Figure 1. Nucleolus biogenesis in human cells. During interphase, the nucleolus has three main components: the fibrillar centers (FC) in yellow, the dense fibrillar component (DFC) in blue, and the granular component (GC) in green. During the transition of G2 to mitosis, transcriptional machinery stops its functions, and during the prophase, all these complexes are distributed around the condensed chromosomes. However, the rDNA in some chromosomes remains decondensed ready to reactivate transcription (yellow and blue). The red mark on the metaphase chromosome is a signal that pol I transcription is temporarily repressed. During the transition of $M / G 1$, the reform of active NORs gives rise to the nucleolus, and the transcription process is retaken (Hernandez-Verdun, D. et al. 2002).

\subsubsection{Behavior during the cell cycle}

In mammalian cells occurs a coordinated nucleolar reform during each cell cycle with protein complexes and other molecules that preexisting during mitosis. (Figure 1). In this way, at the beginning of mammalian mitosis, UBF and other Pol I-related factors remain associated with less condensed rDNA. However, Pol I itself does not appear to be present. These regions can be visualized on mitotic chromosomes scattered as secondary constrictions less condensed than the surrounding chromatin (Sirri, Hernandez-Verdun, and Roussel, 2002). Heterochromatic regions of NOR during interphase do not have UBF nor other factors related to Pol I; therefore, they are fully condensed during mitosis. (McKeown and Shaw, 2009; Németh and Grummt, 2018).

Nucleolar disassembly begins with the ordered release of rRNA processing complexes at the beginning of the mitosis, followed by RNA polymerase (Pol I) transcription inhibition and subsequent loss of visible nucleoli until the end of the prophase at this stage. Some factors related to the transcriptional machinery of Pol I remain associated with previously active NORs, while certain DFC and GC factors are derived for a provisional perichromosomal compartment. This includes fibrillarin, nucleolin, and 45S rRNA partially processed (Boisvert et al., 2007).

As a part of the nucleolus dynamics, reassembly begins at telophase with the reversal of phosphorylations effect and the reactivation of rDNA transcription in mitotic NORs pre-loaded with RNA Pol I complexes. In sequence, transient foci called "pre-nuclear bodies" containing protein accumulations are formed. These foci are important for DFC and GC reassembly during nucleolar assembly. After that, at the beginning of the G1 stage, the individual NORs 
begin to merge into multiple small nucleoli and then fusing to form mature and more prominent nucleoli. (Németh and Grummt, 2018).

\subsection{The maize $45 S$ rDNA}

The classical study of McClintock (1934) in the pachytene chromosome of maize showed the association between the nucleolus and a particular cytological structure positioned in the short arm of chromosome 6 . This region was considered a likely nucleolus assembly site known as the nucleolus organizer region (NOR). The nucleolus is directly associated with a specific chromosomal region known as the secondary constriction of the NOR; in the proximal region, there is a sizeable heterochromatic region (the NOR heterochromatin) in the distal region of secondary constriction is located in the satellite region, a remainder of chromosome 6.

Further studies analyzing the pachytene stage of microsporogenesis documented that $17 \mathrm{~S}$ and $26 \mathrm{~S}$ rRNAs genes of maize are within and not simply associated with or near to the NOR (Phillips, 1978). It was also demonstrated by Givens and Phillips (1976) through duplications of chromosomal regions entirely within the NOR by the use of double interchange stocks, causing an increase in the percentage of the DNA homologous to the rRNA genes.

According to the rRNA organization inside NORs in maize, most of these copies are located in the heterochromatin region. At the same time, a small number of them are present in the secondary constriction. Considering that heterochromatin involves inactive genes, the small fraction of rRNA genes located at the secondary constriction is transcriptionally active during the microsporogenesis (Phillips, Kleese, and Wang, 1971; Givens and Phillips, 1976). Approximately 10-30\% of the genes at the secondary constriction in pachytene nuclei are active in synthesizing both $17 \mathrm{~S}$ and $26 \mathrm{~S}$ rRNAs and organizing the assembled nucleolus. On the other hand, rRNA genes located in NOR heterochromatin can be activated by translocation to a different chromosome (Phillips et al. 1971).

The transcription activity of the distal region of NOR, which involves the formation of the nucleolus at the secondary constriction, suppresses the activity of the proximal NOR region (heterochromatin). However, inactivation of the distal NOR region could generate the reverse effect in the proximal region, making it active. This would verify that all rRNA genes can carry out the transcriptional activity and assembling nucleoli (Buescher, Phillips and Brambl, 1984).

\subsubsection{Structure of $45 \mathrm{~S}$ rDNA in maize}

In maize, the rRNA genes are repeated about 10,000 times (Phillip et al. 1971). Clusters of rDNA tandem repeat were undergone to restriction endonuclease digestion analysis to define the repeat unit. It was carried out using different enzymes like EcoRI and BamHI. All the results showed a tandem "head to tail" array of 9kb rDNA repeats as a transcription unit of maize. Moreover, several maize inbred lines were compared using this methodology. Although all of them had the expected length of $9 \mathrm{~kb}$ in the repeat unit, some differences in the restriction sites and length of the spacer region were observed (Buescher 1984).

The small subunit $17 \mathrm{~S}$ rRNA gene was characterized by shotgun sequencing Messing et al. (1984). It was compared with other $18 \mathrm{~S}$ subunits to determine the extremes 5' and 3'. Results showed that maize $17 \mathrm{~S}$ had a length of 1809 nucleotides and an important GC content of 50.9\%. Considering both characteristics, the maize 17S rRNA gene revealed sequence homology when compared with rats (78.6\%), Xenopus (79.4\%), and yeast (80.6\%). 
About the maize rDNA spacer region, as it was explained, the total length of rDNA repeats is strangely uniform, compared to what happens in many species of plants and animals where the variety of lengths in the repeats is quite frequent. This is because the rDNA spacers region differs in the number of subrepeats that compose them. But besides the uniform length, maize spacer regions also contain similar repetitive elements, being the outside subrepeats are less conserved than the internal sub-repeats (McMullen, Phillips and Rubenstein, 1991). This fact seems a form of selection against spacer variation, which was observed in a composite barley population where a selection of specific rDNA spacer variants was evidenced (Saghai-Maroof et al. 1984 apud McMullen et al. 1991).

\subsection{Nucleolus/Secondary Constrictions 45S rDNA: Heteromorphism}

The rDNA copy number variations described above at the molecular level may involve changes in chromosome level, causing structural variations in the region containing the $45 \mathrm{~S}$ rDNA locus, which could affect the activity of nucleoli during the cell interphase.

Several studies using FISH have documented rDNA sites often display intraspecific heteromorphism in number and size. For example, in a comparative analysis of mitotic chromosomes of Theobroma cacao and Theobroma grandiflorum was found that in both species, the $45 \mathrm{~S}$ rDNA site was co-localized with CMA+ band, so both bands were frequently heteromorphic in size and distended in one or both homologous chromosomes (Dantas and Guerra, 2010). Another research confirmed a high heteromorphism level of 45S rDNA in 37 wild and domesticated bean accessions, with 6 to 18 sites per accession and a wide variation of size within chromosome pairs (Pedrosa-Harand et al., 2006). However, some sites may be outside of the FISH detection limits, and their eventual amplification in different populations may account for the numerical polymorphism (Roa and Guerra, 2012).

Among all the copy numbers of the $45 \mathrm{~S}$ rDNA present in a cell, a percentage will be active and another inactive depending on the cell metabolic demand. Active $45 \mathrm{~S}$ rDNA loci generally are decondensed within the body of the nucleolus and, the nucleolar volume is correlated with nucleolar activity (Falahati, Pelham-Webb and Blythe S, 2016).

Crotalaria juncea is an example of the activity of ribosomal gene clusters. Using silver staining and FISH techniques have described the presence of $45 \mathrm{~S}$ rDNA locus on the short arm of chromosome 1 , constantly forming a secondary constriction and an additional site with optional activity on the short arm of chromosome 4. During interphase, the presence of up to 4 nucleoli was occasionally observed, two correspondings to the NOR region of chromosome 1 and 2, to the NOR region of chromosome 4, in both cases, a degree of heteromorphism including variations in the nucleolus size (such as large, medium, and small) was reported between the nucleoli of the same pair of homologs (Mondin, Santos-Serejo, and Aguiar-Perecin, 2007).

\subsection{Laboratory inbred lines and hybrids}

To carry out studies about the influence of heterochromatic regions such as knobs was planned to develop pure lines in the Department of Genetics at "Luiz de Queiroz" College of Agriculture - ESALQ, University of São Paulo - USP. The derivations were made from the commercial variety Jac-Duro (Flint type endosperm) donated by Agroceres Seeds, Brazil (Fig. 2). The original knobs composition of these materials was segregating knobs for 
chromosomes K3L, K5L, K7S, K9S, and homozygous knobs for chromosomes K6L, K7L, and K8L (consider S and $\mathrm{L}$ as short and long chromosome arm respectively) (Decico, 1991).

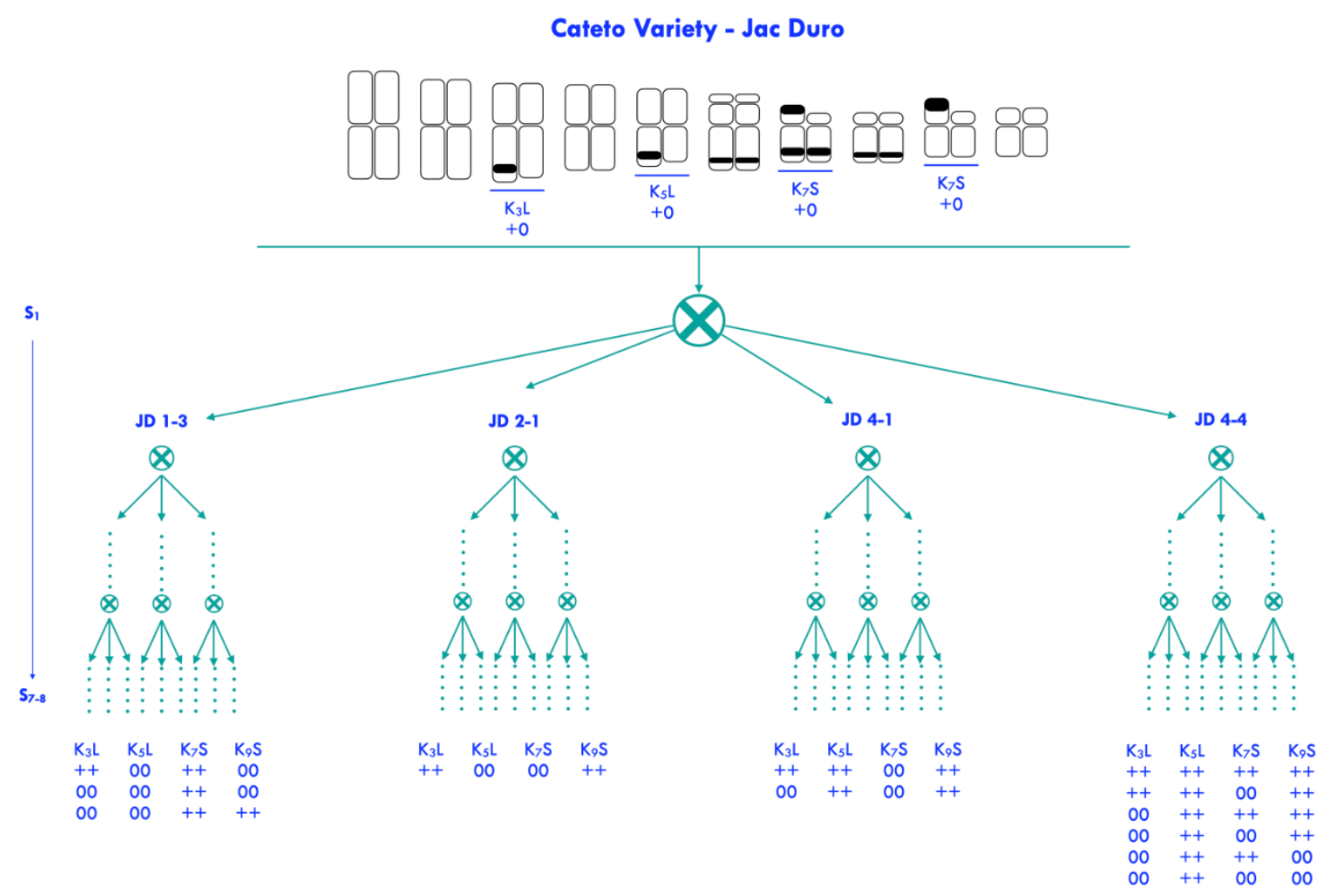

Figure 2. The schematization of the program to obtain inbred lines. The one commercial plant of Jack Duro variety had a determinate composition of knobs: K3L, K5L, K7S, K9S as segregating knobs; and K6L, K7L, K8L as homozygous knobs. After several self-fertilization cycles, four linage families were obtained: JD 1-3, JD 2-1, JD 4-1, and JD 4-4. Each family contains a different number of lineages with a specific knob composition (++: the presence of knob, 00: absence of knob). Source: Carvalho (2020).

Preliminary analyses carried out by Aguiar-Perecin and Decico (1988) with C-band in mitotic metaphase chromosomes showed expected Mendelian segregation. Subsequently, the presence or absence of knobs in specific positions was selected from the self-fertilization cycles of all inbred lines (Decico, 1991). The frequency of C-bands on S3 (240-14-1 and 240-14-2) and S2 (240-14-4) generations was also determined. From the S3 inbred line families, the 240-14-1 genotype was segregated into two-knob positions, K3L and K9S, while the 240-14-2 genotype segregated for one locus, K9S. The 240-14-4 genotype from the S2 inbred line family was segregated into the four loci: K3L, K5L, K7S, and K9S. Homozygous knobs in the chromosomes K6L, K7L, and K8L were maintained in all the inbred lines. These biological materials were derived until S9 progenies, establishing four lines named JD 1-3, JD 2-1, JD 4-1, and JD 4-4.

Bertão (1998) studied two lines with differences in their heterochromatic knob content and their respective hybrid. The results showed new evidence of $\mathrm{C}$-bands corresponding to the larger knobs in the pachytene, which alter the size of mitotic chromosomes. Moreover, a protocol for FISH was standardized, using a repetitive DNA probe specific for heterochromatic knobs. The results showed correspondence between the repetitive DNA signals with the location and size of the C-bands. Subsequently, a complete characterization of cytogenetic variability was carried out. 
This involving meiotic analysis, C-band, and FISH of the S6 sister inbred lines (JD 1-3 and JD 4-4), their hybrids, and KYS compared to the inbred line (Bertão, 1998).

The diversity of the probes used, such as $180 \mathrm{pb}$ knob repeat, centromeric satellite (CentC), centromeric satellite 4 (Cent4), subtelomeric clone 4-12-1, 5S ribosomal DNA, and nucleolus organizing region, described the karyotype diversity into the inbred lines. Although, it was demonstrated that the knob pattern of the lines was consistently homogeneous. The possibility of the heterozygous condition presented in the hybrids would reduce local recombination was discussed (Mondin et al., 2014).

Decico (1991); Aguiar-Perecin et al. (2000); Mondin et al. (2014) described that maize is a crop characterized by the presence of three different types of constitutive heterochromatin distinguished by C-banding, such as centromeric heterochromatin (CentC), knobs (180 bp), and NOR-heterochromatin, exclusively present in the chromosome 6 . The fact that the literature supports the possible influence of the number of knobs with the flowering time of the plant allows us to infer that the knowledge of the conformation and segregation of each type of chromatin is essential to understand the adaptive value of heterochromatin in the development of an organism.

Although the collection of inbred lines and hybrids has been extensively characterized for various types of repetitive DNA, but until now, a systematic mapping of $45 \mathrm{~S} \mathrm{rDNA}$ has not been performed. Therefore, if we consider the occurrence of heteromorphisms reported in the literature, this collection of inbred lines represents an excellent opportunity to understand the origin of these $45 \mathrm{~S} \mathrm{rDNA}$ size variations and their consequences for the nucleolus formation. 


\section{MATERIAL AND METHODS}

\subsection{Plant material}

In the present study, seeds were produced by the breeding program of our laboratory to obtain inbred lines. These inbred lines were obtained by the sibling crosses of S4 and S5 progenies, which were produced by S2 and S3 progenies of the only one plant of the commercial variety Jac - Duro (Agroceres Seeds, Brazil) (Figure 2). The outcomes were four families of near-isogenic (S9) maize inbred lines: JD 1-3, JD 2-1, JD 4-4, and JD 4-1 with specific knobs composition (Table 1A). Crosses formed hybrids between JD 1-3 and JD 4-4 families (Table 1B).

Table 1A. Total inbreds line with their knobs composition. Analysis registration to each inbred line in fibrillarin immunodetection (Nucleolar analysis) and physical mapping of the 45S rDNA (FISH $45 \mathrm{~S}$ rDNA) is shown. $\mathrm{Y}:$ yes, $\mathrm{N}$ : not.

\begin{tabular}{|c|c|c|c|c|c|c|c|}
\hline \multirow{2}{*}{ Family } & \multirow{2}{*}{ Inbred line } & \multicolumn{4}{|c|}{ Knobs } & \multirow{2}{*}{$\begin{array}{l}\text { Nucleolar } \\
\text { analysis }\end{array}$} & \multirow{2}{*}{$\begin{array}{c}\text { FISH 45S } \\
\text { rDNA }\end{array}$} \\
\hline & & K3L & K5L & K7S & K9S & & \\
\hline \multirow{6}{*}{ JD 1-3 } & $132331 / 1-00$ & 0 & 0 & ++ & ++ & $\bar{Y}$ & $\mathrm{Y}$ \\
\hline & $133422-04$ & ++ & 0 & ++ & 0 & $\mathrm{Y}$ & $\mathrm{Y}$ \\
\hline & 131311/1-00 & 0 & 0 & ++ & ++ & $\mathrm{Y}$ & $\mathrm{Y}$ \\
\hline & 133421-04 & ++ & 0 & ++ & 0 & $\mathrm{Y}$ & $\mathrm{Y}$ \\
\hline & 131511-04 & 0 & 0 & ++ & ++ & $\mathrm{Y}$ & $\mathrm{Y}$ \\
\hline & $133427-04$ & 0 & 0 & ++ & 0 & $\mathrm{Y}$ & $\mathrm{Y}$ \\
\hline \multirow{5}{*}{ JD 2-1 } & $211121 / 1-04$ & ++ & 0 & 0 & ++ & $\mathrm{Y}$ & $\mathrm{Y}$ \\
\hline & 211131-04 & ++ & 0 & 0 & ++ & $\mathrm{Y}$ & $\mathrm{Y}$ \\
\hline & 213112-04-04 & ++ & 0 & 0 & ++ & $\mathrm{Y}$ & $\mathrm{Y}$ \\
\hline & $211211 / 2-04$ & ++ & 0 & 0 & ++ & $\mathrm{Y}$ & $\mathrm{Y}$ \\
\hline & $213311 / 1$ & ++ & 0 & 0 & ++ & $\mathrm{Y}$ & $\mathrm{Y}$ \\
\hline \multirow{9}{*}{ JD 4-4 } & $441311 / 2-00$ & ++ & ++ & ++ & ++ & $\mathrm{Y}$ & $\mathrm{Y}$ \\
\hline & 441324/1-00 & ++ & ++ & ++ & ++ & $\mathrm{Y}$ & $\mathrm{Y}$ \\
\hline & $442213 / 1-00^{*}$ & ++ & ++ & ++ & ++ & $\mathrm{N}$ & $\mathrm{N}$ \\
\hline & $442242 / 1-00$ & 0 & ++ & 0 & ++ & $\mathrm{Y}$ & $\mathrm{Y}$ \\
\hline & $442612 / 1-00$ & 0 & ++ & 0 & ++ & $\mathrm{Y}$ & $\mathrm{Y}$ \\
\hline & $441123 / 3-04$ & ++ & ++ & ++ & ++ & $\mathrm{Y}$ & $\mathrm{Y}$ \\
\hline & $441132 / 2-04$ & ++ & ++ & ++ & ++ & $\mathrm{Y}$ & $\mathrm{Y}$ \\
\hline & $444332-04$ & 0 & ++ & ++ & 0 & $\mathrm{Y}$ & $\mathrm{Y}$ \\
\hline & 44431-00 & 0 & ++ & 0 & 0 & $\mathrm{Y}$ & $\mathrm{Y}$ \\
\hline \multirow{6}{*}{ JD 4-1 } & 41122 & ++ & ++ & 0 & ++ & $\mathrm{Y}$ & $\mathrm{Y}$ \\
\hline & 412331 & ++ & ++ & 0 & ++ & $\mathrm{Y}$ & $\mathrm{Y}$ \\
\hline & 41234 & ++ & ++ & 0 & ++ & $\mathrm{Y}$ & $\mathrm{Y}$ \\
\hline & 4124 & ++ & ++ & 0 & ++ & $\mathrm{Y}$ & $\mathrm{Y}$ \\
\hline & 41242 & ++ & ++ & 0 & ++ & $\mathrm{Y}$ & $\mathrm{Y}$ \\
\hline & KYS & & & & & $\bar{Y}$ & $\mathrm{~N}$ \\
\hline
\end{tabular}

*This lineage did not have enough seeds to perform both characterizations. However, the study was considered because it was part of the parents of some hybrids shown in Table $1 \mathrm{~B}$. 
Table 1B. Analysis registration to each hybrid in fibrillarin immunodetection (Nucleolar analysis) and physical mapping of the 45S rDNA (FISH 45S rDNA). Y: yes, N: not.

\begin{tabular}{|c|c|c|c|}
\hline Cross-type & Hybrid & $\begin{array}{l}\text { Nucleolar } \\
\text { analysis }\end{array}$ & $\begin{array}{c}\text { FISH } 45 s \\
\text { rDNA }\end{array}$ \\
\hline \multirow{22}{*}{ JD 4-4 X JD 4-4 } & $44431 \times 442242 / 1$ & $\mathrm{Y}$ & $\mathrm{Y}$ \\
\hline & $44431 \times 442612 / 1$ & $\mathrm{Y}$ & $\mathrm{Y}$ \\
\hline & $44431 \times 441324 / 1$ & $\mathrm{Y}$ & $\mathrm{Y}$ \\
\hline & $44431 \times 442213 / 1$ & $\mathrm{Y}$ & $\mathrm{Y}$ \\
\hline & $442242 / 1 \times 44431$ & Y & Y \\
\hline & $442242 / 1 \times 441311 / 2$ & $\mathrm{Y}$ & $\mathrm{Y}$ \\
\hline & $442242 / 1 \times 441324 / 1$ & $\mathrm{~N}$ & Y \\
\hline & $442612 / 1 \times 44431$ & Y & $\mathrm{N}$ \\
\hline & $442612 / 1 \times 442242 / 1$ & $\mathrm{Y}$ & $\mathrm{Y}$ \\
\hline & $442612 / 1 \times 441311 / 2$ & $\mathrm{Y}$ & $\mathrm{Y}$ \\
\hline & $442612 / 1 \times 442213 / 1$ & $\mathrm{Y}$ & $\mathrm{Y}$ \\
\hline & $441311 / 2 \times 44431$ & $\mathrm{Y}$ & $\mathrm{Y}$ \\
\hline & $441311 / 2 \times 442612 / 1$ & $\mathrm{Y}$ & $\mathrm{Y}$ \\
\hline & $441311 / 2 \times 441324 / 1$ & $\mathrm{~N}$ & $\mathrm{Y}$ \\
\hline & $441311 / 2 \times 442213 / 1$ & $\mathrm{Y}$ & $\mathrm{Y}$ \\
\hline & $441324 / 1 \times 442241 / 1$ & $\mathrm{~N}$ & $\mathrm{Y}$ \\
\hline & $441324 / 1 \times 442612 / 1$ & $\mathrm{Y}$ & $\mathrm{Y}$ \\
\hline & $441324 / 1 \times 441311 / 2$ & $\mathrm{Y}$ & $\mathrm{Y}$ \\
\hline & $441324 / 1 \times 442213 / 1$ & $\mathrm{Y}$ & $\mathrm{Y}$ \\
\hline & $442213 / 1 \times 4443 / 1$ & Y & Y \\
\hline & $442213 / 1 \times 442612 / 1$ & $\mathrm{Y}$ & Y \\
\hline & $442213 / 1 \times 441311 / 2$ & $\mathrm{Y}$ & $\mathrm{Y}$ \\
\hline \multirow{2}{*}{ JD 4-4 X JD 1-3 } & $442612 / 1 \times 131311 / 1$ & $\mathrm{Y}$ & $\mathrm{Y}$ \\
\hline & $441324 / 1 \times 131311 / 1$ & $\mathrm{Y}$ & $\mathrm{Y}$ \\
\hline \multirow{2}{*}{ JD 1-3 X JD 4-4 } & $131311 / 1 \times 442612 / 1$ & $\mathrm{Y}$ & $\mathrm{N}$ \\
\hline & $131311 / 1 \times 441324 / 1$ & Y & $\mathrm{Y}$ \\
\hline \multirow{2}{*}{ JD 1-3 X JD 1-3 } & $131311 / 1$ x 132331/1 & $\mathrm{Y}$ & $\mathrm{Y}$ \\
\hline & $132331 / 1 \times 131311 / 1$ & $\mathrm{Y}$ & $\mathrm{Y}$ \\
\hline
\end{tabular}

\subsection{Methods}

\subsubsection{Germination}

Seed samples of the inbred lines and hybrids were soaked in a petri dish with water for 8 hours at a controlled temperature of $28{ }^{\circ} \mathrm{C}$. After that time, the seeds were sown in moistened Sphagnum, keeping the same temperature. After 3 to 4 days, the root tips reached a size of 1 to $3 \mathrm{~cm}$ in length, necessary to perform the harvest and pre-treatment of the root tips. 


\subsubsection{Fibrillarin immunodetection assay}

\subsubsection{Root tips fixation for immunodetection}

The root tips were directly fixed in 4\% paraformaldehyde in 1X PBS for 10 minutes under vacuum at $1 \mathrm{~atm}$ without pretreatment. Then the root tips were washed in 1X PBS in the same conditions for 10 minutes, after which they were placed in a new $1 \mathrm{X}$ PBS until the slide preparation.

\subsubsection{Preparation of slides for immunodetection}

The slides were prepared following the squash technique using 1X PBS solution to dissociate the root tip meristem. The coverslip was removed by immersion in liquid nitrogen, and the slide was immediately kept in 1X PBS and covered with a paraffin coverslip to prevent dehydration of the material. Subsequently, the slides were placed in a humid chamber until use.

\subsubsection{Immunodetection of the targets}

Slides were blocked in a BSA $0.1 \%$ in $1 \mathrm{X}$ PBST solution at $37^{\circ} \mathrm{C}$ for 1 hour. Then, they were incubated in a humid chamber with the primary mouse anti-fibrillarin antibody diluted in blocking solution 1: 500 , at $4^{\circ} \mathrm{C}$, overnight.

After incubation, the slides were washed twice in 1X PBST solution for 5 minutes. Then they were incubated with the secondary rabbit anti-mouse TRITC antibody (1: 150) at $37^{\circ} \mathrm{C}$ for 1 hour and then washed twice in the $1 \mathrm{X}$ PBST solution for 5 minutes. The slides were counterstained and mounted with 7ul of DAPI (4 ', 6diamidino-2-fenilindol) - Vectashied H-100 solution, finally stored in the dark for the dye stabilization before analysis in the fluorescence microscope.

\subsubsection{Physical mapping of the $45 \mathrm{~S}$ rDNA by FISH in mitotic chromosomes}

\subsubsection{Root tips pre-treatment and fixation}

Roots tips were harvested as described above and pre-treated in a solution of 8-hydroxyquinoline 300ppm plus cycloheximide 25ppm (19:1) for 2 hours and 45 minutes under a controlled temperature of $28{ }^{\circ} \mathrm{C}$.

After pre-treatment, root tips were fixed in Carnoy solution composed of ethanol and acetic acid (3:1) and placed under stirring at $28^{\circ} \mathrm{C}$ for 24 hours and subsequently preserved at four ${ }^{\circ} \mathrm{C}$ until the preparation of the slides. 


\subsubsection{Preparation of slides for FISH}

The slides for FISH were prepared according to the cell squash approach standardized by Schwarzacher and Heslop-Harrison (2000), with minor variation in the enzymatic cocktail, composed of $2 \%$ cellulase, $20 \%$ pectinase, and $1 \%$ macerozyme. The coverslip was removed by immersion in liquid nitrogen and kept in Coplin jars at $20{ }^{\circ} \mathrm{C}$ with silica gel until use.

\subsubsection{The $45 S$ rDNA probe}

The physical mapping of the 45S rDNA sites in the inbred lines and hybrids was carried out using the complete motif sequence of the rRNA genes (18S - 5.8S - 25S) of maize cloned in the plasmid pUC8 in the Eco RI site; which was cordially provided by Dr. R. L. Phillips (University of Minnesota, USA).

\subsubsection{Probe production and labeling for FISH}

Plasmid DNA was extracted using the Qiagen Tip 20 kit following the manufacturers instructions after bacteria clone growth which contains the maize ribosomal DNA insert. The quality of the extracted DNA was analyzed by $0.8 \%$ agarose gel electrophoresis.

The probe was produced by labeling the $45 \mathrm{~S}$ rDNA plasmid with biotin via Nick Translation, according to the manufacturer's instructions. Dot blot tests were performed to check the efficiency of the labeling.

\subsubsection{FISH using $45 S$ rDNA probe}

Chromosome preparations for FISH involve slides washing with RNAse (5ug/ul) and pepsin (5ug/ul) to eliminate RNA and protein excesses, respectively. After washing, the chromosome preparations were fixed in a 4\% paraformaldehyde solution in milli-Q water for 5 minutes and dehydrated in a 70\%, $96 \%, 100 \%$ alcoholic series for 5 minutes each.

Before hybridization, 25ul of hybridization mixture was prepared for each slide containing $50 \%$ formamide, 2X SSC, $10 \%$ dextran sulfate, $0.1 \%$ SDS, $1 \mathrm{mg} / \mathrm{ml}$ herring sperm DNA and $3.75 \mathrm{ul}$ of the labeled probe (40ng/ul). Tubes containing the hybridization mixture were denatured at $85-90{ }^{\circ} \mathrm{C}$ for 10 minutes and immediately immersed on ice for 10 minutes. Hybridization mixture was added onto the slide, and then the slides were sealed and placed in the thermal cycler to be hybridized with a cycle of $92^{\circ} \mathrm{C}$ for 10 minutes followed by $37^{\circ} \mathrm{C}$ for 20 hours.

After hybridization, the slides were immersed in 2x SSC at room temperature until the coverslip drop off the slide. Then, the preparations followed to consecutive washes at $42{ }^{\circ} \mathrm{C}$ to reach $74 \%$ of the degree of stringency, in sequence: once $2 \mathrm{x}$ SSC for 5 minutes, twice $20 \%$ formamide in $0.5 \mathrm{x}$ SSC for 5 minutes each, one time at $0.5 \mathrm{x}$ SSC for 5 minutes. Finally, they were washed once in $0.5 x$ SSC for 5 minutes at room temperature.

Detection of the biotin-labeled probe was performed using the primary mouse anti-biotin antibody (Dako), followed by the rabbit anti-mouse TRITC antibodies (Dako) and the anti-rabbit swine TRITC (Dako). The dilution of 
the three antibodies used was 1:50. The slides were counterstained with DAPI $(0.2 \mathrm{ug} / \mathrm{ml})$ and mounted using 6ul of Vectashield H-100.

\subsubsection{Microscopy and image analysis}

Cytological preparations were analyzed using a Zeiss Axiophot 2 microscope using the appropriate filters. Imagens were acquired by a PCO CCD camera and digitalized throughout the ISIS software (MetaSystems, Germany). Nucleolus images and FISH images were captured with 630X and 1000X magnification, respectively.

Digitalized images of the nucleolus and secondary constriction of homologous chromosomes of the inbred lines and hybrids were analyzed using Image J (V. 1.47) (Rasband, 2018).

Shape descriptors of nucleolus morphology were measured in 2D, including:

A. Geometric descriptors:

- Area (expressed as $\mu \mathrm{m}^{2}$ ): Total number of pixels present in the filled shape of the cell image, later transformed to squared micrometers (Lobo J., See E.Y., Biggs M., 2016).

- Perimeter (expressed in $\mu \mathrm{m})$ : The distance surrounding the actual shape of the nucleolus in 2D (Kalkhoran S.B. et al. 2017).

- Diameters or Aspect Ratio (AR): Representing major to minor diameter.

- Feret's diameter (expressed in $\mu \mathrm{m}$ ): Defined as the longest distance between any two points within the selected region (Kalkhoran S.B. et al. 2017).

- Circularity (calculated by the formula: $4 \pi \mathrm{x}$ Area/Perimeter2): Perfect circular shape has a circularity value close to 1.0 , whereas more elongated shapes have a circularity value that is closer to 0 (Lobo J., See E.Y., Biggs M., 2016).

B. Non-geometric descriptors:

- Integrated Optical Density (IOD): OD refers to optical density or also called absorbance. So that, IOD results from integrating the grey level values of the segmented area (binary image) (Vidal, 1997).

- Raw Integrated Density (Raw IOD): The sum of the values of intensity of the pixels in all the planes making up the whole cell (Fernández-Arjona et al., 2019).

\subsubsection{Statistic analysis}

The database was built from eight variables used to characterize the nucleolar morphology based on the fibrillarin immunodetection signals. The variables were area, perimeter, major and minor diameter, Feret's diameter, circularity, Integrated Optical Density (IOD), and Raw Integrated Density (Raw IOD). In addition, shape descriptors 
for the secondary constriction of the homologous chromosomes were "Feret's diameter $(\mu \mathrm{m})$ and length $(\mu \mathrm{m})$, Integrated Optical Density (IOD), and Raw Integrated Density (Raw IOD).

According to the Paris Conference (1975), heteromorphism is a term used to describe situations where are observed deviations from the normal chromosome morphology. In this case, the standard conditions for our study are the homomorphic states between both secondary constrictions in the homologous chromosome 6 and, and consequently, for the two nucleoli during interphase.

Another reference about indices classification was reported by Fuchs (2009), working with Crotalaria retusa. The author used secondary constriction sizes and the nucleoli area in the binucleolar nucleus, generating indices (highest value/lowest value) of the variables obtained to determine the differential expression. Consequently, the homomorphic condition was attributed to the index with value $=1$, while values greater than 1 represent the heteromorphic condition.

In our study, indices were calculated for each variable based on the relationship between the highest and lowest values. Subsequently, four categories were empirically established according to their degree of heteromorphism: Homomorphic $(I=1)$, slightly heteromorphic $(1<\mathrm{I}<1.5)$, significantly heteromorphic $(\mathrm{I}=1.5)$, and notoriously heteromorphic (I>1.5).

Logarithmic transformation was performed for each one of the indices. Univariate statistical analysis and multivariate analysis using a linear mixed-effects model were performed for each variable. We included the mitotic phase effects (P - prophase, PM - prometaphase, or M - metaphase), type (inbred lines or Hybrid), and the two-way interactions between phase and type in the linear predictor for the rDNA 45S variables, and the type effects in the linear predictor for the nucleolus variables. We also included random intercepts per lineage/hybrid and an unstructured variance-covariance matrix for different variables per cell (experimental unit). We assessed the significance of the effects through likelihood-ratio (LR) tests between nested models.

\subsubsection{Pilot test}

A preliminary characterization was carried out to address heteromorphism in some inbred lines and hybrids_-polymorphism of secondary constrictions during metaphase.

To detect heteromorphism in the secondary constrictions of the homologous pairs of chromosome 6, FISH analysis was performed on the vast majority of metaphase chromosomes, also including some cells in prophase and prometaphase. FISH with the $45 \mathrm{~S}$ rDNA probe in the preliminary test showed the locations of the NORs sites confirming they occur as a single block in the distal region of the short arm in the chromosome 6 , and no additional $45 \mathrm{~S}$ sites on the remaining chromosomes are observed, as expected according to McClintock (1934) and Gives \& Phillips (1976). However, it was observed that these single blocks of NOR express heteromorphism patterns between homologous pairs in some cases (Fig. 3). 


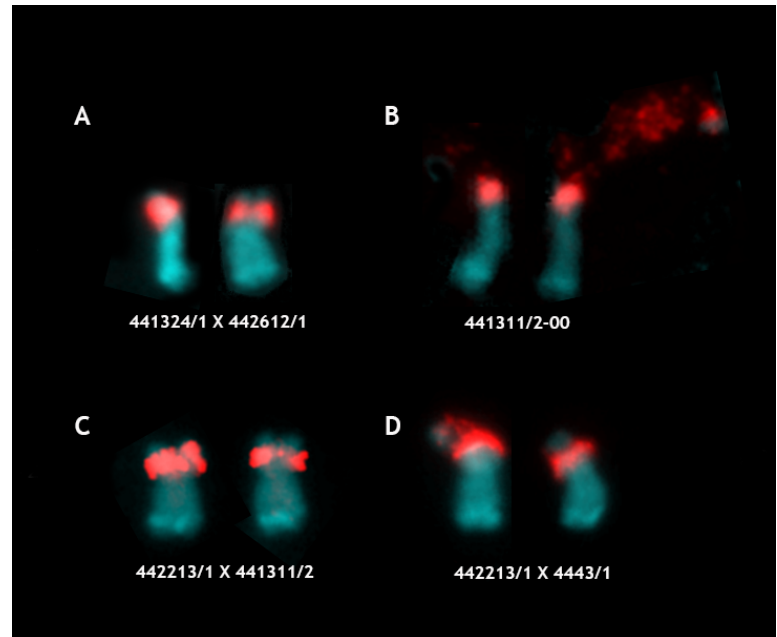

Figure 3. Mitotic metaphases for chromosome 6 exhibiting NOR regions with different heteromorphic levels between homologous. A and C: example of two slightly heteromorphic hybrids, B: notoriously heteromorphic inbred line. D: significativaly heteromorphic hybrid.

\subsubsection{Nucleolar polymorphism during interphase}

To verifying whether there is a correlation between the observed variation in the size of 45S rDNA sites with nucleolar behavior, an immunodetection assay for fibrillarin was performed as a marker of the nucleolus during the cell cycle.

The antibody revealed fibrillarin labeling inside the nucleoli and in certain phases of the cell cycle, such as the onset of prophase, telophase, and cytokinesis. Fibrillarin protein is located predominantly in the dense fibrillar component (DFC) due to its essential role in pre-rRNA maturation, covering the most extensive area inside the nucleolus.

This approach allowed the analysis of binucleolate interphase nuclei, visible before nucleolar fusion. These nuclei presented nucleoli with variable morphometric patterns: the first pattern corresponds to two prominent nucleoli of approximately the same size, the second pattern two small nucleoli of similar size, and the third pattern two nucleoli of different size, being one major and one minor, is the last considered as heteromorphism. In the three cases, the nucleoli formed correspond to the $45 \mathrm{~S}$ ribosomal genes activity from each of the homologs of the chromosomal 6 (Fig. 4). Based on the preliminary observations, a qualitative classification was proposed for FISH nucleoli to describes their morphological variability. 


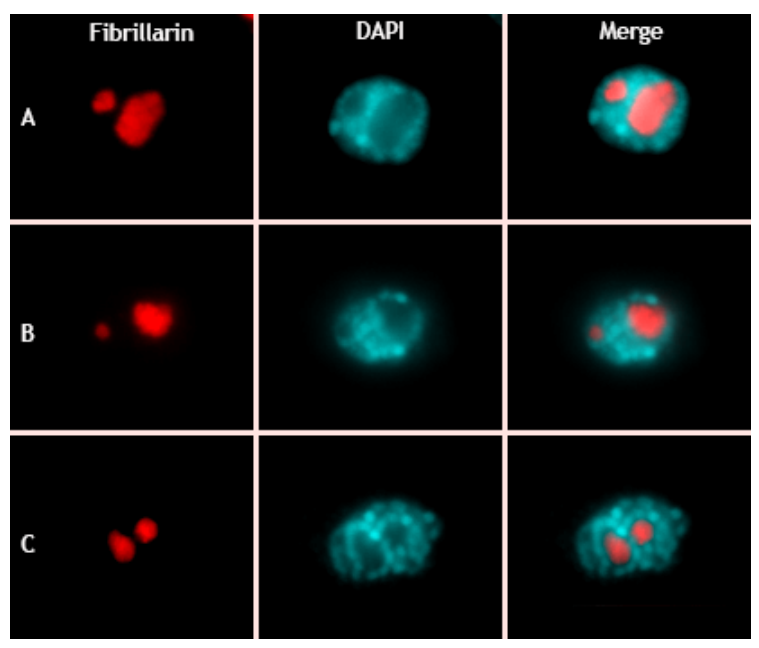

Figure 4. Interphase nuclei before nucleolar fusion, showing different cases of morphometric variations between the nucleoli. All cases showed are present in the 442242/1 x 44431 hybrid. A and B are examples of notoriously heteromorphic nucleoli, and $\mathbf{C}$ is a case of significantly heteromorphic nucleoli.

Therefore, the preliminary analysis results using a small group of inbred lines and hybrids reinforce nucleolar configuration pattern association to the $45 \mathrm{~S}$ rDNA differential expression in the homologous chromosomes.

The pilot test results prompted the large-scale mapping of the entire collection of near-isogenic inbred lines and their respective hybrids, including a quantitative analysis in addition to the qualitative characterization. 


\section{RESULTS}

\subsection{Mapping the collection of inbred lines and hybrids}

\subsubsection{Qualitative characterization}

Using the $45 \mathrm{~S}$ rDNA probe FISH approach in metaphase cells and fibrillary by immunodetection in interphase cells, it was possible to describe the expression of $45 \mathrm{~S}$ rDNA in the collection of four families of inbred lines derived from the commercial variety Jack Duro (JD): JD 1-3, JD 2-1, JD 4-4, JD 4-1; as well as in the hybrids formed between the JD 1-3 and JD 4-4 families. In the microphotographs obtained for all the materials, it was possible to observe variations in the level of heteromorphisms between slight, significant, and notorious.

\subsubsection{Characterization of 45 S rDNA by FISH}

A total of 22 inbred lines and 23 hybrids were analyzed with the same level of condensation in most cases, concerning cells in metaphase. However, few cases of prometaphase and prophase cells were considered. On the three condensation states, it was possible to identify the $45 \mathrm{~S}$ rDNA FISH signals in the NOR regions of the homologous of pair 6. DAPI counterstaining revealed $\mathrm{DAPI}^{+}$bands in highly condensed heterochromatic regions known as knobs, corroborating the knobs composition expected for each inbred lines and hybrid (composition described in Table 3). For chromosome 6, the presence of a homozygous knob in the distal region of the long arm of the chromosome was confirmed.

Furthermore, observations of the $45 \mathrm{~S}$ rDNA FISH signals revealed secondary constrictions of different sizes (heteromorphic) and similar sizes (homomorphic) in all genotypes analyzed. Hereafter, the behavior of each genotype will be described according to its family (inbred lines) or in a cross (hybrid).

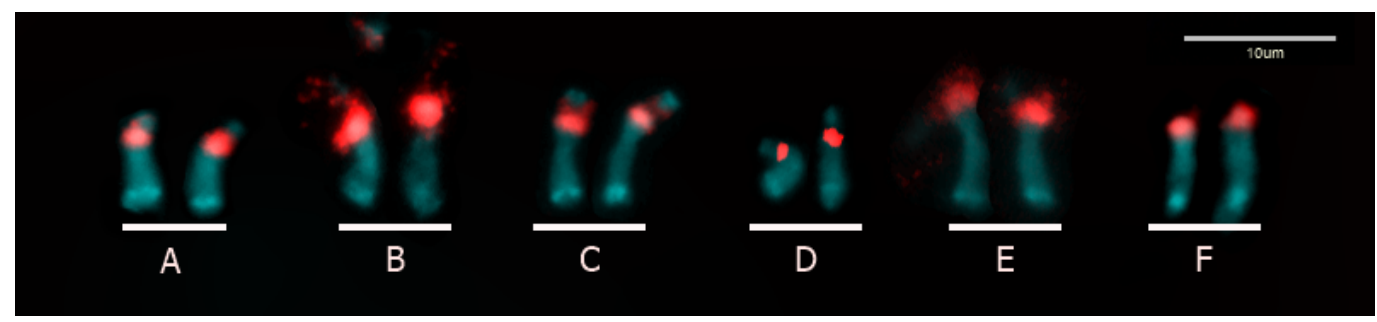

Figure 5. FISH in mitotic chromosomes showing 45S rDNA in inbred lines, JD 1-3 family. A. 132331/1-

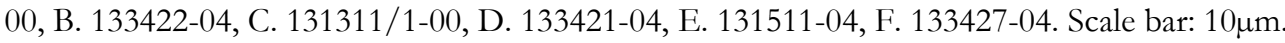




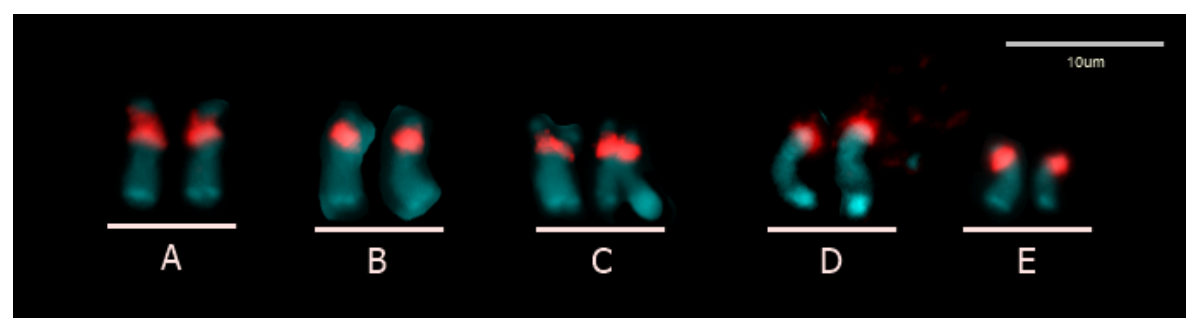

Figure 6. FISH in mitotic chromosomes showing 45S rDNA in inbred lines, JD 2-1 family. A. 211121/1-

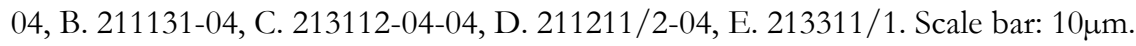

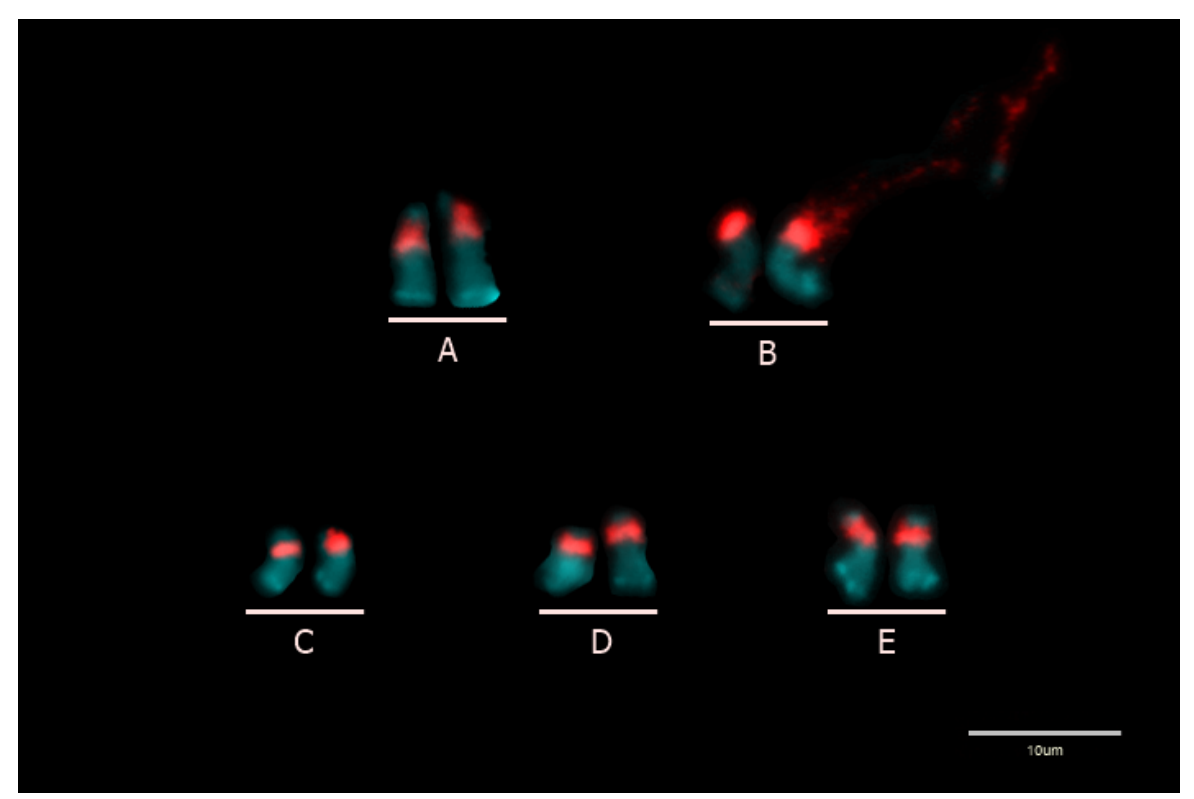

Figure 7. FISH in mitotic chromosome showing 45S rDNA in inbred lines, JD 4-1 family. A. 41122, B. 412331, notoriously heteromorphic inbred line, C. 41234, D. 4124, E. 41242. Scale bar: $10 \mu \mathrm{m}$. 


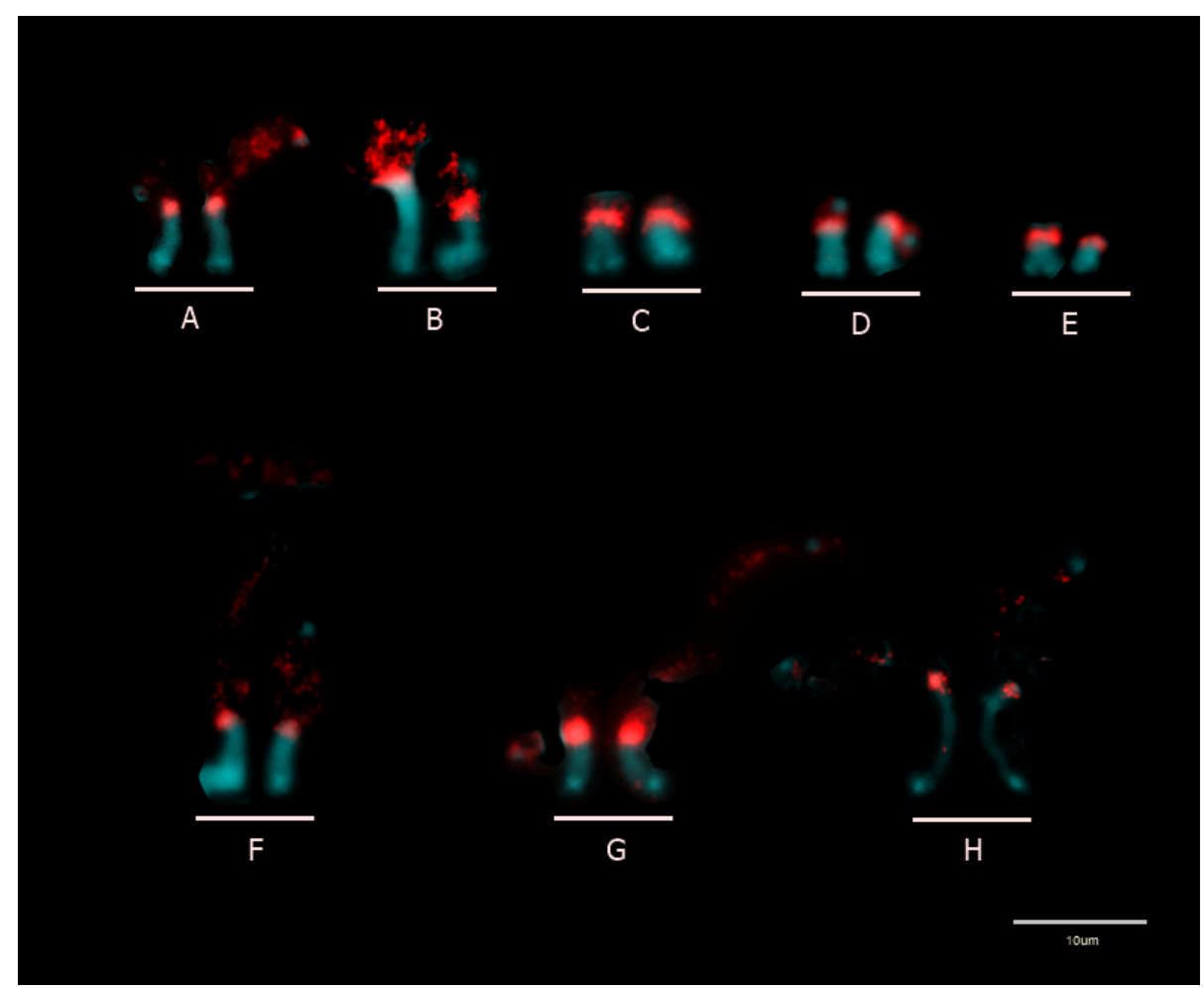

Figure 8. FISH in mitotic chromosome showing 45S rDNA in inbred lines, JD 4-4 family. A. 441311/200, B. 441324/1-00, C. 442612/1-00, D. 441123/3-04, E. 441132/2-04, F. 442242/1-00, G. 444332-04, H: 44431-00. Note that A, B, F, G, and $\mathrm{H}$ can be qualitatively classified as notoriously heteromorphic. Scale bar: $10 \mu \mathrm{m}$.

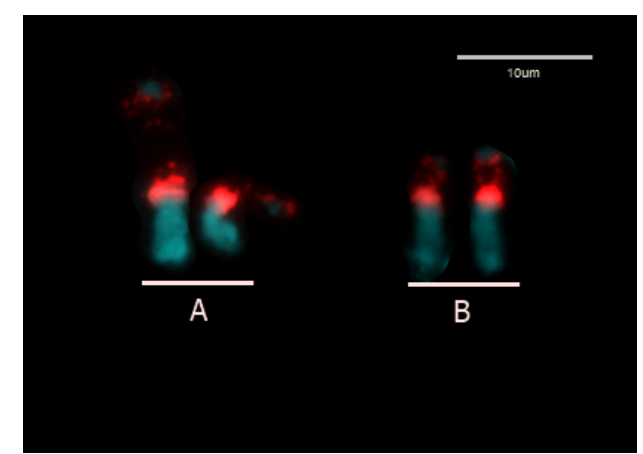

Figure 9. FISH in mitotic chromosome showing 45S rDNA in hybrids, the progeny of the JD 1-3 X JD 1 3. A. $132331 / 1 \times 131311 / 1$; B. $132331 / 1 \times 131311 / 1$. Scale bar: $10 \mu \mathrm{m}$. 


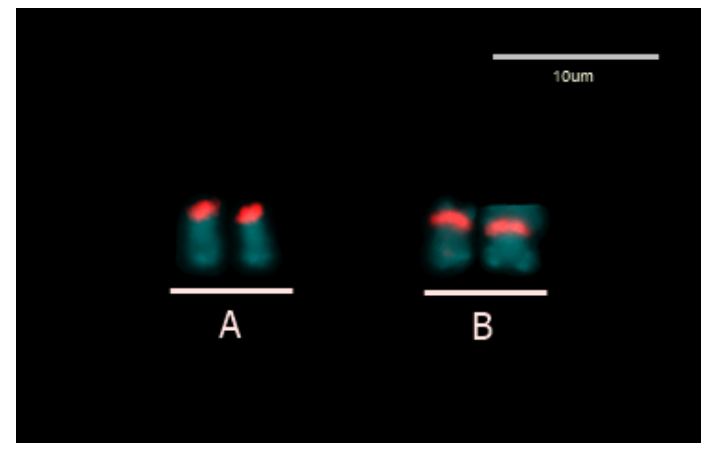

Figure 10. FISH in mitotic chromosome showing $45 \mathrm{~S}$ rDNA in hybrids, the progeny of the JD 4-4 X JD 1-3. A. $442612 / 1 \times 131311 / 1$, B. $441324 / 1 \times 131311 / 1$. Scale bar: $10 \mu \mathrm{m}$. 

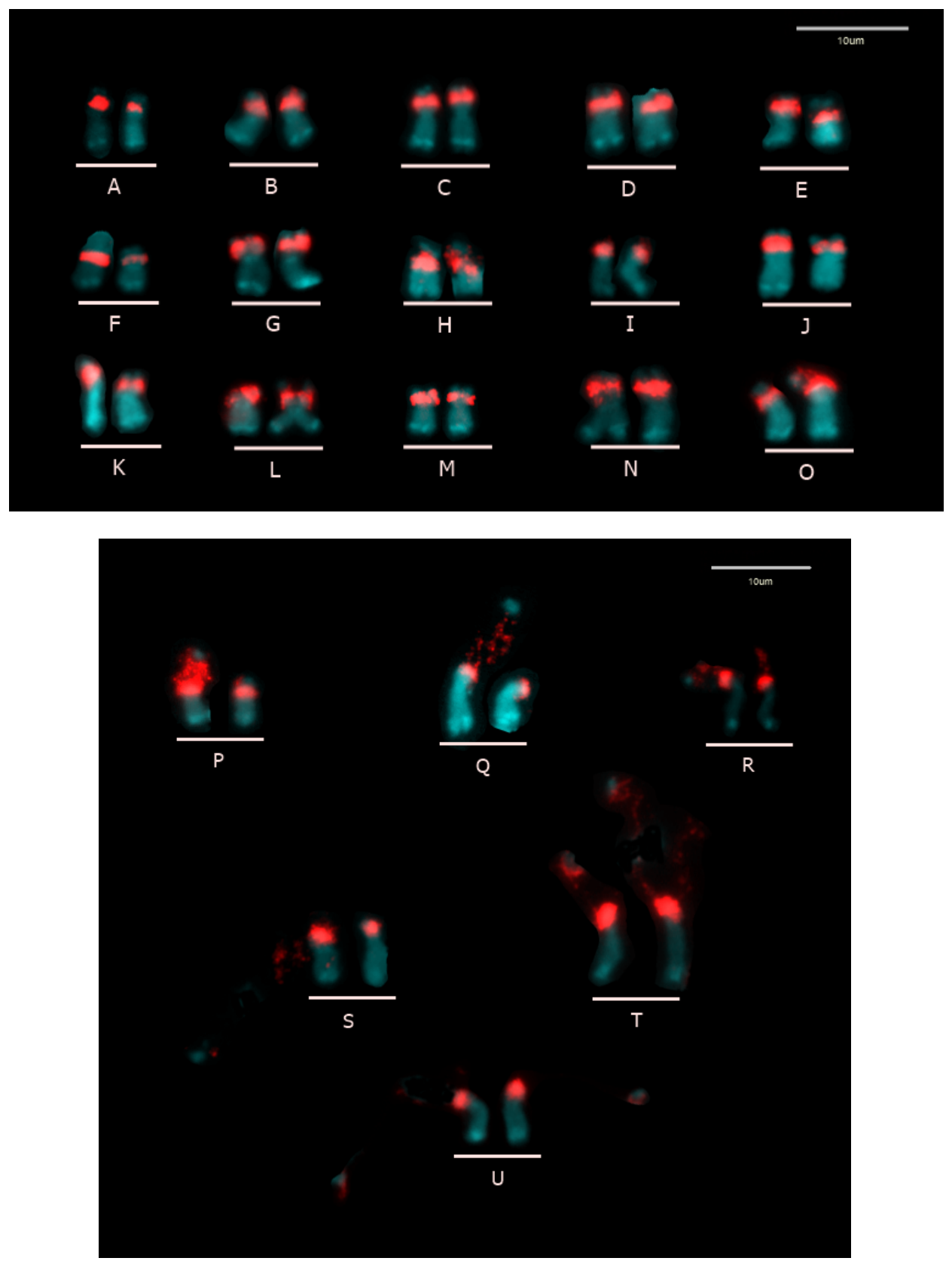

Figure 11. FISH in mitotic chromosome showing 45S rDNA in hybrids, the progeny of the JD 4-4 family. A. 44431 x 442242/1, B. 44431 x 442612/1, C. 44431 x 441324/1, D. 44431 x 442213/1, E. 442242/1 x 44431, F. 442242/1 x 441324/1, G.442612/1 x 442242/1, H. 442612/1 x 442213/1, I. 441311/2 x 44431, J. 441311/2 x 442612/1, K. 441311/2 x 441324/1, L. 441324/1 x 442612/1, M. 441324/1 x 441311/2, N. 441324/1 x 442213/1, O. 442213/1 x 4443/1, P. 442213/1 x 442612/1, Q. 442213/1 x 441311/2., R. 441324/1 x 442241/1, S. 442612/1 x 442242/1, T. 441311/2 x 442213/1, U. 442242/1 x 441311/2. Note that Q, S, T, and U can be qualitatively classified as notoriously heteromorphic. Scale bar: $10 \mu \mathrm{m}$.

\subsubsection{Nucleolar characterization by Immunodetection of Fibrillarin}

A morphological analysis of the nucleolus was carried out from 26 inbred lines and 25 hybrids analyzed for the $45 \mathrm{~S}$ rDNA configuration. Despite the morphological analysis of the nucleoli focused on the binucleolate nuclei, 
the complete process of nucleoli disassembly and reassembly could be visualized by observing mononucleolar nuclei in the interphase and cells in different division stages. Nucleolar fusion was observed along the interphase, resulting in more prominent nucleoli, coinciding with the great demand for protein synthesis involved in this cell cycle phase. During prophase, the gradual nucleolar structure separation was observed, causing the fibrillarin signal to become more diffuse, becoming completely null during metaphase, when the chromatin reaches the maximum condensation degree. Towards the end of mitosis, reassembly of the two nucleolar structures was observed in the anaphase, telophase, and cytokinesis.

The mapping of the entire collection of inbred lines and hybrids corroborated the preliminary immunodetection analysis results. Several cases of heteromorphism among the genotypes analyzed were found. Cytological analyzes confirmed heteromorphisms in some genotypes in terms of the $45 \mathrm{~S}$ rDNA extension on mitotic metaphases and differences in nucleolar structuring during interphase. Next, each genotype nucleolar behavior will be described according to its family (inbred lines) or hybrid.

\subsubsection{Quantitative characterization}

Qualitatively, the presence of heteromorphism among the genotypes was confirmed (Figure 5 and 6). A morphometric analysis with statistical evaluation was carried out.

The morphometric analyzes of the secondary constrictions and nucleoli made it possible - in the first instance - to determine heteromorphism levels from the indices calculated for each of the variables under study. Based on the idea of "normal chromosome morphology" of the Paris Conference (1975), in this study, the homomorphic condition for both secondary constrictions of chromosome 6 and their respective nucleoli in interphase was considered as usual and expected.

In the present study, we assumed this same consideration empirically from the indices obtained for each variable analyzed in both study units. (Fig. 12). 


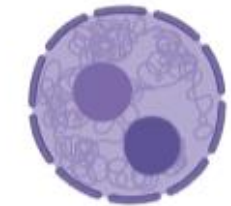

$\mathrm{I}=1$

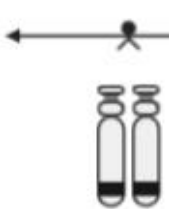

Homomorphic

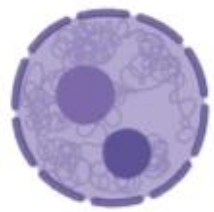

$1<\mathrm{I}<1.5$
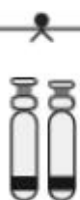

Slightly Heteromorphic

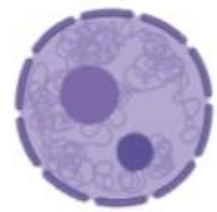

$\mathrm{I}=1.5$
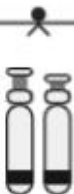

Significantly Heteromorphic

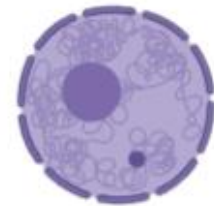

I $>1.5$
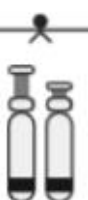

Notoriusly Heteromorphic

\section{Created in BioRender.com bio}

Figure 12. Categories referring to the value of the variable indices studied, calculated as a ratio between the major and minor secondary constrictions and the major and minor nucleoli.

The qualitative results of fibrillarin immunodetection are presented below.:
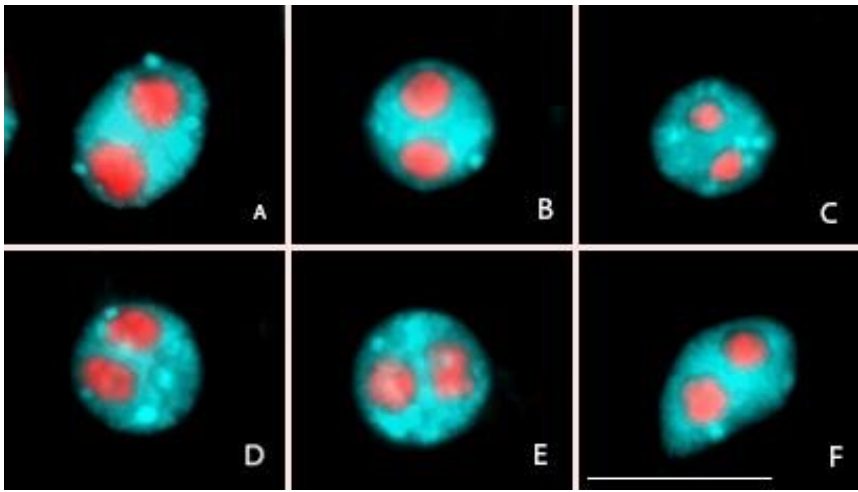

Figure 13. Fibrillarin immunodetection showing nucleolus morphology in inbred lines, JD 1-3 family. A.

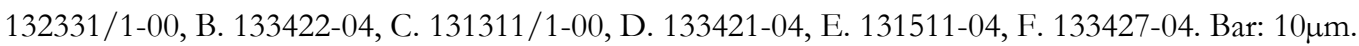
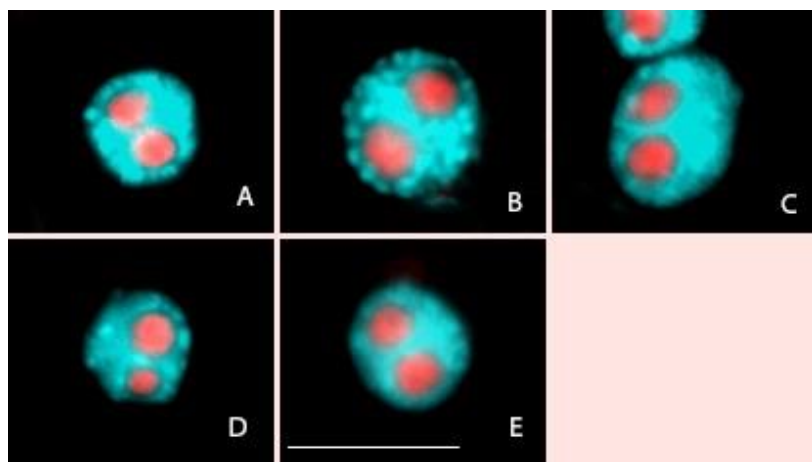

Figure 14. Fibrillarin immunodetection showing nucleolus morphology in inbred lines, JD 2-1 family. A.

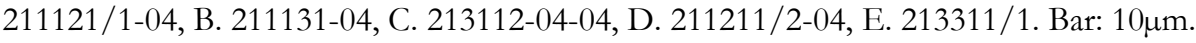




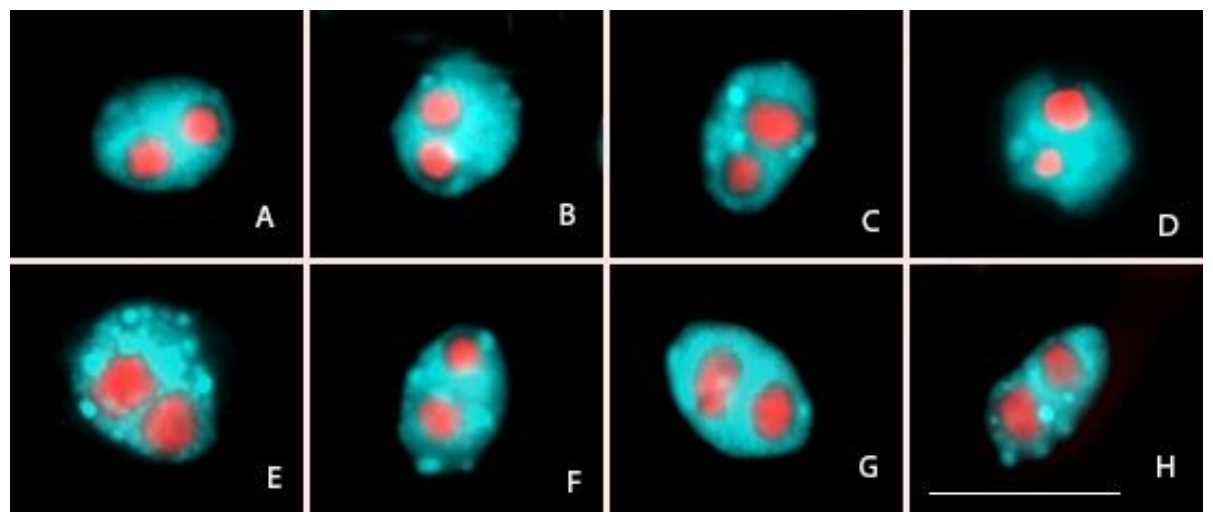

Figure 15. Fibrillarin immunodetection showing nucleolus morphology in inbred lines, JD 4-4 family. A. 441311/2-00, B. 441324/1-00, C. 442242/1-00, D. 442612/1-00, E. 441123/3-04, F. 441132/2-04, G. 444332-04, H: 44431-00. Bar: $10 \mu \mathrm{m}$.

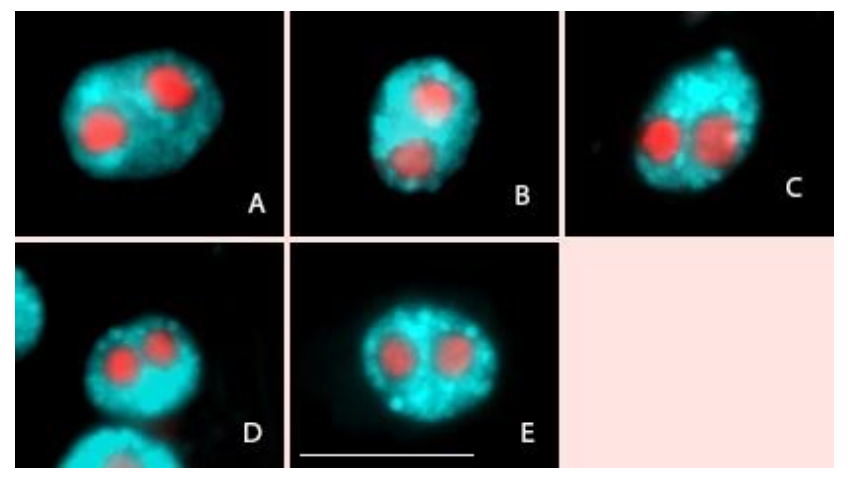

Figure 16. Fibrillarin immunodetection showing nucleolus morphology in inbred lines, JD 4-1 family. A.

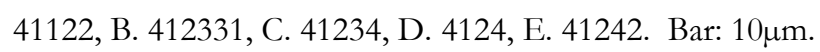




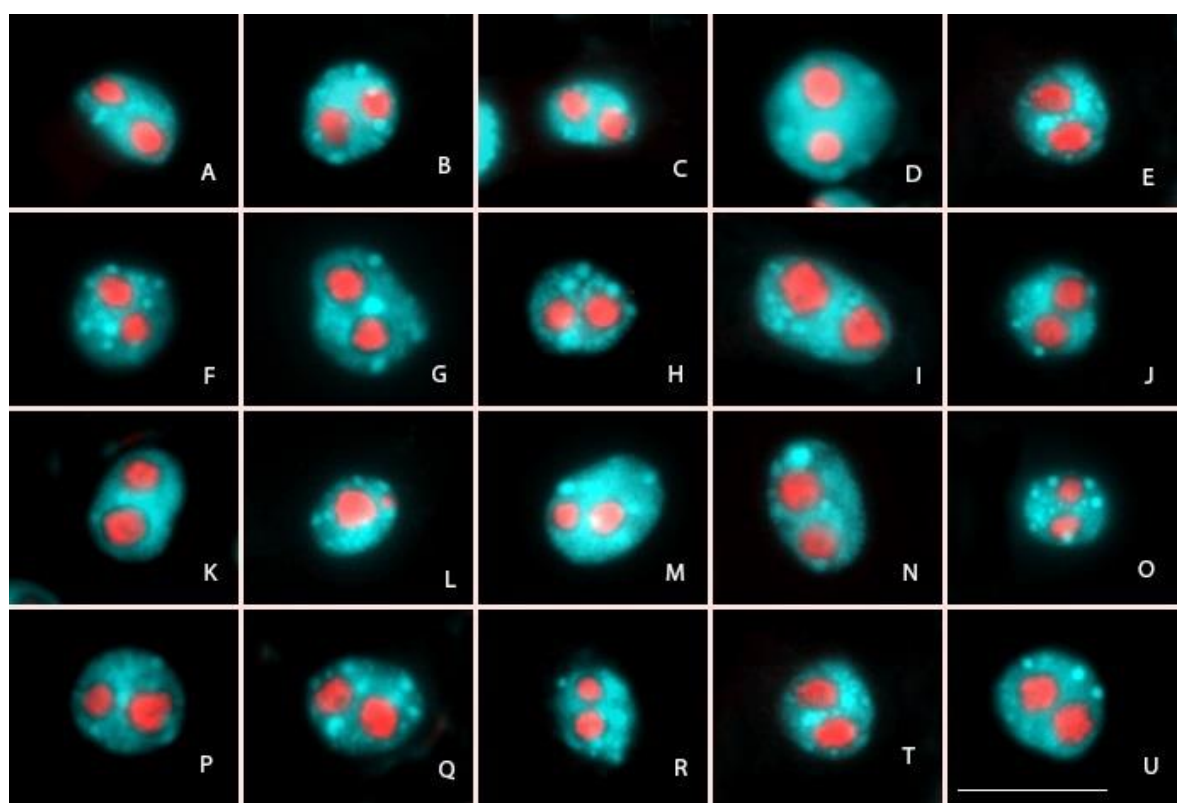

Figure 17. Fibrillarin immunodetection showing nucleolus morphology in hybrids, progeny of the JD 4-4 family. A. 44431 x 442242/1, B. 44431 x 442612/1, C. 44431 x 441324/1, D. 44431 x 442213/1, E. 442242/1 x 44431, F. 442242/1 x 441311/2, G. 442612/1 x 4443, H. 442612/1 x 442242/1, I. 442612/1 x 442242/1, J. 442612/1 x 442213/1, K. 441311/2 x 44431, L: 441311/2 x 442612/1, M: 441311/2 x 441324/1, N: 441311/2 x 442213/1, O: 441324/1 x 442241/1, P: 441324/1 x 442612/1, Q: 441324/1 x 441311/2, R: 441324/1 x 442213/1, S: 442213/1 x 4443/1, T: 442213/1 x 442612/1, U: 442213/1 x 441311/2. Bar: $10 \mu \mathrm{m}$.

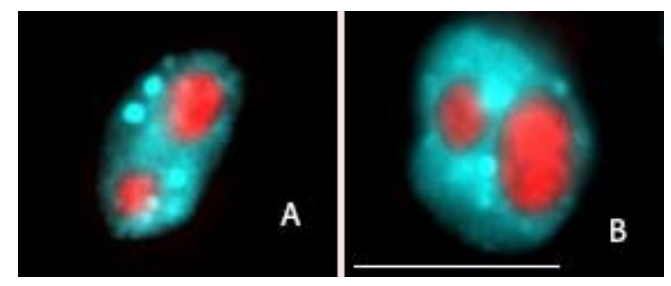

Figure 18. Fibrillarin immunodetection showing nucleolus morphology in hybrids, progeny of the JD 4-4 x JD 1-3 family A. 442612/1 x 131311/1, B. 441324/1 x 131311/1 Bar: 10 $\mu \mathrm{m}$.

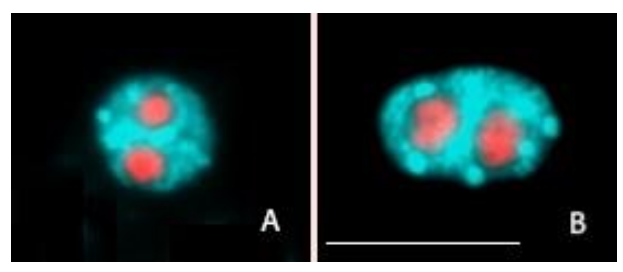

Figure 19. Fibrillarin immunodetection showing nucleolus morphology in hybrids, progeny of the JD 1-3 X JD 4-4.

A. $131311 / 1$ x 442612/1, B. $131311 / 1$ x 441324/1. Bar: $10 \mu \mathrm{m}$ 


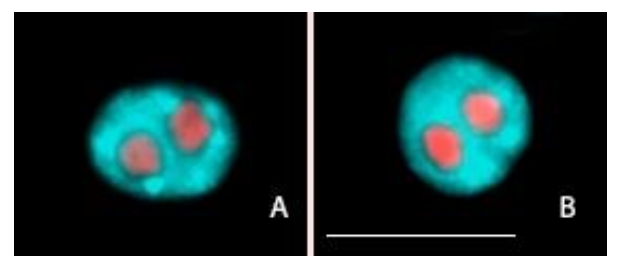

Figure 20. Fibrillarin immunodetection showing nucleolus morphology in the hybrid progeny of the JD 13 X JD 1-3. A. $132331 / 1$ x 131311/1, B. 132331/1 x 131311/1. Bar: $10 \mu \mathrm{m}$.

\subsubsection{45S rDNA statistical analysis}

As a part of the FISH assay were captured mainly metaphases cells (M), but also prometaphase (PM) and prophase cells (P, in lesser amount) were considered. For these reasons, a mixed-effects analysis ruled out any possible condensation effect on the morphological secondary constriction evaluation in inbred lines and hybrids. This result shows that the $45 \mathrm{~S}$ rDNA of the secondary constriction varies independently of the cell cycle phase. As shown in Figure 21, in each panel, the four variables under study are represented both for hybrids and inbred lines, well as the cut lines (0). Only variables crossing the vertical downward from 0 will have a statistical differentiation $(p<0.05)$. It is reported that in all the phases for the two types of material, the bars of each index show overlap to a different degree, so they are not considered significantly different. Therefore, some phase effect on the behavior of the 45S rDNA is ruled out. Furthermore, regardless of the phases, Integrated Optical Density (IOD) and Raw Integrated Optical Density (Raw IOD) showed a similar index, greater than the Feret and length indices. 

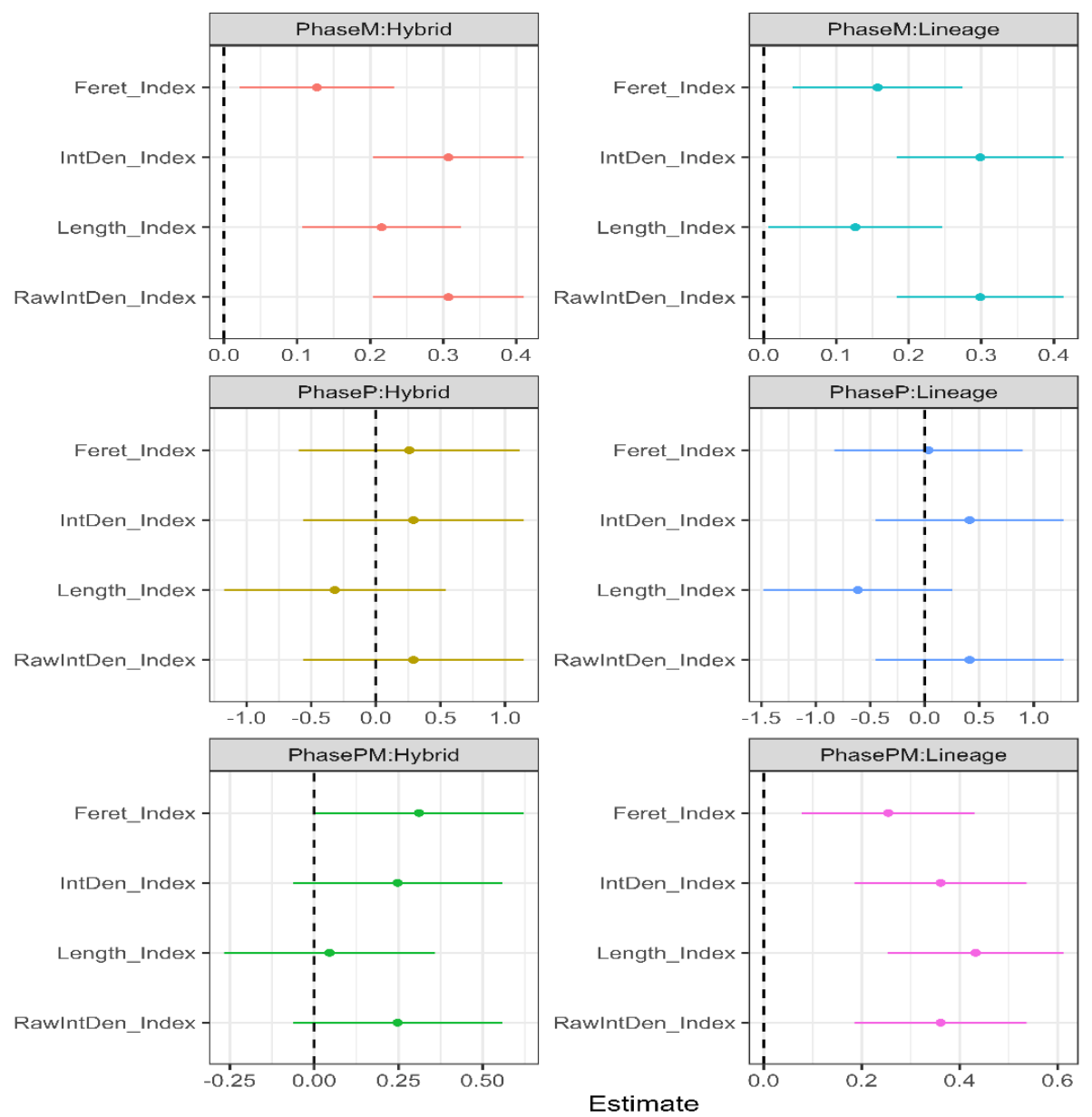

Figure 21. Analysis of the mitotic phase effect (metaphase, prometaphase, and prophase) on the variable indices describes the 45S rDNA morphology in inbred lines and hybrids.

\subsubsection{The $45 S$ rDNA heteromorphism in inbred line families}

Multivariate analysis for the 45S rDNA based on the indices of the four selected variables: Feret's diameter, length, integrated density, and raw integrated density; confirmed the presence of heteromorphisms, well as homomorphisms between the evaluated genotypes (Figure 22). The multivariate bar plot shows that the differential expression of the 45S rDNA was heteromorphic in a greater degree for the inbred lines 441311, 211211, 412331, 44431, 441132, and 213112, as they presented a greater random effect above 0. On the other hand, the less heteromorphic lines are represented by the bars below 0 in the barplot, mainly 442242/1-00, 133427-04, and 441123/3 04. The remaining inbred lines also describe less heteromorphic behavior.

To corroborate the results of the multivariate analysis with the results obtained by Heatmap (Figure 23), the categories of the variable indices (Figure 12) were empirically correlated with the Heteromorphism Degree scale of the Heatmap (Table 2). 
Table 2. Correlation of categories of the indices with the scales of the Heatmap

\begin{tabular}{|c|c|c|c|c|}
\hline Heat map & 1 & $1<\mathrm{X}<2$ & $2 \leq X \leq 4$ & $4<X \leq 5$ \\
\hline \multirow{3}{*}{$\begin{array}{l}\text { Figure 12: } \\
\text { Categories referring } \\
\text { to the value of the } \\
\text { indices of the } \\
\text { variables studied }\end{array}$} & \multirow{3}{*}{$\begin{array}{l}=1 \\
\text { lomorphic }\end{array}$} & $1<\mathrm{I}<1.5$ & 1.5 & $>1.5$ \\
\hline & & Slightly & Significantly & Notoriously \\
\hline & & Heteromorphic & Heteromorphic & Heteromorphic \\
\hline
\end{tabular}

The Heatmap did not show a defined structuring between inbred lines and hybrids considering integrated density, raw integrated density, and Feret diameter, described for both NOR and nucleolus. However, all genotypes were grouped into five clusters according to the degree of heteromorphism for the variables analyzed.

In this way, the inbred lines identified with high heteromorphism level in the multivariate analysis were distributed as follows:

$>441311$-> Cluster 4, Heatmap scale $\cong 3$. Index Category: Significantly Heteromorphic

$>$ 211211, 412331 -> Cluster 3, Heatmap scale $1<\mathrm{X}<2$. Index Category: Slightly Heteromorphic

$>$ 44431, 441132 and 213112 -> Cluster 5, Heatmap $2<\mathrm{X}<4$ scale: Index Category: Significantly Heteromorphic.

Inbred lines described as less heteromorphic in multivariate analysis 442242 / 1-00, 133427-04, and 441123 / 3-04; well as the remaining lines, were grouped into cluster 2 of the scale $1<\mathrm{X}<2$ of the Heatmap, corresponding to the Slightly Heteromorphic category. Based on the colorimetric scale, most of the inbred lines are close to homomorphism, mainly the JD 1-3 family lines such as 133427-04, 132331 / 1-00, 131511-04, 133422-04, and 13342104. Statistical support described the presence of heteromorphism in general in all the inbred lines studied.

However, higher grade heteromorphism was rare, with 6 cases out of 26 studied. The six cases belong to the families JD 4-4 (3 cases), JD 2-1 (2), JD 4-1 (1). Lower-degree heteromorphism was described in the remaining lines, being the JD 1-3 family that presented lower variable indices, close to homomorphism.

In addition, it is reported that the lines of the JD 1-3 family, classified as Slightly Heteromorphic, also produced nucleoli that fit into cluster 2 , on the scale $1<\mathrm{X}<2$, index category: Slightly Heteromorphic. There are no reports of true homomorphism for any inbred line concerning $45 \mathrm{~S}$ rDNA in the secondary constriction.

\subsubsection{2. $45 \mathrm{~S}$ rDNA in Hybrid families}

The multivariate random effect barplot shows a higher degree of heteromorphism for the hybrids 442213 x 44431, 442612/1 x 441311/2, 442213/1 x 442612/1, and 442213/1 x 441311/2 for presenting a greater random effect per peak of 0 . The opposite effect, a lower degree of heteromorphism, was observed in the remaining hybrids, mainly in 441311/2 x 442213/1 and 442242/1 x 441311/2 (Figure 22).

Corroborating these results, the Heatmap shows that the most heteromorphic hybrids are classified as follows:

$>442213$ x 44431 -> Cluster 1, Heatmap $2<\mathrm{X}<4$ scale. Index category: Significantly Heteromorphic.

$>442612 / 1$ x 441311/2 -> Cluster 4, Heatmap $2<\mathrm{X}<4$ scale. Index category: Significantly Heteromorphic. 
442213/1 x 442612/1 -> Cluster 5, Heatmap $1<\mathrm{X}<2$ scale. Index Category: Slightly Heteromorphic 442213/1 x 441311/2 -> Cluster 3, Heatmap $1<\mathrm{X}<2$ scale. Index Category: Slightly Heteromorphic.

The hybrids 441311/2 x 442213/1 and 442242/1 x 441311/2 with less heteromorphism according to multivariate barplot are located in cluster 2 of the Heatmap. Although numerically, they can be categorized as Heatmap scale $1<\mathrm{X}<2$ into the index category "Slightly Heteromorphic". Its color gradient allows us to assume that they value about 1 , closer to being homomorphic.

One aspect to consider about these two groups of hybrids differentiated by the heteromorphism degree to the other genotypes analyzed is that they only involve five different JD 4-4 family lines.

Parent configurations of the more heteromorphic hybrids reveal the participation of inbred lines with a high to medium degree of heteromorphism. This is evident for the hybrid 442612/1 x 441311/2, where the classification of both lines was previously described. However, the other three hybrids have the inbred line 442213, which is not described in the present work. In these three cases, one of the described parents is known to be significantly heteromorphic such as 44431, 442612/1, and 441311/2. This allows us to suppose that inbred line 442213, when acting as a female parent, does not appear to have an additive effect on the final composition of the 45S rDNA of the hybrid (Table 3).

The most heteromorphic inbred lines 441311/2, participates as the progenitor of hybrids with the higher and lower degree of heteromorphism. However, its role in the formation of less heteromorphic hybrids is striking. It happens that, despite acting as the female and male progenitor, no additive effect of its heteromorphism was observed. On the other hand, it seems it is dominated by the different progenitor genotypes of the hybrids, respectively (Table 4). 
Table 3. Progenitor configurations of the most heteromorphic hybrids for $45 \mathrm{~S}$ rDNA sites.

\begin{tabular}{|c|c|c|}
\hline & q & $\hat{\sigma}$ \\
\hline Hybrids & \multicolumn{2}{|c|}{$442213 \times 44431$} \\
\hline Classification & \multicolumn{2}{|c|}{$\mathrm{I}=1.5$; Significantly Heteromorphic } \\
\hline Parents & 442213 & 44431 \\
\hline Classification & N.D. & $\begin{array}{c}\mathrm{I}=1.5 \text {; Significantly } \\
\text { Heteromorphic }\end{array}$ \\
\hline Effect & N.D. & "+" \\
\hline Hybrids & \multicolumn{2}{|c|}{$442612 / 1 \times 441311 / 2$} \\
\hline Classification & \multicolumn{2}{|c|}{$\mathrm{I}=1.5$; Significantly Heteromorphic } \\
\hline Parents & $442612 / 1$ & $441311 / 2$ \\
\hline Classification & $\begin{array}{c}1<\mathrm{I}<1.5 \text {; Slightly } \\
\text { Heteromorphic }\end{array}$ & $\begin{array}{c}\mathrm{I}=1.5 \text {; Significantly } \\
\text { Heteromorphic }\end{array}$ \\
\hline Effect & "+" & "+" \\
\hline Hybrids & \multicolumn{2}{|c|}{$442213 / 1 \times 442612 / 1$} \\
\hline Classification & \multicolumn{2}{|c|}{$1<\mathrm{I}<1.5$; Slightly Heteromorphic } \\
\hline Parents & 442213 & $442612 / 1$ \\
\hline Classification & N.D. & $\begin{array}{l}1<\mathrm{I}<1.5 \text {; Slightly } \\
\text { Heteromorphic }\end{array}$ \\
\hline Effect & N.D. & "+" \\
\hline Hybrids & \multicolumn{2}{|c|}{$442213 / 1 \times 441311 / 2$} \\
\hline Classification & \multicolumn{2}{|c|}{$1<\mathrm{I}<1.5$; Slightly Heteromorphic } \\
\hline Parents & 442213 & $441311 / 2$ \\
\hline Classification & N.D. & $\begin{array}{c}\mathrm{I}=1.5 \text {; Significantly } \\
\text { Heteromorphic }\end{array}$ \\
\hline Effect & N.D. & "+" \\
\hline
\end{tabular}

Table 4. Progenitor configurations of the less heteromorphic hybrids for $45 \mathrm{~S}$ rDNA sites.

\begin{tabular}{|c|c|c|}
\hline & q & $\hat{o}$ \\
\hline Hybrids & \multicolumn{2}{|c|}{$441311 / 2 \times 442213 / 1$} \\
\hline Classification & \multicolumn{2}{|c|}{$1<\mathrm{I}<1.5$; Slightly Heteromorphic } \\
\hline Parents & $441311 / 2$ & 442213 \\
\hline Classification & $\begin{array}{c}\mathrm{I}=1.5 ; \text { Significantly } \\
\text { Heteromorphic }\end{array}$ & N.D. \\
\hline Effect & "-" & N.D. \\
\hline Hybrids & \multicolumn{2}{|c|}{$442242 / 1 \times 441311 / 2$} \\
\hline Classification & \multicolumn{2}{|c|}{$1<\mathrm{I}<1.5$; Slightly Heteromorphic } \\
\hline Parents & $442242 / 1$ & $441311 / 2$ \\
\hline Classification & $\begin{array}{c}1<\mathrm{I}<1.5 \text {; Slightly } \\
\text { Heteromorphic }\end{array}$ & $\begin{array}{c}\mathrm{I}=1.5 \text {; Significantly } \\
\text { Heteromorphic }\end{array}$ \\
\hline Effect & "-" & "-" \\
\hline
\end{tabular}




\subsection{Univariate behavior for inbred lines and hybrids}

Additionally, the individual behavior of each variable was described by univariate analysis, showing only Integrated Optical Density (IOD) and Raw Integrated Density (Raw IOD) were statistically significant to explain variations in the $45 \mathrm{~S}$ rDNA region behavior for inbred lines and hybrids (Appendix A). 


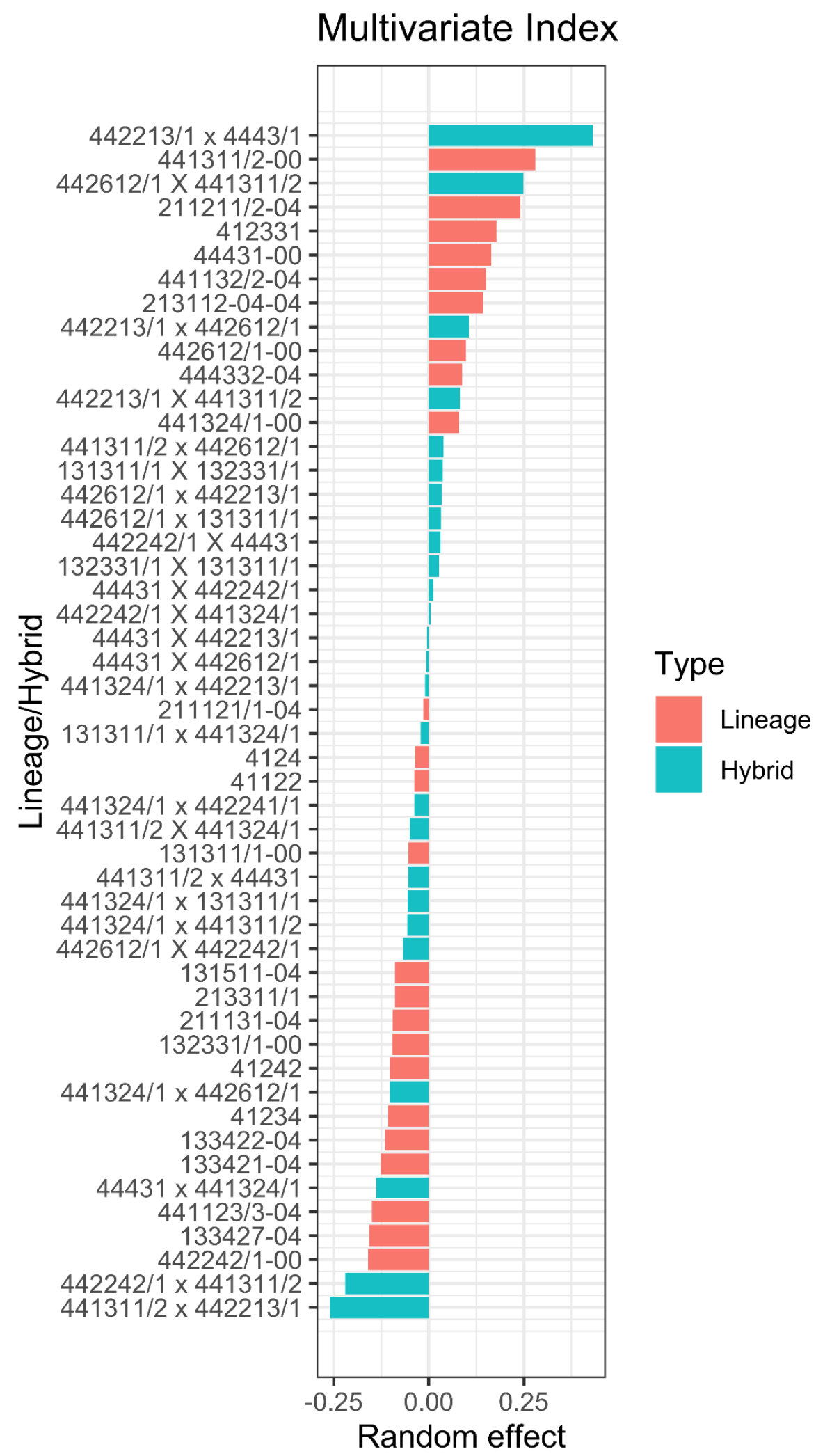

Figure 22. Multivariate barplot of the random effect of the logarithmic transformation of indices for four variables that describe the expression of 45S rDNA signal in the secondary constriction of chromosome 6 for inbred lines and hybrids. 


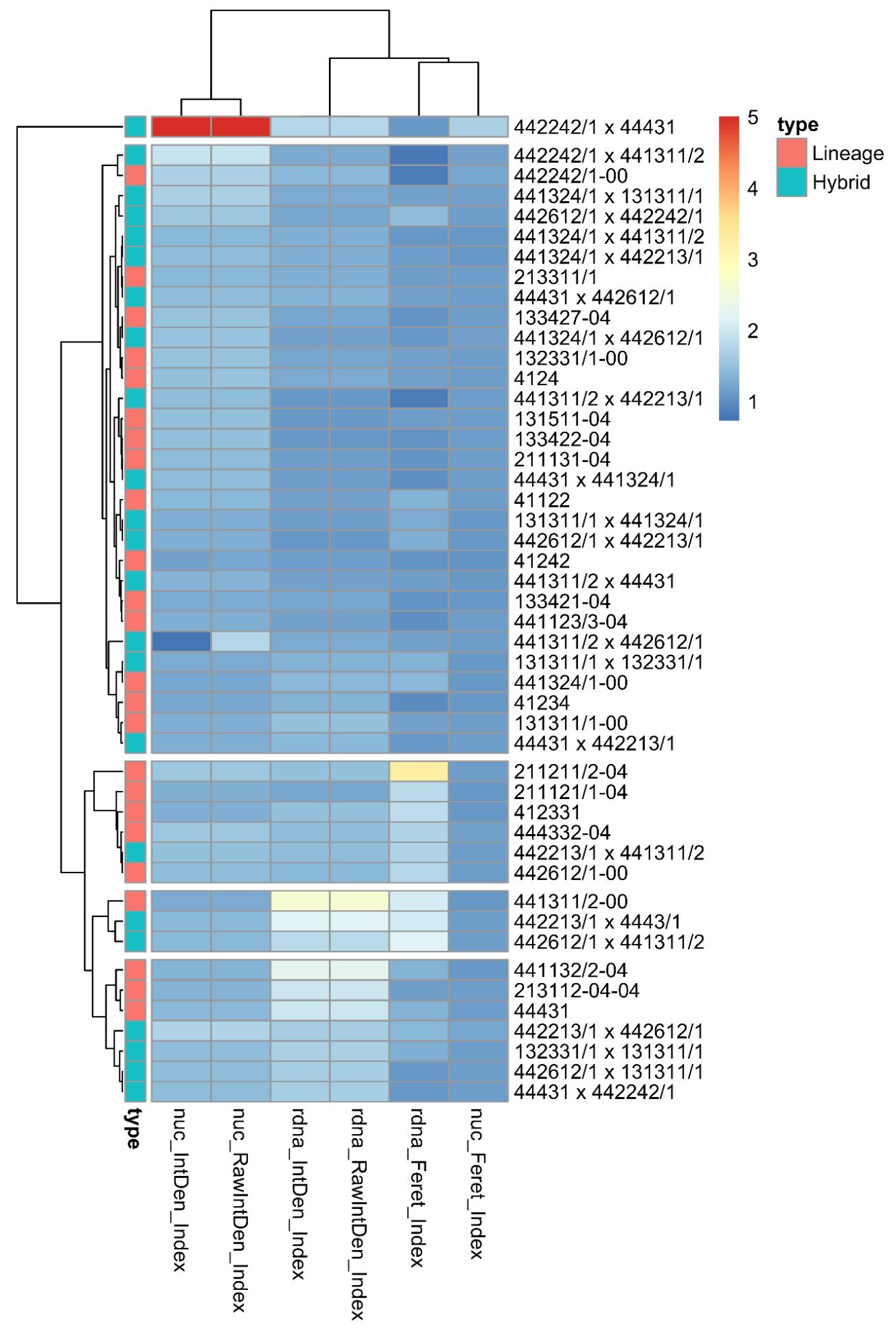

Figure 23. Heatmap and cluster analysis. The horizontal axis shows the variables IOD, IOD RAW, and Feret's diameter used to describe the nucleolus and the $45 \mathrm{~S}$ rDNA signals. On the right side of the heatmap, the lineages and hybrids arranged in a total of 5 clusters are observed, while on the left side, a dendrogram is based on the degree of heteromorphism of inbred lines, and hybrids are shown. A color scale indicates the degree of heteromorphism, and scale 1 indicates homomorphism while five more heteromorphic. 


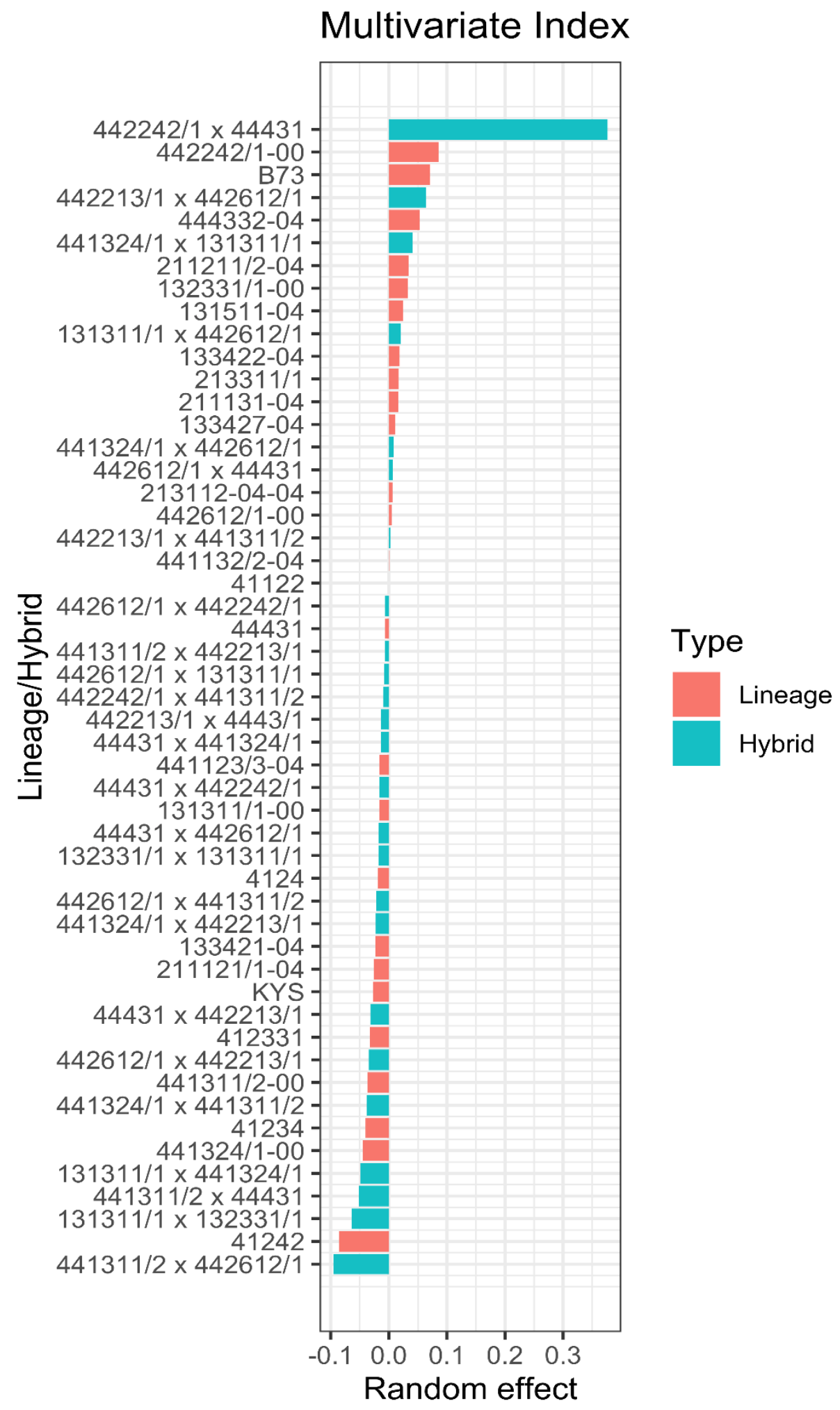

Figure 24. Multivariate barplot of the random effect of the logarithmic transformation of indices for seven variables that describe the expression of the nucleolus, before the nuclear fusion, for inbred lines and hybrids. 


\subsubsection{Nucleolus:}

\subsubsection{Nucleolus variables interactions}

In the binucleolar nucleus, the morphology of each nucleolus was described using the eight variables mentioned in item 3 (See Materials and Methods) for both inbred lines and hybrids. The indices of each variable were calculated and subjected to multivariate analysis to describe the interaction between them.

In the Figure 25, the panel initially shows there is no contrasting difference between hybrids and lines. Indeed, only one of the hybrids has a highly significant difference compared to the other genotypes analyzed (Figure 24). However, a distribution pattern was observed in the hybrid indices or Integrated Optical Density (IOD) and Raw Integrated Density (Raw IOD). So, these variables have higher indices, slightly close to the area index. The index of diameters, Feret, perimeter, and circularity make up another grouping with lower values. This type of pattern was also described in the group of lines. It is explained by the fact that the variables of area, Integrated Optical Density (IOD) and Raw Integrated Density (Raw IOD), are more associated with the density description. In contrast, the diameters, Feret, perimeter, and circularity variables are more related to the definition of shape.
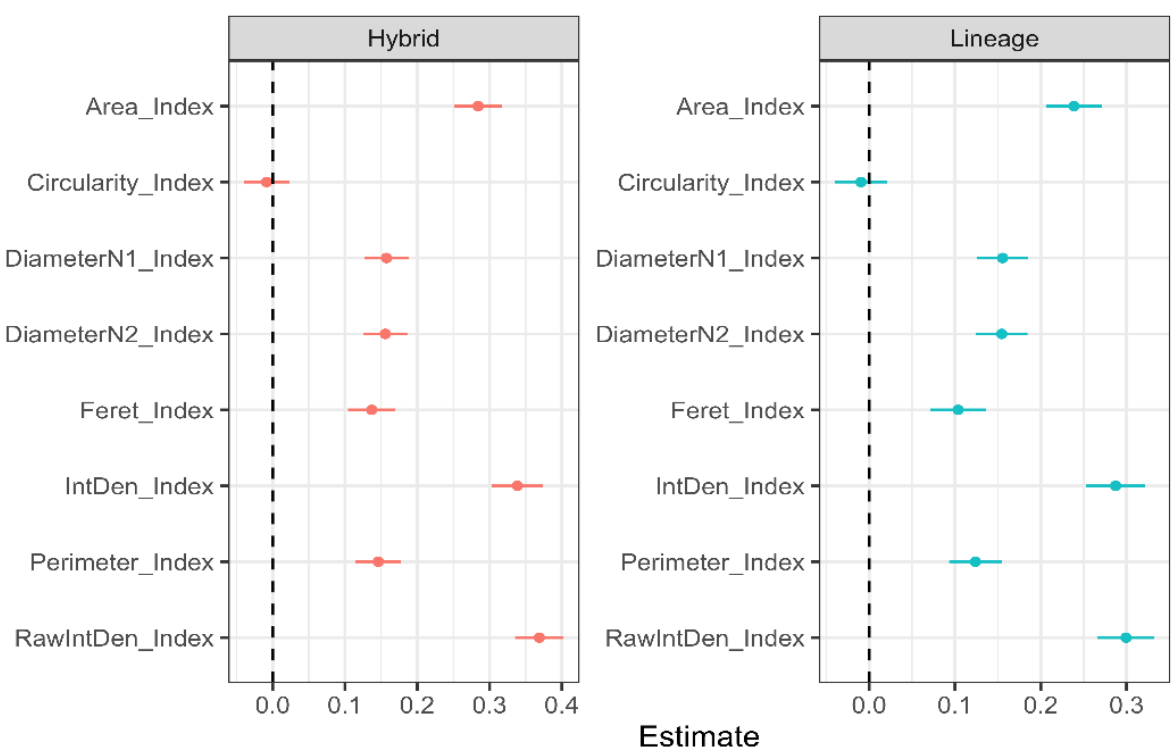

Figure 25. Analyses of indices of the variables that describe nucleolus of inbred lines and hybrids.

\subsubsection{Homomorphism and heteromorphism in inbred lines families}

The lines 442242, 444332, and the variety B73 were identified as the most heteromorphic presenting a more significant random effect above 0 by the interaction of the eight variables by multivariate analysis. On the other hand, a less heteromorphic effect was observed in Lines 41242, 441324, and 41234 with random effect values below 0 . The remaining lines have less heteromorphic behavior (Figure 24).

Using the same strategy used for the 45S rDNA analysis, the results corroborate with the Heatmap, considering the integrated density, raw integrated density, and Feret diameter variables described for both NOR and nucleolus.

The most heteromorphic nucleoli lines are classified as follows: 
$>442242$-> Cluster C2, Heatmap $1<\mathrm{X}<2$ scale. Index Category: Slightly Heteromorphic.

$>444332$-> Cluster C3, Heatmap $1<\mathrm{X}<2$ scale. Index Category: Slightly Heteromorphic.

$>$ B73 -> N.D. in Heatmap because its 45S rDNA was not characterized.

Regarding the less heteromorphic inbred lines 41242, 441324, and 41234, all three belong to cluster 2, on the $1<\mathrm{X}<2$ scale of the Heatmap, which corresponds to the Slightly Heteromorphic category. However, judging by the colorimetric scale, their index would be closer to homomorphism. The remaining lines are also classified on the 1 $<\mathrm{X}<2$ scale of the Heatmap, mainly within cluster 2 .

It is considered that concerning the evaluated inbred lines, there is little morphological variability between nucleoli within the same cell, maintaining a low degree of heteromorphism. The most heterozygous lines belong to the JD 4-4 (2) family, while the less heteromorphic belong to the JD 4-1 (2) and JD 4-4 (1) families.

\subsubsection{Homomorphism and heteromorphism in hybrids}

The hybrid $442242 \times 44431$ is the most heteromorphic among inbred lines and hybrids, as shown by the barplot and in the Heatmap. Likewise, the hybrid 442213 x 442612 is described as the second most heteromorphic; while the less heteromorphic hybrids are 441311/2 x 442612/1, 131311/1 x 132331/1, and 441311/2 x 44431 .

Complementing the classification with the Heatmap, further details are described:

Heteromorphic hybrids:

$>442242$ x 44431 -> Cluster C1, Heatmap scale $4<\mathrm{X}<5$. Index Category: Notoriously Heteromorphic.

$>442213$ x 442612 -> Cluster 5, Heatmap $2<\mathrm{X}<4$ scale. Index Category: Significantly Heteromorphic.

Less heteromorphic hybrids 441311/2 x 442612/1, 131311/1 x 132331/1, and 441311/2 x 44431 are found in Cluster 2, on the $1<\mathrm{X}<2$ scale of the Heatmap, which corresponds to the Slightly Heteromorphic category. However, judging by the colorimetric scale, its index would be closer to homomorphism. Furthermore, the Heatmap showed remaining hybrids are also classified as Slightly Heteromorphic on the $1<\mathrm{X}<2$ scale of the Heatmap.

Regarding the parental configuration of both progenitor types, it was observed that only in the most heteromorphic hybrid 442242 x 44431, one of the parents is the lines 442242 described as heteromorphic for nucleoli. However, the other progenitors of the hybrids are lines slightly heteromorphic but not described as homomorphic within the lines group (Table 5).

In the case of the less heteromorphic hybrids, none of the progenitors were individually described as homomorphic. However, the two lines entering as a female progenitor 441311/2 and 131311/1 are lines with heteromorphism values close to 1 (tendency to homomorphism). These lines were crossed with male progenitors individually described as slightly heteromorphic. With these results, it is possible to infer a certain dominance of the inbred lines 441311/2 and 131311/1 when used as female progenitors over male progenitors (Table 6).

Parental configuration of both heteromorphic and less heteromorphic hybrids involves five inbred belonging to the JD 4-4 family, 442242/1, 44431, 442612/1, and 441311/2, which have analysis for both 45S rDNA and nucleolus. The only exception is the inbred line 442213, which remains to be analyzed. Finally, it is highlighted that these hybrids were formed inside the family JD 4-4 x JD 4-4 and JD 1-3 x JD 1-3. 
Table 5. Progenitor configurations of the most heteromorphic hybrids in the nucleolus analyses

\begin{tabular}{|c|c|c|}
\hline & $q$ & 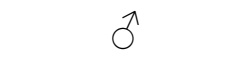 \\
\hline Hybrids & \multicolumn{2}{|c|}{$442242 \times 44431$} \\
\hline Classification & \multicolumn{2}{|c|}{ I $>1.5$; Notoriously Heteromorphic } \\
\hline Parents & $442242 / 1 *$ & 44431 \\
\hline Classification & $\begin{array}{c}1<\mathrm{I}<1.5 \text {; Slightly } \\
\text { Heteromorphic }\end{array}$ & $\begin{array}{c}1<\mathrm{I}<1.5 \text {; Slightly } \\
\text { Heteromorphic }\end{array}$ \\
\hline Effect & $"+"$ & $"+"$ \\
\hline Hybrids & \multicolumn{2}{|c|}{$442213 \times 442612$} \\
\hline Classification & \multicolumn{2}{|c|}{$\mathrm{I}=1.5$; Significantly Heteromorphic } \\
\hline Parents & 442213 & $442612 / 1$ \\
\hline Classification & N.D.* & $\begin{array}{c}1<\mathrm{I}<1.5 \text {; Slightly } \\
\text { Heteromorphic }\end{array}$ \\
\hline Effect & N.D.* & "+" \\
\hline
\end{tabular}

*N.D. not determinate. As shown in table 1, this lineage was not characterized because it did not have sufficient seeds for both experiments.

Table 6. Progenitor configuration of the less heteromorphic hybrids in the nucleolus analyses

\begin{tabular}{|c|c|c|}
\hline & q & $\hat{0}$ \\
\hline Hybrids & \multicolumn{2}{|c|}{$441311 / 2 \times 442612 / 1$} \\
\hline Classification & \multicolumn{2}{|c|}{$1<$ I $<1.5$; Slightly Heteromorphic. } \\
\hline Parents & $441311 / 2$ & $442612 / 1$ \\
\hline Classification & $\begin{array}{l}1<\mathrm{I}<1.5 \text {; Slightly } \\
\text { Heteromorphic, } \\
\text { closest to } 1\end{array}$ & $\begin{array}{c}1<\mathrm{I}<1.5 \text {; Slightly } \\
\text { Heteromorphic }\end{array}$ \\
\hline Effect & $"+"$ & "-" \\
\hline Hybrids & \multicolumn{2}{|c|}{$131311 / 1$ x 132331/1 } \\
\hline Classification & \multicolumn{2}{|c|}{$\mathrm{I}=1.5$; Significantly Heteromorphic } \\
\hline Parents & $131311 / 1$ & $132331 / 1$ \\
\hline Classification & $\begin{array}{l}1<\mathrm{I}<1.5 \text {; Slightly } \\
\text { Heteromorphic, } \\
\text { closest to } 1\end{array}$ & $\begin{array}{c}1<\mathrm{I}<1.5 \text {; Slightly } \\
\text { Heteromorphic }\end{array}$ \\
\hline Effect & $"+"$ & "-" \\
\hline Hybrids & \multicolumn{2}{|c|}{$441311 / 2 \times 44431$} \\
\hline Classification & \multicolumn{2}{|c|}{$1<\mathrm{I}<1.5$; Slightly Heteromorphic. } \\
\hline Parents & $441311 / 2$ & 44431 \\
\hline Classification & $\begin{array}{l}1<\mathrm{I}<1.5 \text {; Slightly } \\
\text { Heteromorphic, } \\
\text { closest to } 1\end{array}$ & $\begin{array}{c}1<\mathrm{I}<1.5 \text {; Slightly } \\
\text { Heteromorphic }\end{array}$ \\
\hline Effect & $"+"$ & "-" \\
\hline
\end{tabular}




\subsubsection{Contrasting $45 S$ rDNA and nucleolus random effects}

After identifying inbred lines and hybrids with higher and lower heteromorphism values, possible correlations between the $45 \mathrm{~S}$ rDNA and nucleoli can be inferred from the Heatmap clusters (Figure 23). Based on the Integrated Optical Density (IOD) and Raw Integrated Density (Raw IOD) of the inbred lines and hybrids, the colorimetric scale shows that:

- There is a slight gradient variation in terms of the $45 \mathrm{~S}$ rDNA differential expression among clusters. It is observed that clusters 2 and 3 present the same classification as Slightly Heteromorphic in consensus with the Heatmap 1 $<\mathrm{X}<2$ scale. Clusters 4 and 5 are classified as Significantly Heteromorphic in agreement with the Heatmap $2<\mathrm{X}$ $<4$ scale.

- The nucleolus structuring had a homogeneous behavior among the clusters. Cluster 1 is statistically highly differentiated, with Heatmap scale $4<\mathrm{X}<5$ considered notoriously heteromorphic. Clusters 2, 3, 4, and 5 are Slightly Heteromorphic for nucleolus, in consensus with the Heatmap $1<\mathrm{X}<2$ scale.

- Cluster 2 groups the largest number of genotypes, 15 lines and 15 hybrids. This cluster has a representative sample of all genotypes analyzed, made up of lines from the four families JD 1-3 (6); JD 4-1 (4); JD 4-4 (3); JD 2-1 (2); well as hybrids of the four types described: JD 4-4 x JD 4-4 (12); JD 4-4 x JD 1-3 (1); JD 1-3 x JD 1-3 (1) and JD 1-3 x JD 4-4 (1). All of them were considered slightly heteromorphic for both 45S rDNA and nucleoli.

- Due to the predominance of slight heteromorphism of the $45 \mathrm{~S} \mathrm{rDNA}$, it could be inferred that the only plant that gave rise to all inbred line families was originally homomorphic to the $45 \mathrm{~S}$ rDNA.

- $\quad$ Finally, three types of correlation between rDNA 45S and nucleolus are reported in table 7.

Table 7. Situations of heteromorphism between rDNA 45S and nucleolus

\begin{tabular}{cccc}
\hline Cluster & $\begin{array}{c}\text { Number of genotypes } \\
\text { (L: Inbred lines; H: } \\
\text { Hybrid) }\end{array}$ & $\begin{array}{c}\text { rDNA 45S } \\
\text { Classification }\end{array}$ & $\begin{array}{c}\text { Nucleolar } \\
\text { Classification }\end{array}$ \\
\hline 1 & $1 \rightarrow 1 \mathrm{H}$ & $\begin{array}{c}\text { Significantly } \\
\text { Heteromorphic }\end{array}$ & $\begin{array}{c}\text { Notoriously } \\
\text { Heteromorphic }\end{array}$ \\
\hline 2 and 3 & $32 \rightarrow 20 \mathrm{~L}+16 \mathrm{H}$ & $\begin{array}{c}\text { Slightly } \\
\text { Heteromorphic }\end{array}$ & $\begin{array}{c}\text { Slightly } \\
\text { Heteromorphic }\end{array}$ \\
\hline 4 and 5 & $10 \rightarrow 4 \mathrm{~L}+6 \mathrm{H}$ & $\begin{array}{c}\text { Significantly } \\
\text { Heteromorphic }\end{array}$ & $\begin{array}{c}\text { Slightly } \\
\text { Heteromorphic }\end{array}$ \\
\hline
\end{tabular}




\section{DISCUSSION}

Different studies using FISH assay report cases of heteromorphisms in number and size related to the $45 \mathrm{~S}$ rDNA. For instance, Pedrosa-Harand et al. (2006) reported a high level of 45S rDNA heteromorphism in 37 accessions of wild and cultivated beans, Dantas and Guerra (2010) studying two species of the genus Theobroma cacao and Theobroma grandiflorum, showed heteromorphism of size and distension in one or both homologs. Rabanal et al. (2017), using FISH, demonstrated heteromorphism of the ribosomal sites using several generations of Arabidopsis thaliana. In our workgroup, the occurrence of heteromorphism in Crotalaria juncea was reported, analyzing the 45S rDNA sites of the chromosomes 1 and 4 and their respective nucleoli during interphase (Mondin et al. 2007). All these works support the fact that it is not unusual to find heteromorphism cases between homologous chromosomes.

In the present work, FISH proved to be a highly sensitive technique showing $45 \mathrm{~S}$ rDNA signals of similar and different sizes, revealing a differential expression between secondary constriction of homologous chromosomes in maize inbred lines and hybrids.

The expected morphological condition is homomorphism that refers to the homologous NORs showing a similar behavior and, therefore, the same expression level. (Folder et al. 2002). Considering chromosomal homomorphism as the normal situation, heteromorphism refers to any different condition from the standard (Paris Conference - supplement, 1975). Some examples of categorization of heteromorphism in classes are given by Caperta et al. (2002). Studying heteromorphism in rye $45 \mathrm{~S}$ rDNA, they established as heteromorphism those secondary constrictions with indices (major/minor) over 1.25. Fuchs (2009), studying Crotalaria retusa, established an index (major/minor) over 1.5 for heteromorphism.

In the present study, a group of heteromorphism classes was empirically determined from our qualitative results (Table 2). I = 1 was considered homomorphic and heteromorphic at any index over 1 . However, three classes were established within heteromorphism: slightly heteromorphic $(1<\mathrm{I}<1.5)$, significantly heteromorphic $(\mathrm{I} \approx 1.5)$, and notoriously heteromorphic (I>1.5).

Secondary constrictions of inbred lines and hybrids were characterized by FISH, observing that there was no structuring between the two groups. Possibly because, during the inbreeding process, the objective of the program was only the controlled segregation of the knobs, for which the segregation of the ribosomal sites was spontaneous or without selection pressure.

According to the data obtained, significant heteromorphism $(\mathrm{I} \approx 1.5)$ cases are reported in 6 of 22 inbred lines of the JD 4-4, 4-1, and 2-1 families where a differential expression of 45S rDNA was observed in the secondary constriction. The remaining inbred lines were slightly heteromorphic, oscillating between $1<\mathrm{I}<1.5$. In the hybrids, the panorama was similar; 4 hybrids of the JD 4-4 family presented a higher heteromorphism level. However, the smaller heteromorphism cases were also reported for the other two hybrids of the JD 4-4 family.

Considering nucleolus biogenesis is activated by the 45S rDNA transcription initiation (Trinkle-Mulcahy, 2018; Potapova and Gerton, 2019), it is possible to associate both structures by morphology and function. In this way, 45S rDNA expression correlates to nucleolar morphology.

Nucleoli observation by fibrillarin immunodetection allowed us to analyze the presence of heteromorphism based on the same classification established for $45 \mathrm{~S}$ rDNA FISH. The results showed that higher and lower degrees of heteromorphism between nucleoli were observed in inbred lines of the JD 4-4 family and hybrids of the same JD 4-4 family. Only one hybrid of the JD 1-3 family was also described as a minor heteromorphism. 
The heteromorphism gradient observed in inbred lines and hybrids of the JD 4-4 family could be related to the inbreeding process by which it was generated. As shown above (Figure 2), four families of lines were generated after successive self-crossing from a single plant. The JD 4-4 family developed a greater number of types of homozygous knob constitutions. This inbred lines variability increases the probabilities of crosses, indirectly generating new scenarios for segregation of the $45 \mathrm{~S} \mathrm{rDNA}$.

The results of hybrids allowed them to know the configuration of their parents, as observed in Tables 3 and 4 referring to the differential expression of $45 \mathrm{~S}$ rDNA and in Tables 5 and 6 referring to nucleoli. Based on these configurations, it is possible to infer the interaction between the parents.

For example, in the 45S rDNA analysis, the 4442213 inbred line played a dual role. As a female progenitor, it appeared to have an additive effect over the male progenitor. In the same way, when it exercises the role of male progenitor, it masks the impact of the female progenitor. Other examples of interaction are the hybrids $442612 / 1 \mathrm{x}$ $441311 / 2$ and 442242/1 x 441311/2. In both cases, the progenitors have a slight to significant heteromorphic classification. The first hybrid is an example of positive regulation once both parents with significant heteromorphism give rise to a hybrid with similar characteristics. The second hybrid presented a lower degree of heteromorphism, even though both parents were heteromorphic in a higher degree. It could be considered a case of negative regulation between the parents (Tables 3 and 4).

Analyzing the nucleolar heteromorphism, we found another type of interaction between the less heteromorphic progenitors of the hybrids (Table 6). In the three cases reported, it is described that the inbred lines which act as the female progenitor, presenting a classification of slight heteromorphism, seem to mask the effect of the male progenitor. It should be noted that the male progenitors in the three cases were more heteromorphic than the female progenitors. These results show indications of possible maternal effect and reciprocal effect. However, further studies are needed to complement this suspicion.

Confirmation of heteromorphisms is related to an increase in the 45S rDNA copy number in one of the homologs. However, one aspect to consider is whether this heteromorphic condition could influence the progenitor genetic action during the crossing. For example, in maize genetic improvement, the increase in seed vigor depends on the parental lines and the crossing directions (Santos et al., 2017). That is why in single-cross hybrids is essential to analyze whether significant maternal (ME) and reciprocal effects (RE) reside in elite population hybrids for seed production purposes (Jumbo and Carena, 2008). For example, a work with maize inbred lines in Mexico found a positive interaction related to plant height in 8 parents and 56 hybrids evaluated for reciprocal effects (RE). (Angel et al., 2009).

Finally, correlating the 45S rDNA and nucleolus results described for the two types of materials used, inbred lines and hybrids, it was possible to observe the $45 \mathrm{~S}$ rDNA behavior trend and its effects (Table 7). No case of homomorphism itself is reported.

This result confirmed a variation in the copy number of the 18S-5.8S-26S rRNA genes by the heteromorphism of all genotypes. However, the nucleoli have a lower degree of heteromorphism than the 45S rDNA region.

The first detail to consider is that the secondary constriction of chromosome 6 is the only $45 \mathrm{~S}$ rDNA locus in the maize genome, so any copy number variation (CNV) should be evidenced in this region. This coincides with Roa and Guerra (2012) that suggest the number of rDNA sites in angiosperms oscillates between two and four. Then species with only one pair should always be functionally active. 
According to Springer et al. (2009), CNV can result from tandem duplications or duplications scattered throughout the genome. On the other hand, Roa and Guerra (2012) hold that, due to the repetitive organization in tandem, rDNA sites may be subject to a higher rate of allelic and non-allelic homologous recombination.

This observation of increasing heteromorphism relative to $45 \mathrm{~S}$ rDNA and somewhat static heteromorphism of nucleoli may explain the extensive epigenetic regulation of $45 \mathrm{~S} \mathrm{rDNA}$ loci.

It should be considered that a higher dose of rDNA does not directly equate to higher levels of expression of rRNA transcripts and consequently does not give rise to more prominent nucleoli. This is because about $50 \%$ of the rDNA loci are transcriptionally inactivated by epigenetic mechanisms (Gibbons et al., 2014).

Another critical detail is rRNA transcription could be compensated with the upregulation of some other rDNA loci instead of activating additional copies of the locus, avoiding a higher energy expenditure (Gibbons et al., 2014). This approach is perhaps not compatible with our case because our model has a single locus. Therefore, nucleolar heteromorphism could play an important role in compensating for the lack of other loci in the maize genome.

The increase in 45S rDNA heteromorphism was observed in some lines and hybrids of family 4-4 after long cycles of self-crossing from a single plant of the commercial variety JD. This is supported by Rabanal et al. (2017), who show a considerable increase in the number of $45 \mathrm{~S}$ rDNA copies in several generations of recombinant inbred lines of Arabidopsis thaliana.

Functionally redundant copies of rDNA in the genome are theoretically expected to provide more resources for transcribing rRNA (Gibbons et al., 2014). Considering the tissue analyzed corresponds to the root meristem cells, it would be recommended in future studies to test the influence of the $45 \mathrm{~S}$ rDNA variations on physiological processes such as germination rate or the number of roots emitted for both inbred lines and hybrids. A possible correlation between $45 \mathrm{~S}$ rDNA copy number and physiological features could be found

Another significant result is the segregation of ribosomal chromatin in a semi-condensed state. Mapping the 45S rDNA mainly by FISH allowed us to describe the behavior of secondary constrictions during the early stages of mitosis. Although the majority of cells analyzed were in metaphases, a few of them were prometaphases and prophases. This raised suspicion about the possible influence of the degree of condensation of chromosomes on the structure of the $45 \mathrm{~S}$ rDNA. However, the results showed no phase effect for any of the genotypes under study. It is assumed that the ribosomal DNA varies independently of the phase and is not affected by the condensation process.

Huang et al. (2006) and McStay and Grummt (2008) reported that the genes transcribed by RNA Pol I in ribosomal chromatin can have two states: actively transcribing (euchromatic) or silent (heterochromatic). So, the secondary constriction represents 18S-5.8S-26S rRNA genes that were highly active during the interphase, and therefore, during the initiation of cell division, this region does not condense.

By not having a condensation effect in the $45 \mathrm{~S} \mathrm{rDNA}$ region, the silencing of this region during mitosis is controlled by post-translational modifications of the transcription machinery. Consequently, mitotic NORs located in secondary constrictions manage to remain approximately ten times less dense than the rest of the chromatin. (Huang et al. 2006).

In this way, $45 \mathrm{~S}$ rDNA could be more affected by chemical changes related to temporal silencing than physical changes during the chromatin condensation process in the cell cycle. Considering this premise, the four variables that described the secondary constriction were chosen. Feret's length and diameter did not significantly differ because they were more related to shape, which is more directly related to physical changes. In contrast, the Integrated Optical Density (IOD) and Raw Integrated Density (Raw IOD) showed more significant values once they describe the density of the analyzed structure. 
The nucleolus assembly and morphology were shown to be directly relationated to 45S rDNA transcription. Fibrillarin immunodetection allowed nucleoli recognition in both mononucleolar and binucleolar nuclei. In both cases, the antibody recognizes the fibrillarin present in the fibrillar center (FC) and in the dense fibrillar component (DFC) of the nucleolus, regions where rRNA synthesis occurs (Loza-Muller et al., 2015). The third component of the nucleolus, the granular component (GC), was externally delimited by the DAPI counter-staining.

For this work, the analysis was based solely on binucleolar cells, a previous state of the cell before nucleolar fusion occurs, reducing to a single nucleolus per cell.

The structured behavior observed in Figure 12 confirms that the selected variables could describe the morphology of the nucleoli to a reasonable degree. In this way, the choice of variables is justified by two critical biological facts:

a. Proper structure assembly guarantees correct function. Like other nuclear bodies, Nucleoli disassemble when cells enter metaphase but then must quickly reassemble at the end of the mitosis to ensure the total metabolic functioning of the cell. In this way, the nucleolus dynamism and the short time available assembly can influence its morphology (Dundr and Misteli, 2010).

b. Nucleolar dimensions could be influenced by genetic events such as variation in the active copy number of the $45 \mathrm{~S}$ rDNA. Although analyzing the active copy number of the $45 \mathrm{~S}$ rDNA was not part of the objectives of this study. The results reported by Olson and Dundr (2005) and Falahati et. (2016) allow us to infer that an increase in the active copy number responds to a greater demand for protein production. Consequently, more prominent nucleoli could be formed due to the need to transcribe a more significant number of ribosomal genes. In situations of lower metabolic demand, the excess copies could be silenced or inactivated, decreasing the number of active copies causing a reduction in the size of the nucleoli. 


\section{CONCLUSIONS}

- Assuming inbred lines and hybrids as two types of material were not observed structural differences between them. However, the correlations between results of $45 \mathrm{~S}$ rDNA expression with the nucleolar morphology allow organizing all the genotypes in clusters, observing a slight heteromorphic gradient of the $45 \mathrm{~S}$ rDNA compared to a homogeneous behavior of the nucleolus clusters.

- The 45S rDNA heteromorphism could be related to an increase or decrease in the copy number variation. However, more studies are necessary to prove if rDNA sites may be subject to a higher rate of unequal recombination. 


\section{RECOMMENDATIONS}

- Epigenetics mechanism could silence this redundant rDNA; in consequence, it does not directly involve larger nucleoli. For this reason, more studies about the epigenetic interactions with heteromorphic genotypes of the inbred lines and hybrids could complement the focus of the present research. 


\section{REFERÊNCIAS}

Aguiar-perecin, M. L. R. De et al. (2000) 'Heterochromatin of maize chromosomes: structure and genetics effects,' Genetics and Molecular Biology, 23(4), pp. 1015-1019. Available at: http://www.scielo.br/pdf/gmb/v23n4/6264.pdf.

Aguiar-Perecin, M. L. R. and Decico, J. U. (1988) 'Preliminary results on the segregation of knobs (C-bands) in inbred lines derived from a flint variety,' Maize Gent. Coop. Newsl. doi: 10.1016/j.compbiomed.2005.11.001.

Angel, M. et al. (2009) 'Combining Ability and Reciprocal Effects in', 35, pp. 285-293.

Barneche, F., Steinmetz, F. and Echevarría, M. (2000) 'Fibrillarin genes encode both a conserved nucleolar protein and a novel snoRNA involved in rRNA methylation in Arabidopsis thaliana', J Biol Chem., 275(35).

Bertaõ, M. R. (1998) Caracterização citogenética de linhagens de milho (Zea mays L.) através de bandamento cromossômico e hibridação molecular in situ. ESALQ, Universidade de São Paulo, Piracicaba.

Boisvert, F. M. et al. (2007) 'The multifunctional nucleolus', Nature Reviews Molecular Cell Biology, 8(7), pp. 574585. doi: $10.1038 / \mathrm{nrm} 2184$.

Buescher, P. J., Phillips, R. L. and Brambl, R. (1984) 'Ribosomal RNA contents of maize genotypes with different ribosomal RNA gene numbers’, Biochemical Genetics, 22(9-10), pp. 923-930. doi: 10.1007/BF00499483.

Caperta, A. D. et al. (2002) 'Genome restructuring in rye affects the expression, organization and disposition of homologous rDNA loci, Journal of Cell Science, 115(14), pp. 2839-2846.

Carmo-Fonseca, M., Mendes-Soares, L. and Campos, I. (2000) 'To be or not to be in the nucleolus', Nature Cell Biology, 2(6), pp. E107-E112. doi: 10.1038/35014078.

Carvalho, R. (2020) Heterochromatic knobs gene-like effects on flowering time, and the seed aging epigenetic-genetic program in maize. University of São Paulo.

Cerdido, A. and Medina, F. J. (1995) 'Subnucleolar location of fibrillarin and variation in its levels during the cell cycle and during differentiation of plant cells', Chromosoma, 103(9), pp. 625-634. doi: 10.1007/BF00357689.

Cerqueira, A. V. and Lemos, B. (2019) 'Ribosomal DNA and the Nucleolus as Keystones of Nuclear Architecture, Organization, and Function', Trends in Genetics. Elsevier Ltd, 35(10), pp. 710-723. doi: 10.1016/j.tig.2019.07.011.

Dantas, L. G. and Guerra, M. (2010) 'Chromatin differentiation between Theobroma cacao L. and T. grandiflorum schum', Genetics and Molecular Biology, 33(1), pp. 94-98. doi: 10.1590/S1415-47572009005000103.

Decico, M. J. U. (1991) Análise da segregaçao de knobs em progenies F2 e de de retrocruzamento derivadas de uma variedade de milho. Luiz de Queiroz College of Agriculture, University of Sao Paulo, Piracicaba.

Doelling, J. H. and Pikaard, C. S. (1996) 'Species-specificity of rRNA gene transcription in plants manifested as a switch in RNA polymerase specificity', Nucleic Acids Research, 24(23), pp. 4725-4732. doi: 10.1093/nar/24.23.4725.

Dundr, M. and Misteli, T. (2010) 'Biogenesis of nuclear bodies.', Cold Spring Harbor perspectives in biology, 2(12). doi: 10.1101/cshperspect.a000711.

Falahati H, Pelham-Webb B, Blythe S, W. E. (2016) 'Nucleation by rRNA Dictates the Precision of Nucleolus Assembly', Current Opinion in Cell Biology, 26(3). doi: 10.1016/j.cub.2015.11.065.Nucleation.

Fernández-Arjona, M. del M. et al. (2019) 'Microglial Morphometric Parameters Correlate With the Expression Level of IL-1 $\beta$, and Allow Identifying Different Activated Morphotypes', Frontiers in Cellular Neuroscience, 13(October), pp. 1-15. doi: 10.3389/fncel.2019.00472. 
Fuchs, M. C. P. (2009) Controle genético e epigenético da expressão heteromórfica de regiões organizadoras do nucléolo em Crotalaria retusa L. (Leguminosae-Papilionoideae). Biblioteca Digital de Teses e Dissertações da Universidade de São Paulo. doi: 10.11606/D.11.2009.tde-14102009-083128.

Gibbons, J. G. et al. (2014) 'Ribosomal DNA copy number is coupled with gene expression variation and mitochondrial abundance in humans', Nature Communications. Nature Publishing Group, 5. doi: $10.1038 /$ ncomms5850.

Gibbons, J. G. et al. (2015) 'Concerted copy number variation balances ribosomal DNA dosage in human and mouse genomes', Proceedings of the National Academy of Sciences of the United States of America, 112(8). doi: $10.1073 /$ pnas.1416878112.

Givens, J. F. and Phillips, R. L. (1976) 'The nucleolus organizer region of maize (Zea mays L.)', Chromosoma, 57(2), pp. 103-117. doi: 10.1007/bf00292910.

Gonzalez, I. L. and Sylvester, J. E. (2007) ‘rRNA Genes: Evolution’, Encyclopedia of Life Sciences, pp. 1-5. doi: 10.1002/9780470015902.a0006131.pub2.

Hamperl, S. et al. (2013) 'Chromatin states at ribosomal DNA loci', Biochimica et Biophysica Acta - Gene Regulatory Mechanisms. Elsevier B.V., 1829(3-4), pp. 405-417. doi: 10.1016/j.bbagrm.2012.12.007.

Jumbo, M. B. and Carena, M. J. (2008) 'Combining ability, maternal, and reciprocal effects of elite early-maturing maize population hybrids', Euphytica, 162(3), pp. 325-333. doi: 10.1007/s10681-007-9618-9.

Kalkhoran S.B., Munro P., Qiao F., Ong S.B., Hall A.R., C.-F. H. (2017) 'Unique morphological characteristics of mitochondrial subtypes in the heart: the effect of ischemia and ischemic preconditioning', Discoveries, 5(1). doi: 10.15190/d.2017.1.Unique.

Lassner, M. and Dvorak, J. (1986) 'Preferential homogenization between adjacent and alternate subrepeats in wheat rDNA', Nucleic Acids Research, 14(13). doi: 10.1093/nar/14.13.5499.

Lobo J., See E.Y., Biggs M., P. A. (2016) 'An insight into morphometric descriptors of cell shape that pertain to regenerative medicine', J Tissue Eng Regen Med., 10(7). doi: 10.1002/term.

McClintock, B. (1934) 'The relation of a particular chromosomal element to the development of the nucleoli in Zea mays', Z. Zellforch. Mikrosk. Anat, 21, pp. 294-335.

Mckeown, P. C. and Shaw, P. J. (2009) 'Chromatin: Linking structure and function in the nucleolus', Chromosoma, 118(1), pp. 11-23. doi: 10.1007/s00412-008-0184-2.

McMullen, M. D., Phillips, R. L. and Rubenstein, I. (1991) 'Molecular Analysis of the Nucleolus Organizer Region in Maize', Developments in Plant Genetics and Breeding, 2(PA), pp. 561-576. doi: 10.1016/B978-0-444-882592.50031-X.

McStay, B. (2016) 'Nucleolar organizer regions: genomic “dark matter” requiring illumination', Iacge 2013, pp. 45-53. doi: $10.1101 / \mathrm{gad} .283838 .116 .1598$.

McStay, B. and Grummt, I. (2008) 'The epigenetics of rRNA genes: From molecular to chromosome biology', Annual Review of Cell and Developmental Biology, 24. doi: 10.1146/annurev.cellbio.24.110707.175259.

Messing, J. et al. (1984) 'Cloning and Sequencing of the Ribosomal RNA Genes in Maize: The 17S Region', DNA, 3(1), pp. 31-40. doi: 10.1089/dna.1.1984.3.31.

Mondin, M. et al. (2014) 'Karyotype variability in tropical maize sister inbred lines and hybrids compared with KYS standard line', Frontiers in Plant Science, 5(OCT), pp. 1-12. doi: 10.3389/fpls.2014.00544. 
Mondin, M., Santos-Serejo, J. A. and Aguiar-Perecin, M. L. R. (2007) 'Karyotype characterization of Crotalaria juncea (L.) by chromosome banding and physical mapping of 18S-5.8S-26S and 5S rRNA gene sites', Genetics and Molecular Biology. Sociedade Brasileira de Genética, 30(1), pp. 65-72. doi: 10.1590/S1415-47572007000100013.

Németh, A. and Grummt, I. (2018) 'Dynamic regulation of nucleolar architecture', Current Opinion in Cell Biology, 52, pp. 105-111. doi: 10.1016/j.ceb.2018.02.013.

Olson, M. O. J. and Dundr, M. (2005) 'The moving parts of the nucleolus', Histochemistry and Cell Biology, 123(3), pp. 203-216. doi: 10.1007/s00418-005-0754-9.

Paris Conference - supplement (1975) 'Standardization in human cytogenetics. Paris Conference (1971)', Cytogenetics and Cell Genetics, pp. 201-238.

Pedrosa-Harand, A. et al. (2006) 'Extensive ribosomal DNA amplification during Andean common bean (Phaseolus vulgaris L.) evolution', Theoretical and Applied Genetics, 112(5), pp. 924-933. doi: 10.1007/s00122-005-0196-8.

Phillips, R. L., Kleese, R. A. and Wang, S. S. (1971) 'The nucleolus organizer region of maize (Zea mays L.): Chromosomal site of DNA complementary to ribosomal RNA', Chromosoma, 36(1), pp. 79-88. doi: 10.1007/BF00326423.

Potapova, T. A. and Gerton, J. L. (2019) 'Ribosomal DNA and the nucleolus in the context of genome organization', Chromosome Research. Chromosome Research, 27(1-2), pp. 109-127. doi: 10.1007/s10577-018-9600-5.

Potapova, T. and Gorbsky, G. (2017) 'The Consequences of Chromosome Segregation Errors in Mitosis and Meiosis', Biology. Multidisciplinary Digital Publishing Institute, 6(1), p. 12. doi: 10.3390/biology6010012.

Preuss, S. and Pikaard, C. S. (2007) 'rRNA gene silencing and nucleolar dominance: Insights into a chromosome-scale epigenetic on/off switch', Biochimica et Biophysica Acta - Gene Structure and Expression, 1769(5-6), pp. 383392. doi: 10.1016/j.bbaexp.2007.02.005.

Rabanal, F. A. et al. (2017) 'Unstable inheritance of 45S rRNA genes in Arabidopsis thaliana', G3: Genes, Genomes, Genetics, 7(4), pp. 1201-1209. doi: 10.1534/g3.117.040204.

Rasband, W.S., ImageJ, U. S. National Institutes of Health, Bethesda, Maryland, USA, https://imagej.nih.gov/ij/, 1997-2018

Ritossa, F. M. (1968) 'Unstable redundancy of genes for ribosomal RNA', Proceedings of the National Academy of Sciences of the United States of America, 60(2). doi: 10.1073/pnas.60.2.509.

Ritossa, F. M. and Scala, G. (1969) 'Equilibrium variations in the redundancy of rDNA in Drosophila melanogaster', Genetics, 61(1), pp. 1-2.

Roa, F. and Guerra, M. (2012) 'Distribution of 45S rDNA sites in chromosomes of plants: Structural and evolutionary implications', BMC Evolutionary Biology, 12(1). doi: 10.1186/1471-2148-12-225.

Rogers, S. O. and Bendich, A. J. (1987) 'Ribosomal RNA genes in plants: variability in copy number and in the intergenic spacer', Plant Molecular Biology, 9(5), pp. 509-520. doi: 10.1007/BF00015882.

Sáez-Vásquez, J. and Delseny, M. (2019) 'Ribosome Biogenesis in Plants: From Functional 45S Ribosomal DNA Organization to Ribosome Assembly Factors', The Plant cell, 31(9), pp. 1945-1967. doi: 10.1105/tpc.18.00874.

Santos, J. F. et al. (2017) 'Reciprocal effect of parental lines on the physiological potential and seed composition of corn hybrid seeds', Seed Science Research, 27(3), pp. 206-216. doi: 10.1017/S0960258517000095.

Schwarzacher, T. and Heslop-Harrison, J. (2000) Practical In Situ Hybridization, BIOS Scientific Publishers, Oxford.

Shaw, P. and Brown, J. (2012) 'Nucleoli: Composition, function, and dynamics', Plant Physiology, 158(1), pp. 44-51. doi: 10.1104/pp.111.188052. 
Sirri, V., Hernandez-Verdun, D. and Roussel, P. (2002) 'Cyclin-dependent kinases govern formation and maintenance of the nucleolus', Journal of Cell Biology, 156(6), pp. 969-981. doi: 10.1083/jcb.200201024.

Springer, N. M. et al. (2009) 'Maize inbreds exhibit high levels of copy number variation (CNV) and presence/absence variation (PAV) in genome content', PLoS Genetics, 5(11). doi: 10.1371/journal.pgen.1000734.

Thompson, W. F. et al. (1997) 'Sites of rDNA transcription are widely dispersed through the nucleolus in Pisum sativum and can comprise single genes', Plant Journal, 12(3), pp. 571-581. doi: 10.1046/j.1365-313x.1997.00557.x.

Trinkle-Mulcahy, L. (2018) Nucleolus, Nuclear Architecture and Dynamics. Elsevier Inc. doi: 10.1016/b978-0-12803480-4.00011-9.

Vidal, B. D. C. (1997) 'Image analysis and definition of nuclear phenotypes', Brazilian Journal of Genetics, 20(4), pp. 749-754. doi: 10.1590/S0100-84551997000400031.

Weis, B. L. et al. (2015) 'Plant-Specific Features of Ribosome Biogenesis', Trends in Plant Science, 20(11), pp. 729740. doi: 10.1016/j.tplants.2015.07.003.

Zhang, Q., Maroof, M. A. S. and Allard, R. W. (1990) 'Effects on adaptedness of variations in ribosomal DNA copy number in populations of wild barley (Hordeum vulgare ssp. spontaneum)', Proceedings of the National Academy of Sciences of the United States of America, 87(22), pp. 8741-8745. doi: 10.1073/pnas.87.22.8741. 


\section{APPENDIX}

APPENDIX A. Univariate analysis of 45S rDNA

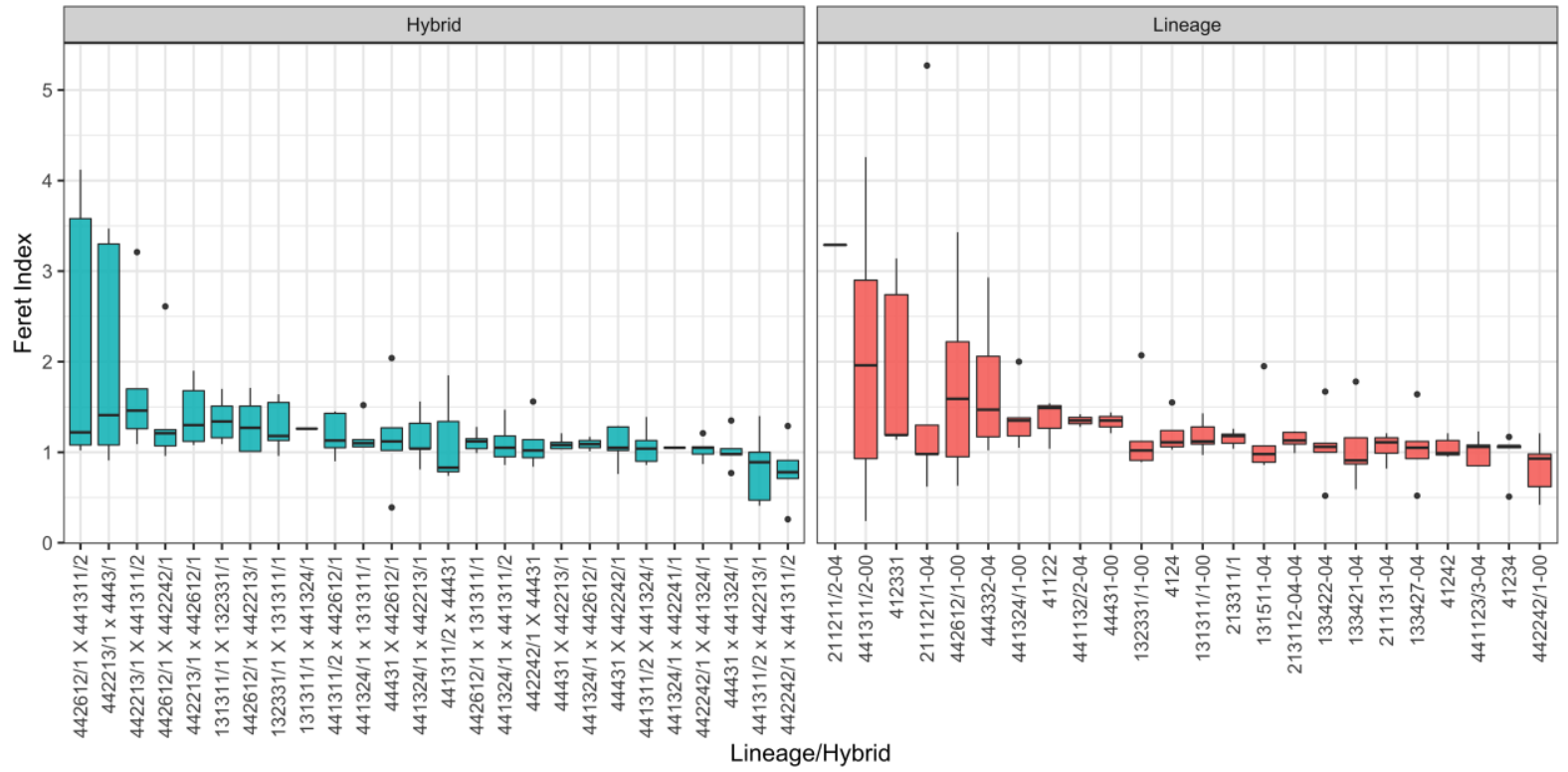

Figure A1. Boxplot of Feret Index for 45S rDNA evaluated in Hybrid and inbred lines.

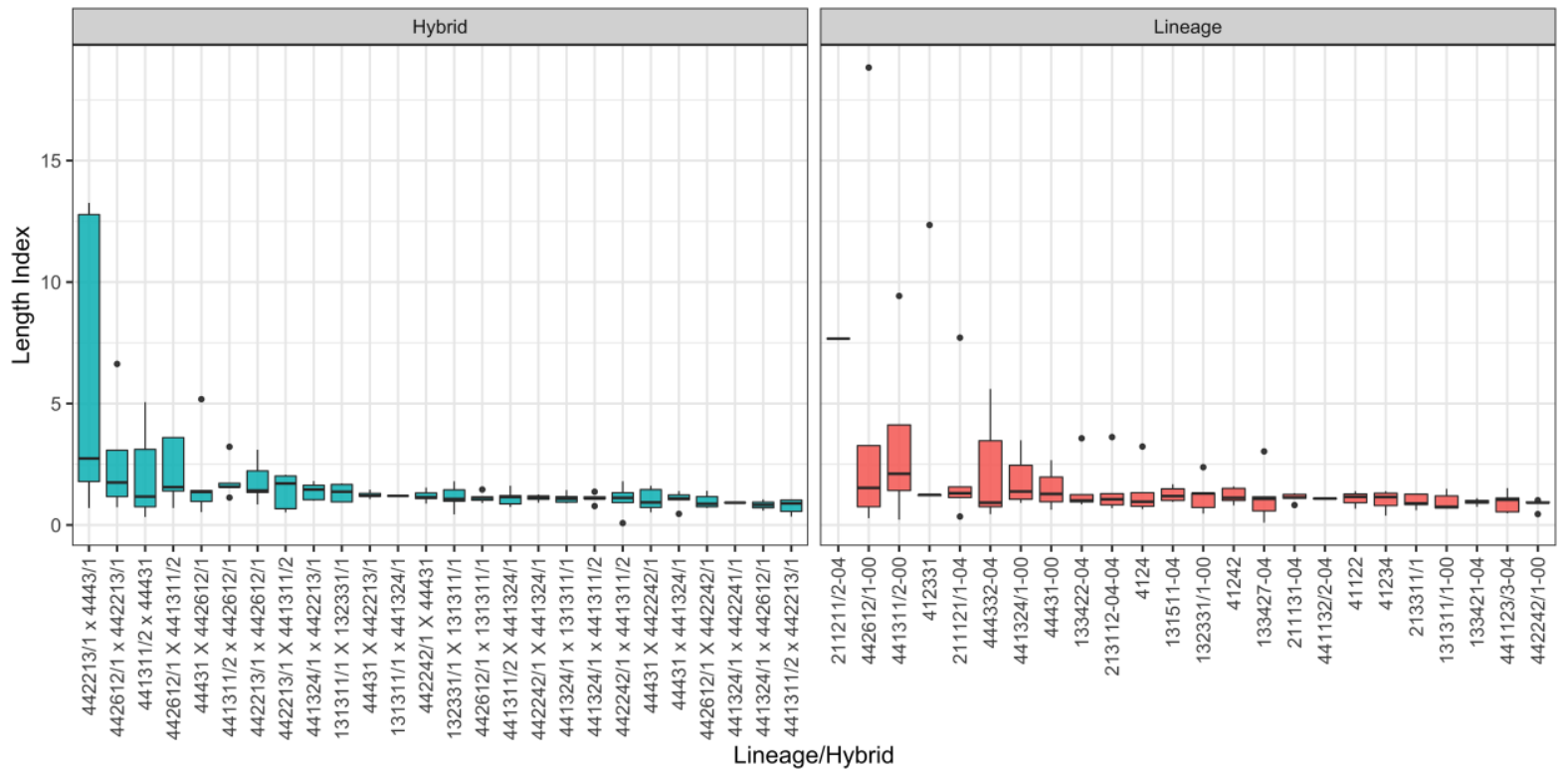

Figure A2. Boxplot of Length for 45S rDNA evaluated in Hybrid and inbred lines. 

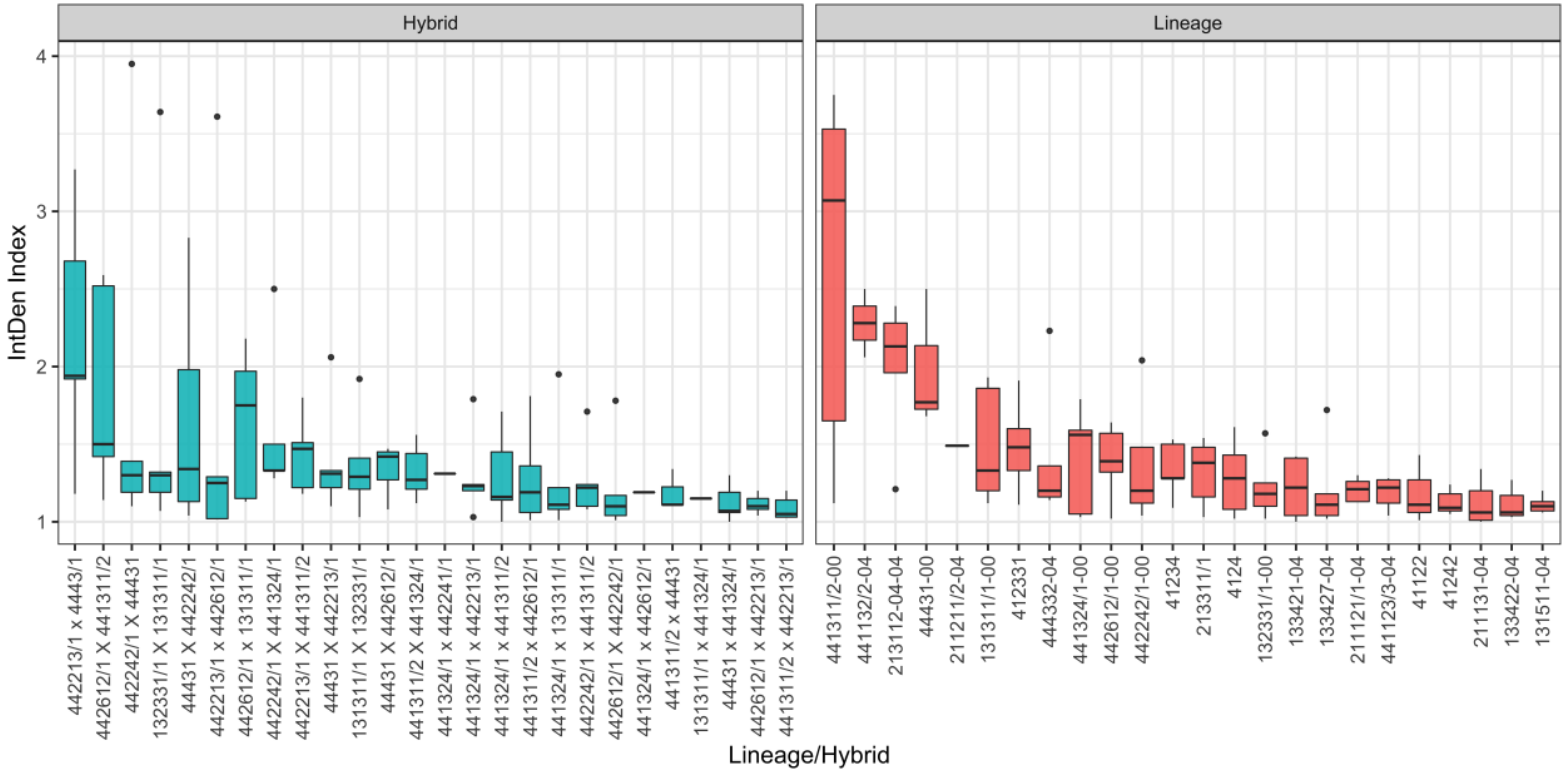

Figure A3. Boxplot of Integrated Optical Density (IOD) for 45S rDNA evaluated in Hybrid and inbred lines.
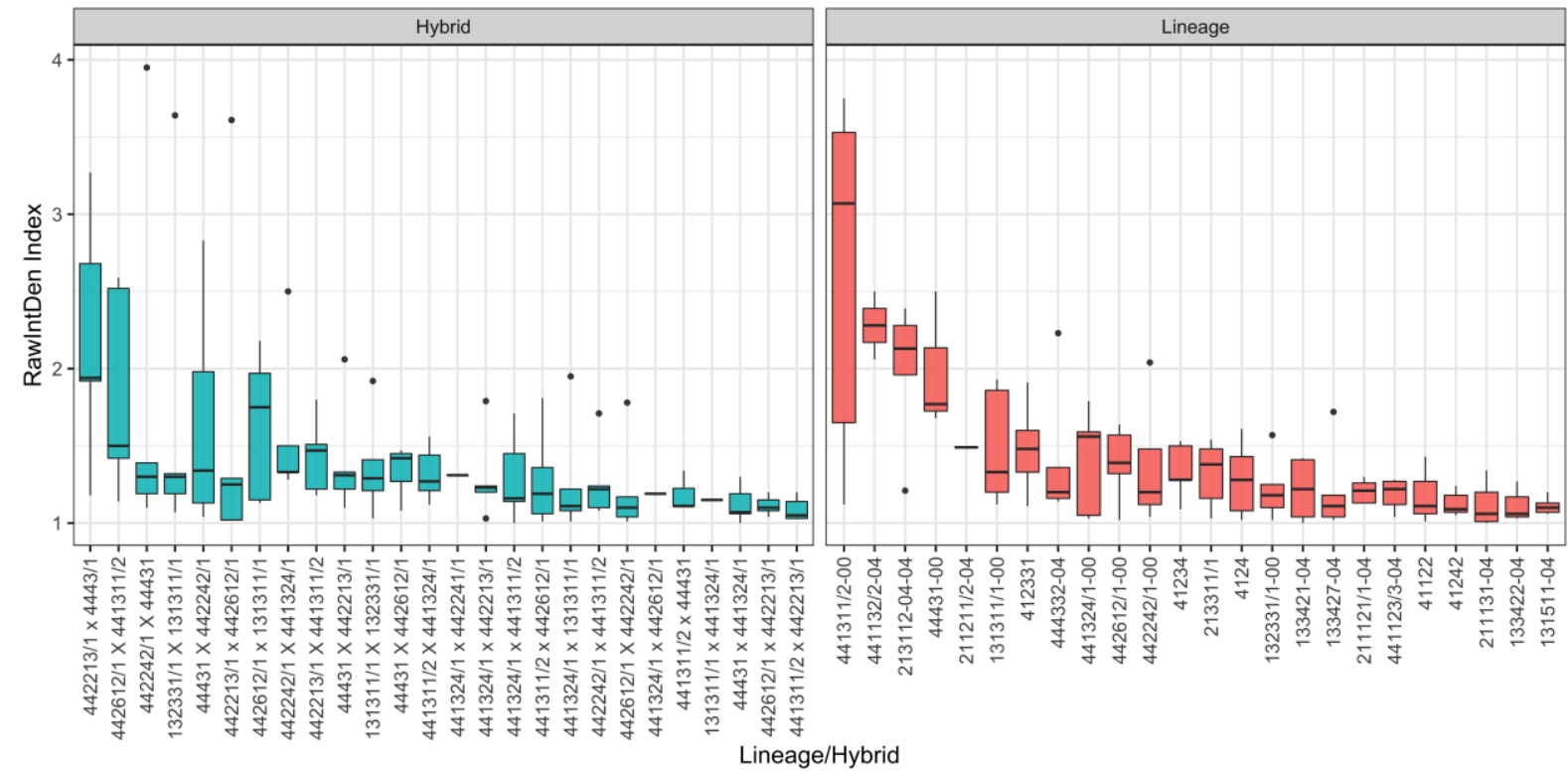

Figure A4. Boxplot of Raw Integrated Optical Density (Raw IOD) for 45S rDNAevaluatedd in Hybrid and inbred lines. 
APPENDIX B: Univariate analysis of nucleolus

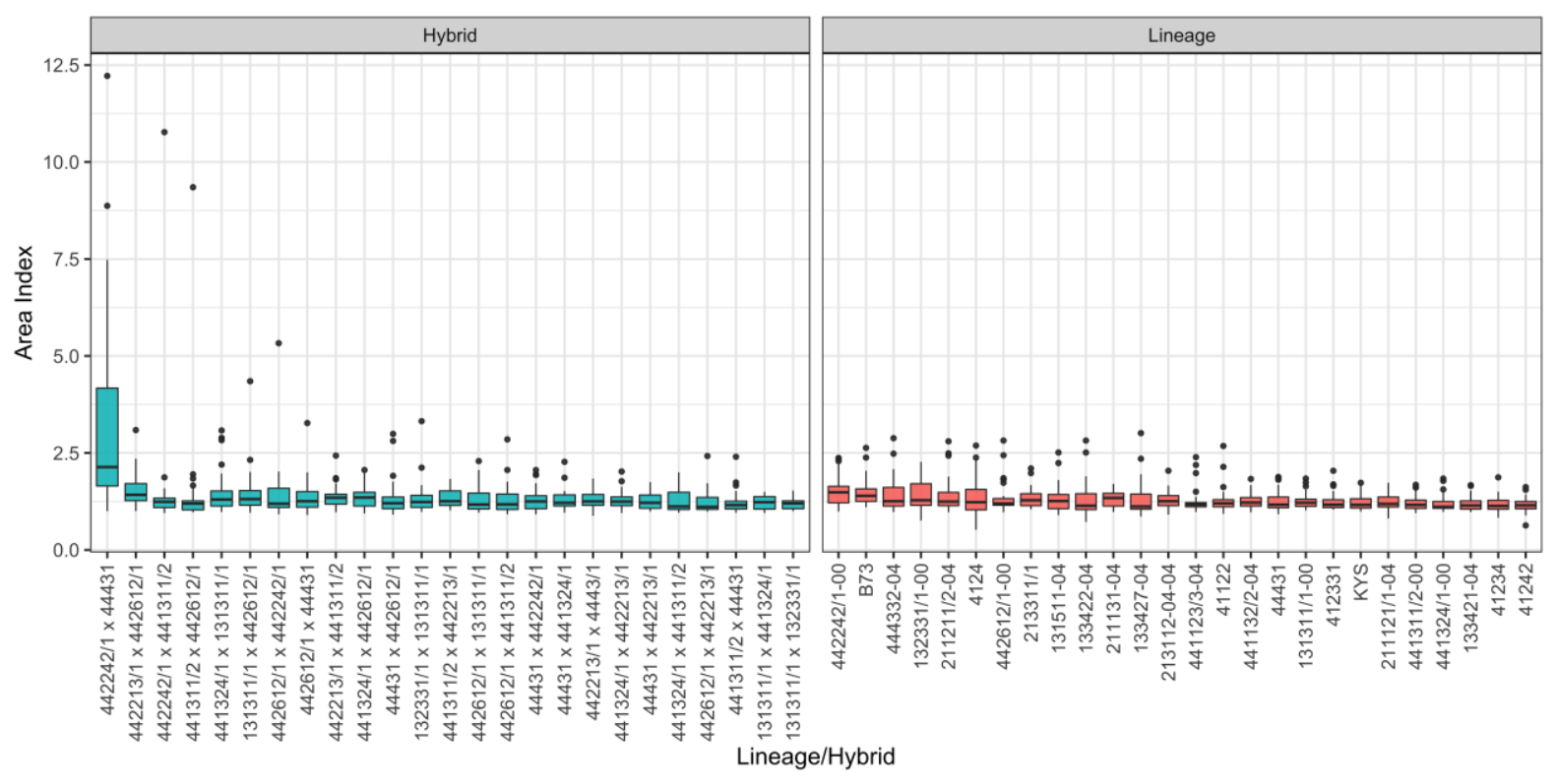

Figure B1. Boxplot of area index of the nucleolus evaluated in Hybrid and inbred lines.

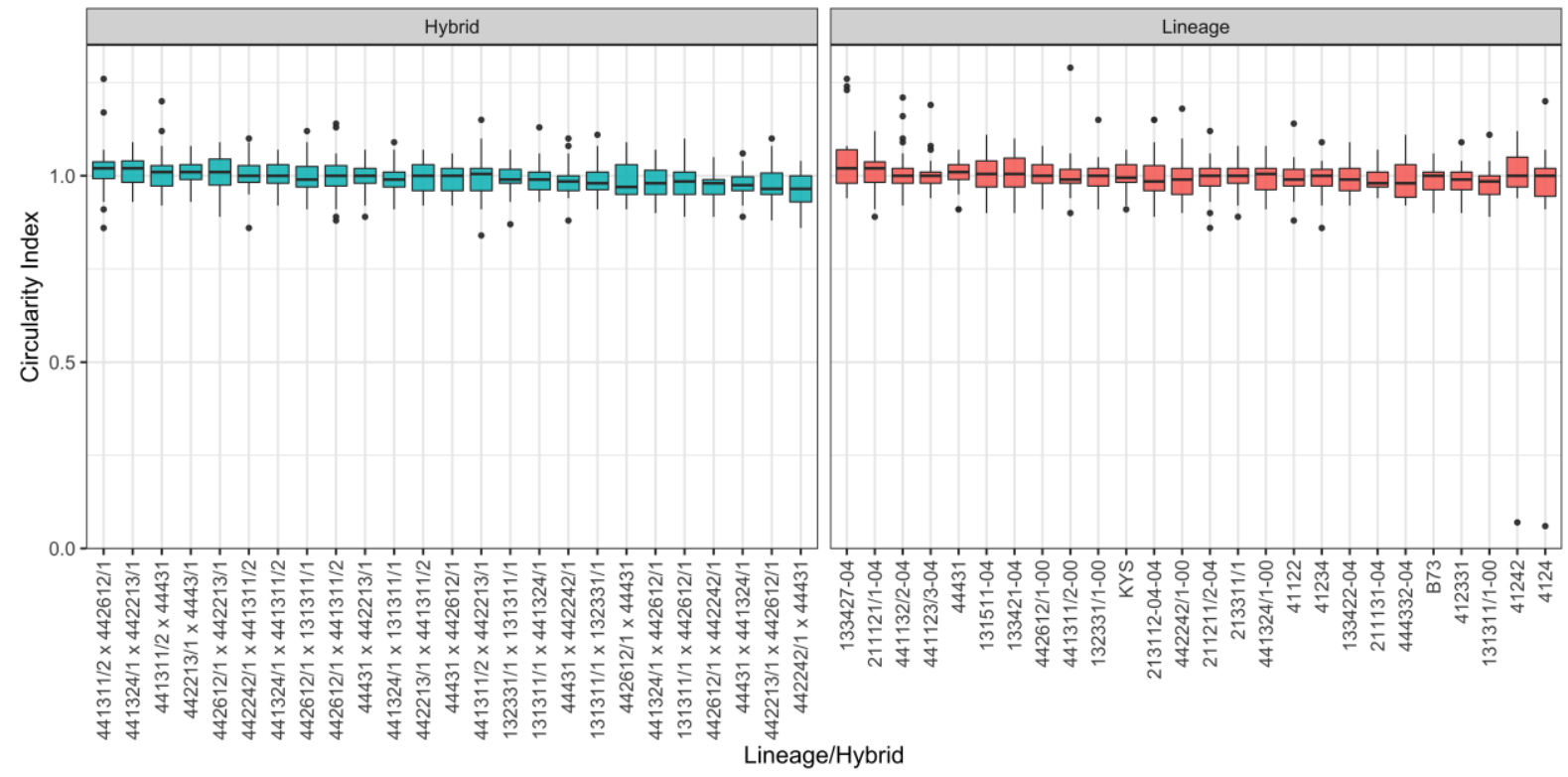

Figure B2. Boxplot of circularity index of the nucleolus evaluated in Hybrid and inbred lines. 


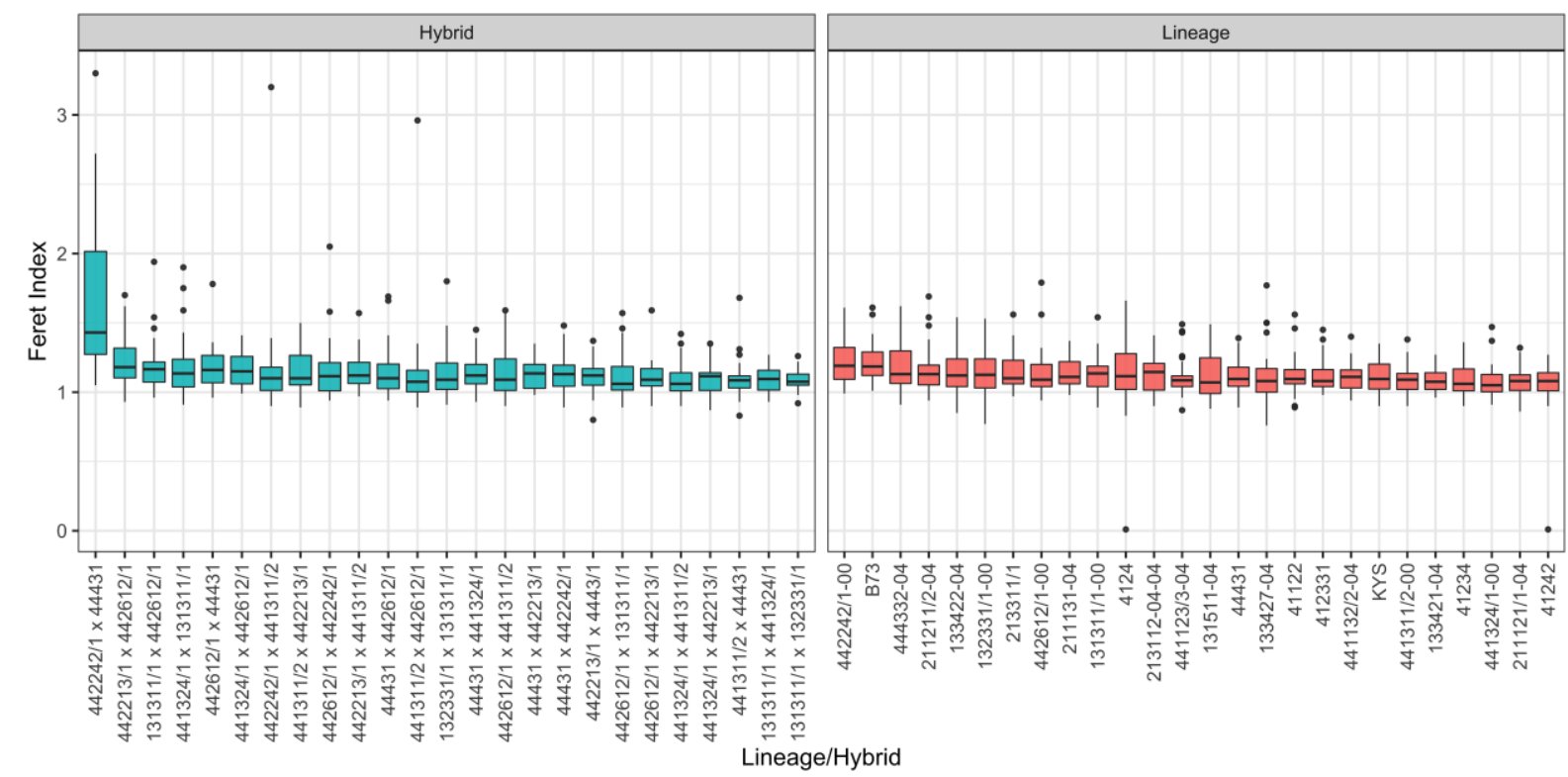

Figure B3. Boxplot of Feret of the nucleolus evaluated in Hybrid and inbred lines.

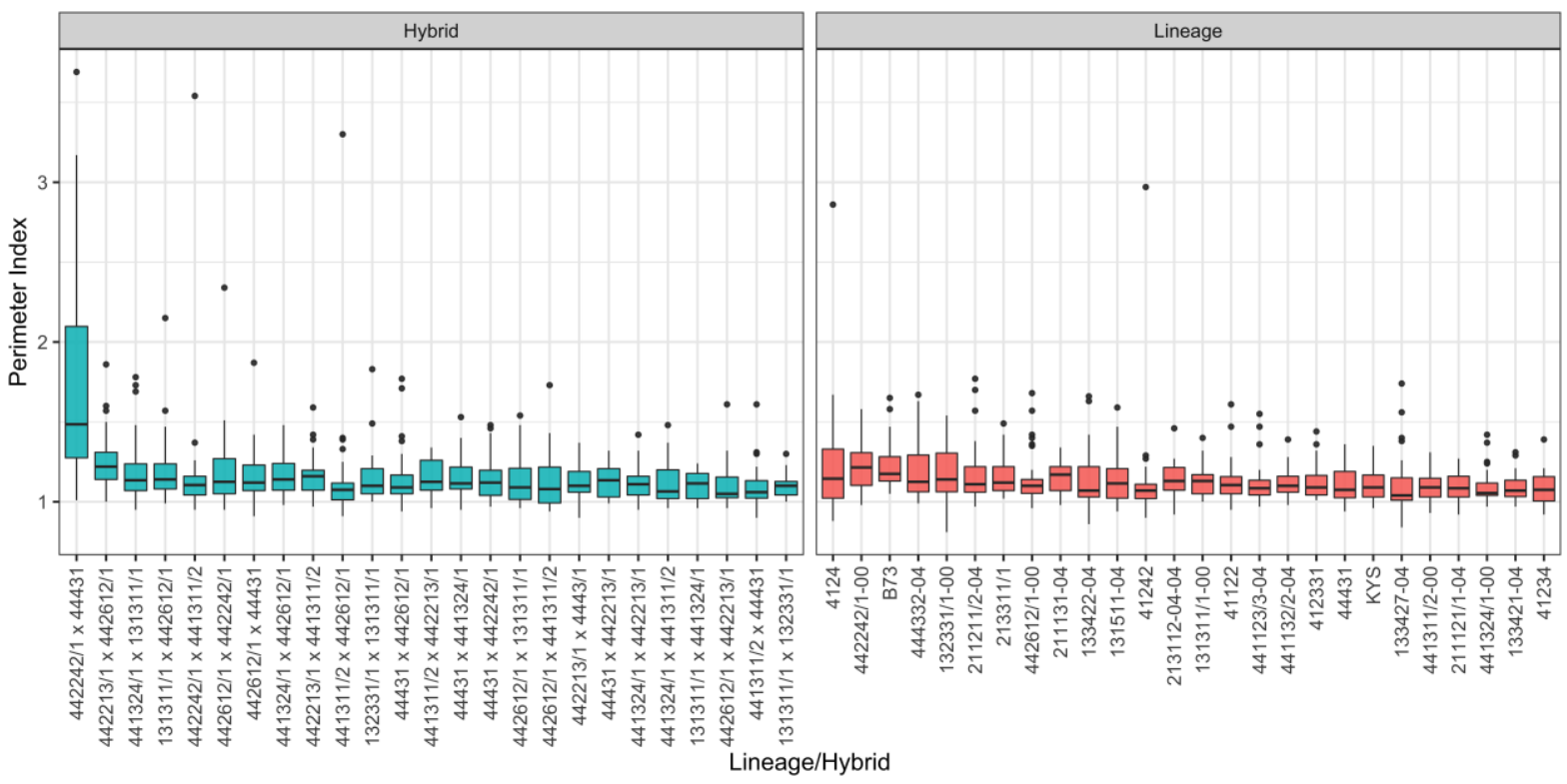

Figure B4. Boxplot of the perimeter of the nucleolus evaluated in Hybrid and inbred lines 


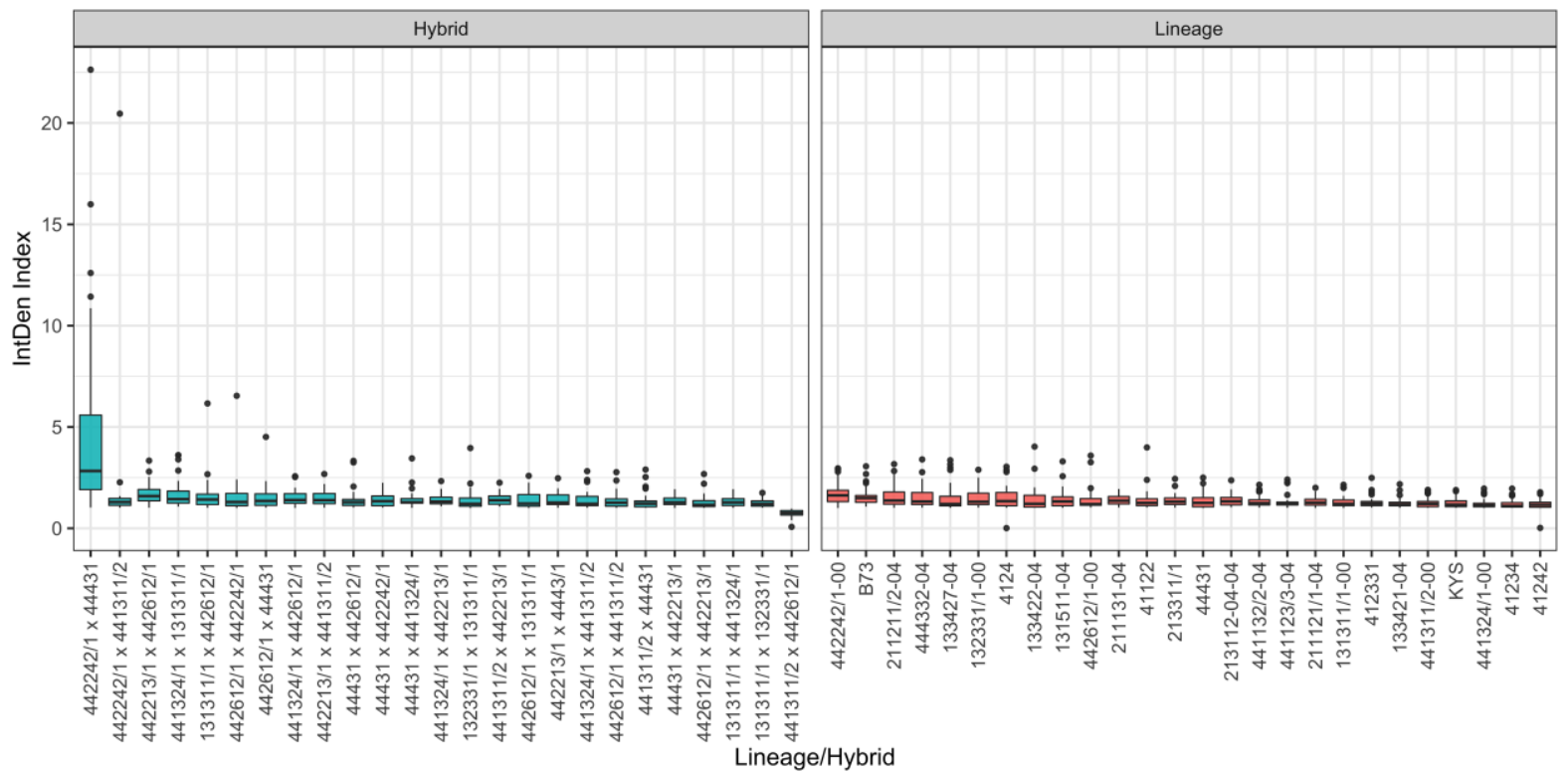

Figure B5. Boxplot of Integrated Optical Density of the nucleolus evaluated in Hybrid and inbred lines.

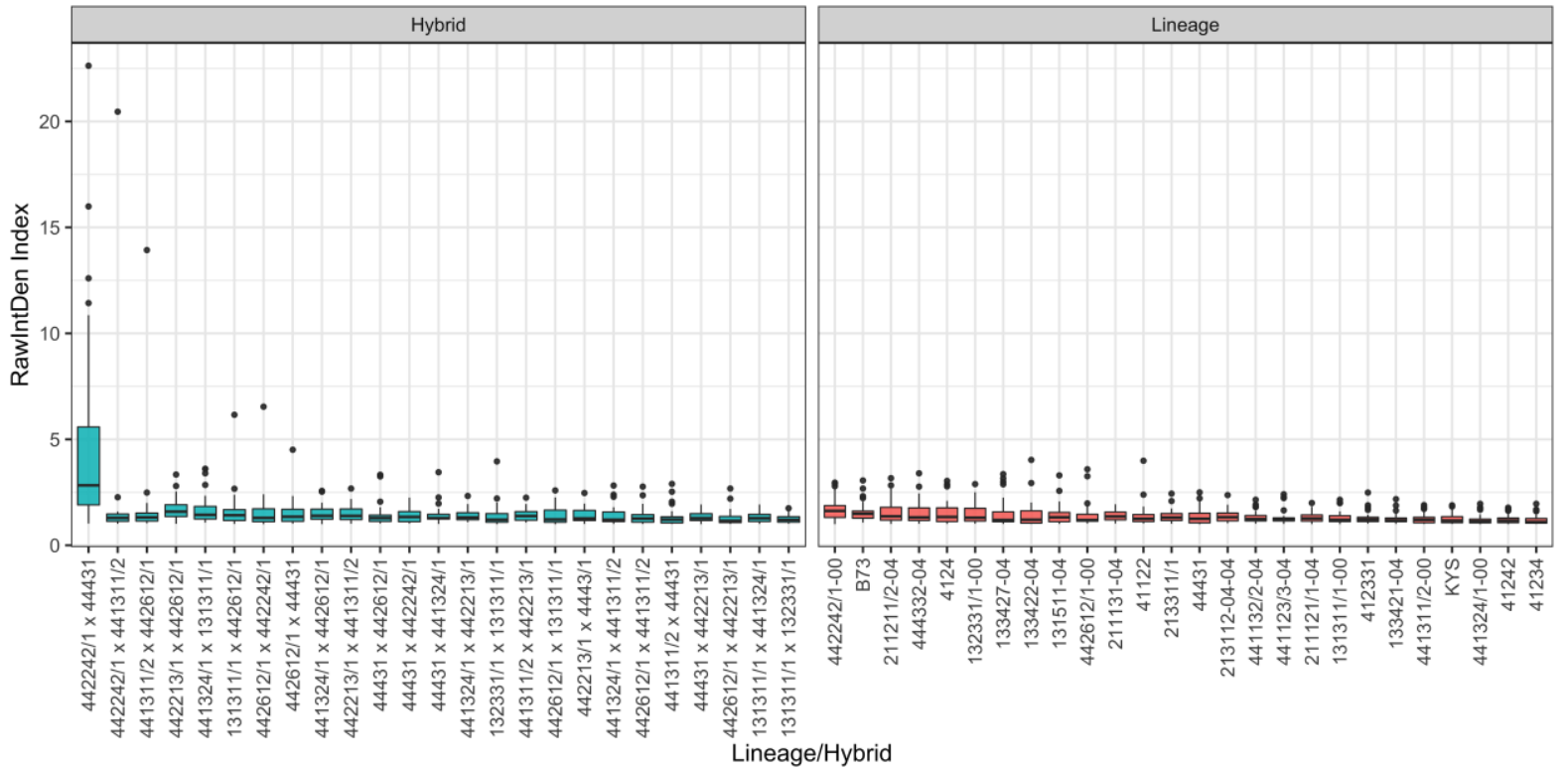

Figure B6. Boxplot of Raw Integrated Optical Density of the nucleolus evaluated in Hybrid and inbred lines. 